CAPACIDADE DE ADSORÇÃO MÁXIMA DE SULFATO DO SOLO

COMO PARÂMETRO ADICIONAL NA RECOMENDAÇÃO DE GESSO

\author{
TSUIOSHI YAMADA \\ Engenheiro Agrônomo
}

Orientador: Prof. Dr. TOSHIAKI KINJO

Tese apresentada à Escola Superior de Agricultura "Luiz de Queiroz", da Universidade de São Paulo, para obtenção do título de Doutor em Agronomia - Área de Concentração: Solos e Nutrição de Plantas.

P I R A C I C A B A

Estado de São Paulo - Brasil

Dezembro - 1988 
Yamada, Tsuioshi

Y19c Capacidade de adsorção máxima de sulfato do solo como parâmetro adicional na recomendação de gesso. Piracicaba, 1988.

$73 \mathrm{p}$. ilus.

Tese - ESALQ

Bibliografia.

1. Gesso agrícola 2. Solo - Química 3. Sulfato em solo - Adsorção I. Escola Superior de Agricultura Luiz de Queiroz, Piracicaba

CDD 631.41 
CAPACIDADE DE ADSORÇÃO MÁXIMA DE SULFATO DO SOLO COMO PARÂMETRO ADICIONAL NÄ RECOMENDAÇÃO DE GESSO

TSUIOSHI YAMADA

Aprovada em : 20.04.1989

Comissão julgadora:

Prof. Dr. Toshiaki Kinjo

ESALQ/USP

Prof. Dr. José Luis Ioriatti Demattê

ESALQ/USP

Prof. Dr. Takashi Muraoka

CENA/USP

Prof. Dr. Godofredo Cesar Vitti

FCAVJ/UNESP

Dr. Bernardo van Raij

IAC

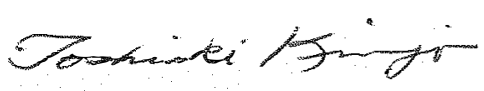

Prof. Dr. TOSHIAKI KINJO

Orientador 
Aos agricultores, em

especial aos dos cerrados,

\section{OFEREÇO}

À minha esposa Mitico

e ao meu filho Renato, 


\section{HOMENAGEM}

Nas pessoas dos meus pais SAIHACHI e UMENO YAMADA rendo homenagem a todos os imigrantes que contribuíram para o desenvolvimento da agricultura brasileira. 


\section{AGRADECIMENTOS}

Ao Prof. Toshiaki Kinjo pela orientação, colaboração, compreensão, estímulo e amizade;

Ao Dr. Marcos A. Pavan pelas sugestões e colaboração nas análises e nas especiações químicas das soluções do solo;

Ao Pesquisador Científico João Bertoldo de Oliveira e ao Professor José Luis I. Demattê pela colaboração na escolha das amostras estudadas;

Ao Dr. Manoel Raimundo Guilherme e ao Químico Cláudio de Jesus Monteiro, da Indústria Mineradora Pagliato Ltda., pela colaboração na análise química dos solos;

À Analista de Sistemas Célia Kage e à Professora Maria Izalina Ferreira Alves pela colaboração na análise estatística dos dados;

Às Engenheiras Agrônomas Silvia Regina Calcedoni Stipp e Suzana Oellers Ferreira pela colaboração durante a elaboração da tese;

Aos Professores Eurípedes Malavolta, Frederico Pimentel Gomes, Jorge de Castro Kiehl, Godofredo Cesar Vitti, Alfredo Scheid Lopes e Klaus Reichardt e ao Pesquisador Científico Dr. Bernardo van Raij pelas valiosas sugestões;

Ao Técnico de Laboratório Sr. Mário Benedito Lodovico pela colaboração na condução dos ensaios;

Às funcionárias da Seção de Pós-Graduação, pela atenção dispensada durante estes longos anos de convivência.

Às diretorias do Instituto da Potassa e do Fosfato (EUA) e do Instituto Internacional da Potassa (Suíça) pela permissão para concluir a presente tese. 
SUMÁRIO

Página

LISTA DE FIGURAS $\ldots \ldots \ldots \ldots \ldots \ldots \ldots \ldots \ldots \ldots \ldots \ldots \ldots \ldots \ldots \ldots \ldots \ldots \ldots$

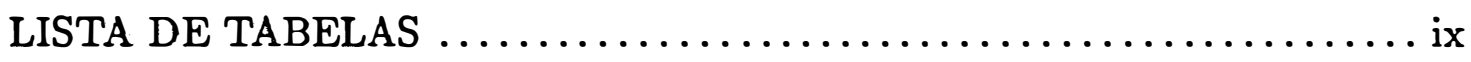

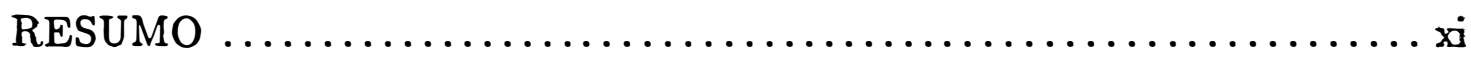

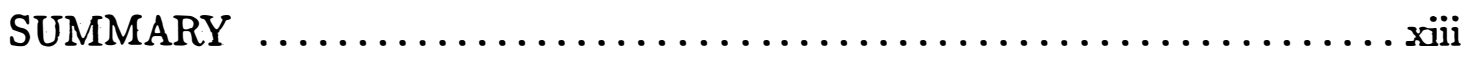

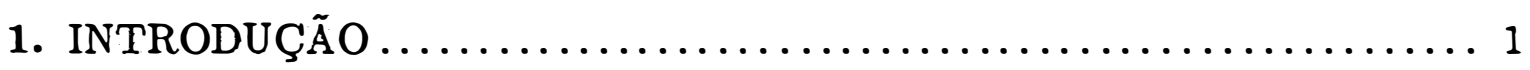

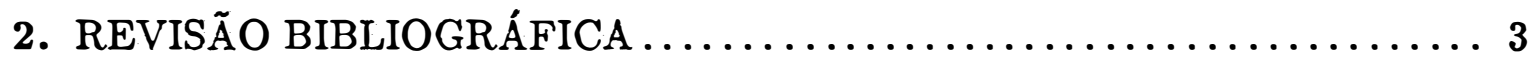

2.1. O enxofre no sistema solo-planta-atmosfera $\ldots \ldots \ldots \ldots \ldots \ldots \ldots \ldots$

2.2. Sulfato na solução do solo $\ldots \ldots \ldots \ldots \ldots \ldots \ldots \ldots \ldots \ldots \ldots \ldots \ldots$

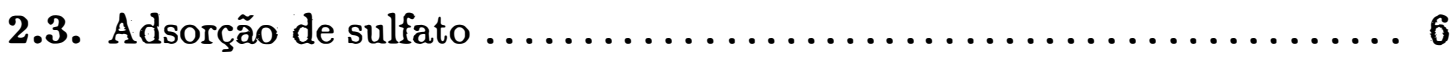

2.3.1. Capacidade de adsorção de sulfato $\ldots \ldots \ldots \ldots \ldots \ldots \ldots \ldots 6$

2.3.2. Fatores que afetam a adsorção $\ldots \ldots \ldots \ldots \ldots \ldots \ldots \ldots \ldots, 7$

2.3.2.1. Natureza do complexo coloidal ............... 7

2.3.2.2. Efeito do $\mathrm{pH} \ldots \ldots \ldots \ldots \ldots \ldots \ldots \ldots \ldots \ldots \ldots, 9$

2.3.2.3. Tempo de reação $\ldots \ldots \ldots \ldots \ldots \ldots \ldots \ldots \ldots \ldots, 9$

2.3.2.4. Concentração de sulfato na solução do solo .........10

2.3.2.5. Natureza dos ânions e cátions presentes no solo ......12

2.3.3. Mecanismos envolvidos na adsorção de sulfato $\ldots \ldots \ldots \ldots \ldots 13$

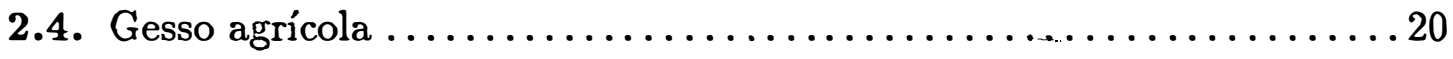

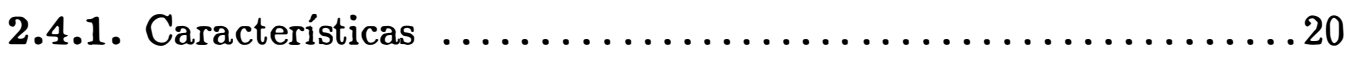


2.4.2. Efeitos agronômicos do gesso $\ldots \ldots \ldots \ldots \ldots \ldots \ldots \ldots \ldots \ldots \ldots \ldots \ldots \ldots$

2.4.3. Critérios de recomendação do gesso $\ldots \ldots \ldots \ldots \ldots \ldots \ldots \ldots 24$

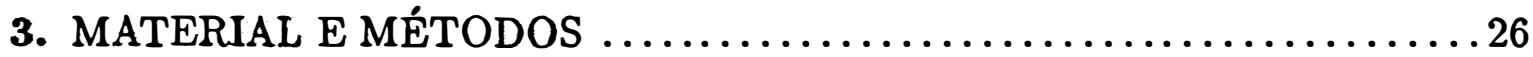

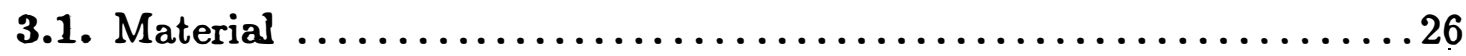

3.1.1. Solos utilizados no estudo da adsorção de sulfato .........26

3.1.2. Solos utilizados no ensaio com trigo $\ldots \ldots \ldots \ldots \ldots \ldots \ldots 26$

3.1.3. Cultivar utilizado no ensaio com trigo $\ldots \ldots \ldots \ldots \ldots \ldots$

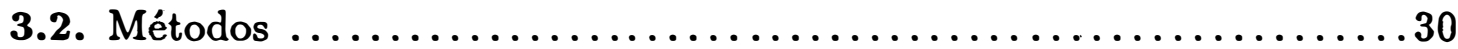

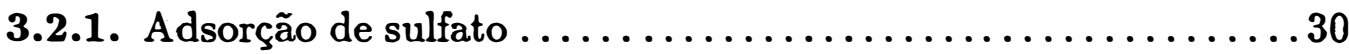

3.2.2. $\mathrm{dpH}=\mathrm{pH} K_{2} \mathrm{SO}_{4}-\mathrm{pH} K C l \ldots \ldots \ldots \ldots \ldots \ldots \ldots \ldots \ldots \ldots \ldots \ldots \ldots \ldots$

3.2.3. Ensaio com trigo: método biológico $\ldots \ldots \ldots \ldots \ldots \ldots \ldots . \ldots 31$

3.2.4. Extrato da pasta saturada ....................... 34

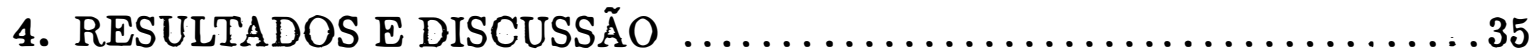

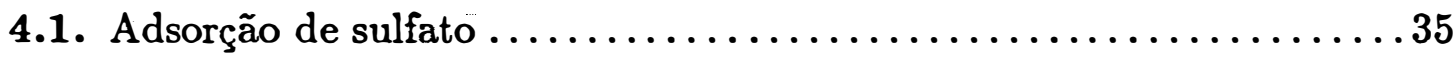

4.2. Ensaio com trigo $\ldots \ldots \ldots \ldots \ldots \ldots \ldots \ldots \ldots \ldots \ldots \ldots \ldots \ldots$

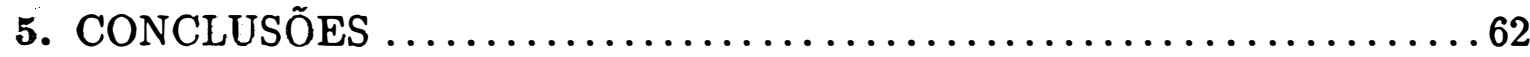

6. REFERÊNCIAS BIBLIOGRÁFICAS $\ldots \ldots \ldots \ldots \ldots \ldots \ldots \ldots \ldots \ldots \ldots \ldots \ldots \ldots \ldots \ldots \ldots$ 
1. Balanço do enxofre no solo e equilíbrio do sulfato da solução com a fase sólida ( modificada de PROBERT \& SAMOSIR, 1983) ................. 3

2. Diagrama de solubilidade para o sistema $\mathrm{Al}-\mathrm{SO}_{4}-\mathrm{HOH}(\mathrm{PAVAN}, 1988) \ldots 19$

3. Representação esquemática das principais reações que ocorrem após a adição de gesso em solos ácidos (PAVAN \& VOLKWEISS, 1986, com modificações) 23

4. Correlação entre a capacidade de adsorção máxima de sulfato e a quantidade de sulfato adsorvida da solução com $20 \mathrm{ppm}$ de $S-S_{4}^{2-} \ldots \ldots \ldots \ldots \ldots 40$

5. Correlação entre a capacidade de adsorção máxima de sulfato e a quantidade de sulfato adsorvida da solução com $30 \mathrm{ppm}$ de $S-S O_{4}^{2-} \ldots \ldots \ldots \ldots . \ldots 41$

6. Correlação entre a capacidade de adsorção máxima de sulfato e a quantidade de sulfato adsorvida da solução com $40 \mathrm{ppm}$ de $S-S_{4}^{2-} \ldots \ldots \ldots \ldots . \ldots 42$

7. Correlação entre a capacidade de adsorção máxima de sulfato e o valor da diferença entre o pH medido em $\mathrm{K}_{2} \mathrm{SO}_{4} 1 \mathrm{~N}$ e o medido em $\mathrm{KCl} 1 \mathrm{~N}(\mathrm{dpH}) .43$

8. Correlação entre a constante de afinidade $(\mathrm{K})$ calculada através da equação de Langmuir e o valor da diferença entre o $\mathrm{pH}$ medido em $\mathrm{K}_{2} \mathrm{SO}_{4} 1 \mathrm{~N}$ e o

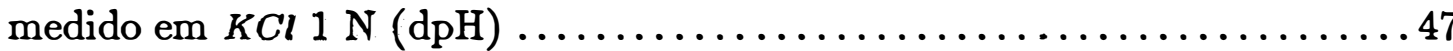

9. Correlação entre o teor de aluminio trocável das amostras de terra e o com-

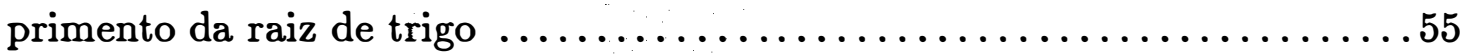

10. Correlação entre a porcentagem de saturação em alumínio na CTC efetiva das amostras de terra e o comprimento da raiz de trigo .............56

11. Correlação entre a porcentagem de saturação em alumínio na CTC a pH 7,0 das amostras de terra e o comprimento da raiz de trigo .............57

12. Correlação entre o teor de cálcio trocável das amostras de terra e o comprimento da raiz de trigo $\ldots \ldots \ldots \ldots \ldots \ldots \ldots \ldots \ldots \ldots \ldots \ldots \ldots \ldots$

13. Correlação entre a porcentagem de saturação em cálcio trocável na CTC efetiva das amostras de terra e o comprimento da raiz de trigo . ........59 
14. Correlação entre a porcentagem de saturação em cálcio trocável na CTC a $\mathrm{pH} 7,0$ das amostras de terra e o comprimento da raiz de trigo $\ldots \ldots \ldots \ldots 60$

15. Correlação entre a porcentagem de saturação em bases das amostras de terra

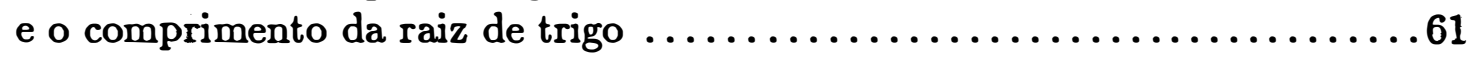




\section{LISTA DE TABELAS}

Página

1. Formação de pares iônicos entre o íon sulfato e alguns cátions, com as respectivas constantes de equilibrio a $25^{\circ} \mathrm{C}$ (LINDSAY, 1979) ........... 5

2. Classificação e granulometria das amostras do horizonte B dos solos estudados

3. Características químicas das amostras estudadas

4. Porcentagem de argila e características químicas da fração argila das amostras estudadas.

5. Tratamentos efetuados nas diferentes amostras de terra no ensaio com trigo 32

6. Quantidades de $\mathrm{CaSO}_{4}, 2 \mathrm{H}_{2} \mathrm{O}$ aplicadas no tratarnento $T_{4}$ das diferentes amostras de terra no ensaio com trigo . . . . . . . . . . . . . . . . . . 33

7. Capacidade de adsorção máxima de sulfato (b) e constante de afinidade (K) das amostras, obtidas através da equação de Langmuir ..............36

8. Quantidades de sulfato adsorvidas pelas annostras de terra após equilíbrio com soluções de $\mathrm{CaSO}_{4}$ com diferentes concentrações iniciais de sulfato . . . 337

9. $\mathrm{pH}$ das amostras de solo tratadas $\operatorname{com} \mathrm{K}_{2} \mathrm{SO}_{4} 1 \mathrm{~N}$ e com $\mathrm{KCl} 1 \mathrm{~N}$ e respectivos

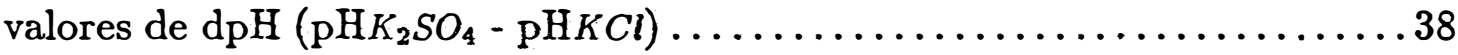

10. Correlações entre a capacidade de adsorção máxima de sulfato (b) obtida pela equação de Langmuir e algumas características dos solos estudados . . .39

11. Correlações entre a constante de afinidade $(K)$ obtida pela equação de Langmuir e algumas características dos solos estudados

12. Efeito dos tratamentos com $\mathrm{CaSO}_{4} \cdot 2 \mathrm{H}_{2} \mathrm{O}$ e $\mathrm{CaCl}_{2} \cdot 2 \mathrm{H}_{2} \mathrm{O}$ no comprimento da raiz de trigo cultivado durante 4 dias nos solos estudados . . . . . . . . . 49

13. Doses de $\mathrm{CaSO}_{4} \cdot 2 \mathrm{H}_{2} \mathrm{O}$ que proporcionaram as melhores respostas, os possíveis efeitos e as doses calculada através de diferentes critérios $\ldots \ldots \ldots \ldots \ldots . \ldots 51$

14. Correlações entre comprimento da raiz de plântulas de trigo e algumas ca- 
racterísticas químicas das amostras de terra após a coleta do ensaio

53

15. Correlações entre o comprimento da raiz de trigo e algumas características dos extratos das pastas saturadas das amostras de terra após a coleta do ensaio 


\title{
CAPACIDADE DE ADSORÇÃO MÁXIMA DE SULFATO DO SOLO COMO PARÂMETRO ADICIONAL NA RECOMENDAÇÃO DE GESSO
}

\author{
Autor: TSUIOSHI YAMADA \\ Orientador: Prof. Dr. TOSHIAKI KINJO
}

\section{RESUMO}

O estudo da adsorção de sulfato foi realizado com 18 amostras de terras retiradas do horizonte $\mathrm{B}$ dos solos, tendo por objetivos: (1) comparar as doses de gesso estimadas pelos critérios existentes do cálcio e do alumínio com a capacidade de adsorção máxima de sulfato e (2) estudar os efeitos de doses de gesso, aplicadas em 10 das 18 amostras de terra, no comprimento da raiz de plântulas de trigo.

Através da forma linear da equação de Langmuir foram calculadas a capacidade de adsorção máxima de sulfato (b) e a constante de afinidade (K) das amostras de terra. Através da análise estatística procurou-se as correlações de b e $\mathrm{K}$ com algumas características químicas dos solos e com o dpH, que é a diferença entre o $\mathrm{pH}$ medido em $\mathrm{K}_{2} \mathrm{SO}_{4} 1 \mathrm{~N}$ e $\mathrm{KCl} 1 \mathrm{~N}$.

No ensaio com trigo foi empregado o método biológico que consiste na medida do comprimento da maior raiz de plântulas de trigo crescidas por 4 dias em copos plásticos descartáveis de $250 \mathrm{ml}$ de volume, contendo a amostra de terra com o respectivo tratamento. Após o ensaio as amostras foram submetidas à análise química de rotina, além das determinações dos teores de $S-S_{4}^{2-}$ extraído com $\mathrm{CaCl}_{2} \quad 0,04 \mathrm{M}$ e com $\mathrm{Ca}_{\left(\mathrm{H}_{2} \mathrm{PO}_{4}\right)_{2}}$ 0,04 M. Foram analisados também os extratos de pastas saturadas destas amostras e os resultados submetidos a especiação química através do programa GEOCHEM. Através da análise estatística procurou-se as correlações entre estas características e o comprimento da raiz de plântulas de trigo.

Os resultados permitiram concluir que: (1) as doses de gesso calculadas pelos critérios do cálcio e do alumínio são em geral superiores às doses calculadas para atingir a capacidade de adsorção máxima de sulfato do solo; (2) a 
capacidade de adsorção máxima de sulfato correlaciona-se com as quantidades de sulfato adsorvidas em soluções com 20,30 ou $40 \mathrm{ppm}$ de $S-S O_{4}^{2-}$ e ainda com os valores de $\mathrm{dpH}$; (3) em solos podzolizados com elevados teores de alumínio o gesso não favorece o desenvolvimento das raízes de trigo enquanto que em latossolos com excesso de alumínio e/ou com deficiência de cálcio há efeitos positivos; (4) não há correlações entre as doses de gesso calculadas pelos critérios do cálcio e do alumínio com o crescimento das raízes de trigo e (5) a porcentagem de saturação em alumínio é o parâmetro do solo que melhor se correlaciona com o crescimento das raízes de trigo. 


\title{
MAXIMUM SULPHATE ADSORPTION CAPACITY OF THE SOIL AS AN ADDITIONAL PARAMETER ON GYPSUM RECOMENDATION
}

\author{
Author: TSUIOSHI YAMADA \\ Adviser: Prof. Dr. TOSHIAKI KINJO
}

\section{SUMMARY}

Sulphate adsorption was studied in 18 soil samples of the B horizon with the following objectives: (1) to compare gypsum doses calculated through the existing calcium and aluminum criteria with the maximum sulphate adsorption capacity and (2) to study the effects of gypsum applied in 10 of those 18 samples on the root length of wheat seedling.

Through the linear form of the Langmuir equation the values of the maximum sulphate adsorption capacity (b) and of the coefficient of affinity (K) were calculated. Correlations of these values with some chemical characteristics of the soils and with dpH (the difference between $\mathrm{pH}$ measured in $\mathrm{K}_{2} \mathrm{SO}_{4} 1 \mathrm{~N}$ and $\mathrm{KCl} 1 \mathrm{~N}$ ) were studied throught statistical analyses.

The biological method in the wheat trial consisted in the measurement of the longest root of the wheat seedlings grown during 4 days in the $250 \mathrm{ml}$ plastic cups with the soil under the different treatments. After the trial, the soil samples were analysed for routine determinations, and also for the determinations of $\mathrm{S}-\mathrm{SO}_{4}^{2-}$ extracted with $\mathrm{CaCl}_{2} \quad 0,04 \mathrm{M}$ and with $\mathrm{Ca}\left(\mathrm{H}_{2} \mathrm{PO}_{4}\right)_{2} \quad 0,04$ $\mathrm{M}$. Analyses of the saturation extracts were made and the results submitted to GEOCHEM computer program for chemical speciation. The correlations of these data with the wheat seedling root lengths were studied through statistical analyses.

The following conclusions could be obtained: (1) gypsum doses calculated by calcium and aluminum criteria are in general higher than the doses to reach the maximum sulphate adsorption capacity of the soil; (2) maximum sulphate adsorption capacity correlates with the amounts of sulphate adsorbed from solutions with 20,30 or $40 \mathrm{ppm}$ of $S-S_{4}^{2-}$ and also with dpH values; (3) in the podzols with high aluminum content gypsum use doesn't enhance root growth 
as in latosols with excess of aluminum and/or calcium deficiency; (4) gypsum doses calculated by calcium and aluminum criteria don't correlate with wheat root growth and (5) the percentage of aluminum saturation is the soil parameter with the best correlation with wheat root growth. 


\section{INTRODUÇÃO}

A constatação feita no início desta década pelo Centro de Pesquisa Agropecuária do Cerrado, Planaltina-DF, de que o gesso contido no superfosfato simples provocara no milho o desenvolvimento de um sistema radicular mais profundo, comparado à parcela tratada com o superfosfato triplo, marcou época na pesquisa agronômica brasileira. Com isto, multiplicaram-se pelo país os experimentos com o gesso.

Os muitos resultados positivos, apesar de outros não tão conclusivos, entusiasmaram a indústria de fertilizantes e os agricultores na utilização agronômica deste produto.

Por parte da indústria de fertilizantes havia o interesse em dar um destino a este subproduto do processo de obtenção do ácido fosfórico, produzido na proporção de 4,0 a 5,0 toneladas de gesso por tonelada de $P_{2} O_{5}$. Como a capacidade atual de produção da indústria brasileira é de mais de 800 mil toneladas de $P_{2} O_{5}$, isto significa uma disponibilidade anual de quase 4 milhões de toneladas de gesso.

Para os agricultores, principalmente os localizados nas regiões dos cerrados, o gesso causou interesse pela possibilidade vislumbrada de resolver o problema do estresse hídrico causado pelos veranicos. Assim, mesmo na falta de critérios precisos de recomendação, alguns agricultores adotaram esta nova tecnologia.

Os critérios atualmente existentes na recomendação da dose de gesso, para a correção do ambiente radicular dos solos ácidos, baseiam-se na suposição da estequiometria entre a dose aplicada do produto e as alterações desejadas nos teores de cálcio e alumínio no solo.

Sabe-se, porém, que parte do efeito do gesso na melhoria do ambiente radicular é devida ao ânion sulfato, e a movimentação deste no solo é dependente da sua concentração na solução do solo, da quantidade de chuva e da capacidade de retenção (adsorção) de sulfato apresentada pelo solo. Ou seja, para uma dada precipitação pluviométrica e uma dada dose de gesso, quanto maior a 
adsorção, menor será a movimentação do sulfato no perfil do solo e vice-versa.

$\mathrm{O}$ presente trabalho teve por objetivos:

(1) estudar a adsorção de sulfato em amostras de terra do horizonte B de diferentes solos brasileiros e comparar as doses de gesso recomendadas pelos critérios do cálcio e do alumínio trocável com a capacidade de adsorção máxima de sulfato;

(2) estudar os efeitos de doses de gesso aplicadas em diferentes amostras de terra, no ensaio com trigo (Triticum aestivum, cv. Anahuac) e comparar estes efeitos com as doses de gesso recomendadas pelos critérios do cálcio e do alumínio. 


\section{REVISÃO BIBLIOGRÁFICA}

2.1. O enxofre no sistema solo-planta-atmosfera

O enxofre é um elemento relativamente móvel na solução do solo e é sujeito a muitas reações químicas e biológicas, envolvendo as suas formas sólida, líquida e gasosa, com variação da sua valência de +6 no $\mathrm{H}_{2} \mathrm{SO}_{4}$ a -2 no $\mathrm{H}_{2} \mathrm{~S}$. A Figura 1, modificada de PROBERT \& SAMOSIR (1983), permite uma visão simplificada da dinâmica do enxofre no sistema solo-planta-atmosfera. No solo ele ocorre como sulfato na solução, sulfato adsorvido, sulfato precipitado, como enxofre orgânico e como constituinte dos minerais.

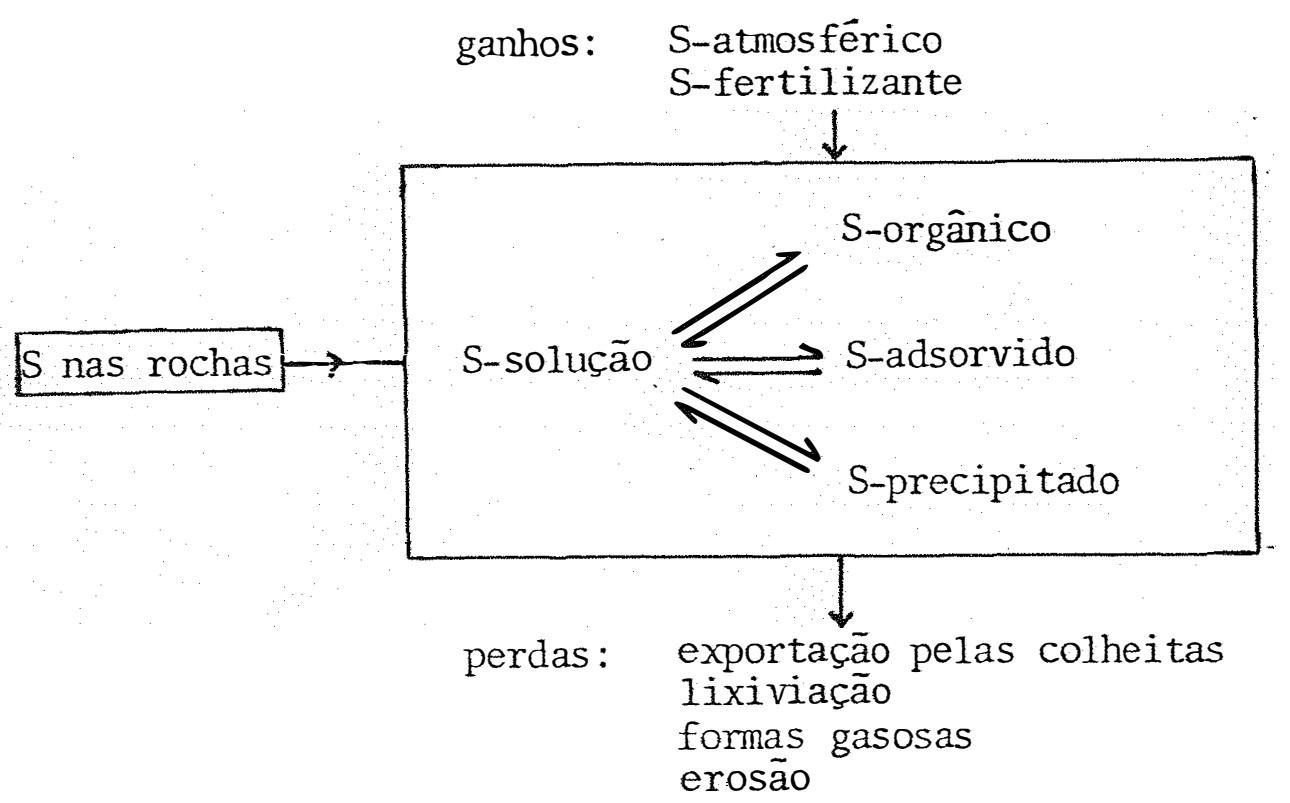

Figura 1. Balanço do enxofre no solo e equilíbrio do sulfato da solução com a fase sólida (modificada de PROBERT \& SAMOSIR, 1983). 
O teor de enxofre total varia bastante entre os solos. Nos solos tropicais o teor médio de enxofre total é, em geral, menor que $250 \mathrm{ppm}$, enquanto que os solos de clima temperado apresentam uma média ao redor de $400 \mathrm{ppm}$ (NEPTUNE et alii, 1975; KAMPRATH \& TILL, 1983; BARBER, 1984).

No Brasil, um dos primeiros estudos sobre o teor de enxofre nos solos foi realizado por MALAVOLTA (1952), que trabalhou com amostras do Estado de São Paulo, obtendo teores médios de enxofre total de $413 \mathrm{ppm}$ no horizonte A, $267 \mathrm{ppm}$ no horizonte B e $150 \mathrm{ppm}$ no horizonte C. Estudos posteriores realizados por NEPTUNE et alii (1975) e NASCIMENTO \& MORELLI (1980) mostraram teores médios de enxofre total ao redor de $230 \mathrm{ppm}$.

A maior parte do enxofre da camada superficial do solo está na forma orgânica. NEPTUNE et alii (1975), estudando amostras de solos brasileiros e americanos, encontraram S- orgânico variando de 77 a $95 \%$ nos primeiros e de 92 a $98 \%$ nos últimos. NASCIMENTO \& MORELLI (1980) não encontraram correlação significativa entre enxofre total e enxofre na forma de sulfato, bem como entre este e o enxofre orgânico, indicativo da não mineralização do enxofre orgânico na proporção de seu teor no solo.

As adições de enxofre no solo ocorrem através das precipitações atmosféricas, em geral menos que $5 \mathrm{~kg} \mathrm{~S} / \mathrm{ha}$.ano (KAMPRATH \& TILL,1983), e através dos fertilizantes, principalmente sulfato de amônio e superfosfato simples.

As perdas de enxofre pelo solo ocorrem através da exportação pelas colheitas, lixiviação, formas gasosas e erosão.

\subsection{Sulfato na solução do solo}

A forma mais importante de enxofre para as plantas é a de sulfato. A concentração de sulfato na solução é governada pelas adições, através de fertilizantes e de precipitações atmosféricas, e pelas reações com a fase sólida,sendo muito variável entre os solos. No entanto, é mais elevada nas regiões temperadas que nas tropicais. FRIED \& SHAPIRO (1961) observaram o sulfato na solução variando de 0,1 a $150 \mathrm{mM}(3,2$ a $4.800 \mathrm{ppm})$, com médias de $0,5 \mathrm{mM}$ (16 ppm) em solo ácido e $24 \mathrm{mM}$ (384 ppm) em solo calcário. Reisenauer (1964), citado por BARBER (1984), estudando 693 amostras de solo, observou variações do sulfato na solução do solo de quase zero a mais de 400 ppm, com quase $80 \%$ das amostras entre 25-e 100 ppm. Em solos tropicais, Fox (1980), citado por BARBER (1984), encontrou concentrações bem menores, variando de 0,4 a $16 \mathrm{ppm}(0,1$ a $0,5 \mathrm{mM})$. 
O sulfato da solução do solo está em equilíbrio dinâmico com o sulfato adsorvido à fase sólida. Sua concentração na solução do solo é dependente da porcentagem em que está saturando o complexo adsorvente, ou seja, ela aumenta com o aumento da porcentagem de sua saturação no complexo adsorvente (FOX, 1984).

De acordo com ADAMS (1971), na solução do solo o sulfato é bastante propenso à formação de pares iônicos, fazendo com que sua concentração efetiva na solução seja, de fato, menor que a acusada na análise. Isto ocorre porque considerável proporção dos cátions e ânions de certos eletrólitos fortes se atraem tão fortemente que eles comportam como se estivessem não-ionizados. Íons associados desta maneira são chamados de "par iônico". No caso de serem ambos de mesma valência, porém de cargas opostas, o par iônico resultante será neutro, como ocorre com o $\mathrm{Ca}^{2+}$ e o $\mathrm{SO}_{4}^{2-}$, formando $\mathrm{CaSO}_{4}^{0}$. Íons com cargas opostas de valências diferentes formain par iônico com carga residual, como ocorre com o $\mathrm{K}^{+}$ e o $\mathrm{SO}_{4}^{2-}$, formando $\mathrm{KSO}_{4}^{-}$ou com o $\mathrm{Al}^{3+}$ e o $\mathrm{SO}_{4}^{2-}$, formando o $\mathrm{AlSO}_{4}^{+}$. As reações de formação de pares iônicos do sulfato com os principais cátions de interesse agronômico e as respectivas constantes de equilíbrio são apresentadas na Tabela 1, feita com dados de LINDSAY (1979).

Tabela 1. Formação de pares iônicos entre íon sulfato e alguns cátions, com as respectivas constantes de equilíbrio, a $25^{\circ} \mathrm{C}$.

\begin{tabular}{|c|c|c|c|c|c|}
\hline \multicolumn{5}{|c|}{ Reação de equilibrio } & \multirow{2}{*}{$\frac{\log \mathrm{K}_{\mathrm{o}}}{3,20}$} \\
\hline $\mathrm{Al}^{3+}$ & + & $\mathrm{SO}_{4}^{2-}$ & $\Longrightarrow$ & $\mathrm{AlSO}_{4}^{+}$ & \\
\hline $\mathrm{Al}^{3^{\top}}$ & + & $2 \mathrm{SO}_{4}^{2-}$ & $\rightleftarrows$ & $\mathrm{Al}\left(\mathrm{SO}_{4}\right)_{2}^{-}$ & 1,90 \\
\hline & + & $3 \mathrm{SO}_{4}^{2-}$ & $\rightleftharpoons$ & $\mathrm{Al}_{2}\left(\mathrm{SO}_{4}\right)_{3}^{0}$ & $-1,88$ \\
\hline & + & $\mathrm{SO}_{4}$ & & $\mathrm{CaSO}_{4}$ & 2,31 \\
\hline $\mathrm{Mg}^{2+}$ & + & $\mathrm{SO}_{4}^{2-}$ & $\rightleftarrows$ & $\mathrm{MgSO}_{4}^{\circ}$ & 2,23 \\
\hline $\mathrm{K}^{+}$ & + & $\mathrm{SO}_{4}^{2-}$ & $\rightleftarrows$ & $\mathrm{KSO}_{4}^{-}$ & 0,85 \\
\hline $\mathrm{Na}^{+}$ & + & $\mathrm{SO}_{4}^{2-}$ & $\longrightarrow$ & $\mathrm{NaSO}_{4}^{-}$ & 0,70 \\
\hline $\mathrm{Fe}^{3+}$ & + & $\mathrm{SO}_{4}^{2-}$ & $\rightleftharpoons$ & $\mathrm{FeSO}_{4}^{+}$ & 4,15 \\
\hline $\mathrm{Fe}^{3+}$ & + & $2 \mathrm{SO}_{4}^{2-}$ & & $\mathrm{Fe}\left(\mathrm{SO}_{4}\right)_{2}^{-}$ & 5,38 \\
\hline $\mathrm{Fe}^{2+}$ & + & $\mathrm{SO}_{4}^{2-}$ & & $\mathrm{FeSO}_{4}^{0}$ & 2,20 \\
\hline $\mathrm{Mn}^{2+}$ & + & $\mathrm{SO}_{4}^{2-}$ & & $\mathrm{MnSO}_{4}^{0}$ & 2,26 \\
\hline $2 \mathrm{n}^{2+}$ & + & $\mathrm{SO}_{4}^{2-}$ & $\Longleftarrow$ & $\mathrm{ZnSO}_{4}^{\circ}$ & 2,33 \\
\hline $\mathrm{Cu}^{2+}$ & + & $\mathrm{SO}_{4}^{2}-$ & & $\mathrm{CuSO}_{4}^{4}$ & 2,36 \\
\hline $\mathrm{Cd}^{2+}$ & + & $\mathrm{SO}_{4}^{2-}$ & $\rightleftharpoons$ & $\mathrm{CdSO}_{4}^{4}$ & 2,45 \\
\hline $\mathrm{Pb}^{2+}$ & + & $\mathrm{SO}_{4}^{2-}$ & $\rightleftharpoons$ & $\mathrm{PbSO}_{4}^{0}$ & 2,26 \\
\hline
\end{tabular}

Fonte: LINDSAY (1979). 


\subsection{Adsorção de sulfato}

\subsubsection{Capacidade de adsorção de sulfato}

Lichtenwalter et alii (1923) e Mattson (1927), segundo METSON \& BLAKEMORE (1978), foram os primeiros pesquisadores a observar que os ânions eram adsorvidos pelos colóides do solo e retidos com diferentes forças.

Desde então inúmeras pesquisas foram conduzidas para determinar os fatores que afetam esta adsorção, bem como os mecanismos envolvidos na mesma. No início, as pesquisas convergiam principalmente para os solos de clima temperado. A partir da década passada, as pesquisas concentradas no estudo dos solos tropicais de cargas variáveis contribuíram para a melhor compreensão dos mecanismos envolvidos na adsorção do sulfato.

É generalizada a afirmativa de que a maior parte do enxofre do solo está na forma orgânica. Isto pode ser verdade quando se considera apenas a camada superficial dos solos em geral. No entanto, nas camadas subsuperficiais dos solos tropicais a maior parte do enxofre está na forma de sulfato. FOX (1982) observou que a adsorção de sulfato aumentava com a profundidade no perfil, registrando $1.310 \mu \mathrm{g}$ de $S-S_{4}^{2-} / \mathrm{g}$ de solo ou $8,18 \mathrm{meq} / 100 \mathrm{~g}$ de solo na camada de 35-60 cm de um Oxissolo em Porto Rico. Na Austrália, Probert (1977), citado por PROBERT \& SAMOSIR (1983), observou que mais de $80 \%$ do enxofre total na camada superior de $3,0 \mathrm{~m}$ do solo estavam na forma de sulfato.

A capacidade de adsorção de sulfato difere muito entre os solos, variando de alguns ppm até dezenas de meq/100 g de solo. Assim, BARROW (1970) relata uma faixa de 0,1-2,0 meq de $S-S_{4}^{2-} / 100 \mathrm{~g}$ de solo para um grupo de solos australianos, quando em equilíbrio com a solução contendo inicialmente 20 ppm de $S-S_{4}^{2-}$. BORNEMISZA \& LHANOS (1967) encontraram valores ao redor de $2 \mathrm{meq} / 100 \mathrm{~g}$ em Latossolos e em solos vulcânicos da Costa Rica. GEBHARDT \& COLEMAN (1974) citam que os solos do México, Colômbia e Havaí, derivados de cinzas vulcânicas, apresentam grandes capacidades de adsorção de sulfato: 10-20 $\mathrm{meq} / 100 \mathrm{~g}$ para as amostras superficiais e $15-60 \mathrm{meq} / 100 \mathrm{~g}$ para as subsuperficiais.

No Brasil, ALOISI et alii (1980), trabalhando com amostras superficiais do Estado de São Paulo, obtiveram valores de adsorção máxima variando de 5,18 a $55,56 \mu \mathrm{g}$ de $S-S O_{4}^{2-} / \mathrm{g}$ de solo $(0,032$ a $0,35 \mathrm{meq} / 100 \mathrm{~g})$, não muito diferentes dos obtidos por NEPTUNE et alii (1975) em 4 amostras do Estado de São Paulo e duas do Paraná, que variaram de 7 a $64 \mu \mathrm{g}$ de $S-S O_{4}^{2-} / \mathrm{g}$ de solo $(0,043$ a $0,40 \mathrm{meq} / 100 \mathrm{~g})$. COUTO et alii (1979), trabalhando com três solos do Estado 
de São Paulo, observaram valores de adsorção máxima de sulfato de 0,2 a 0,4 meq/100 g e de 0,4 a 1,1 meq/100 g, respectivamente, para os horizontes $A_{p}$ e $B_{2}$. ALVAREZ (1974), trabalhando com duas amostras superficiais de Latossolos do Estado de Minas Gerais, observou valores de adsorção máxima de sulfato da ordem de $39,7 \mu \mathrm{g}$ de $S-S_{4}^{2-} / \mathrm{g}$ de solo $(0,25 \mathrm{meq} / 100 \mathrm{~g})$ para o Latossolo Roxo e de 27,1 $\mu \mathrm{g}$ de $S-S_{4}^{2-} / \mathrm{g}$ de solo $(0,17 \mathrm{meq} / 100 \mathrm{~g})$ para o Latossolo Vermelho-Amarelo.

Percebe-se, pois, que a capacidade de adsorção máxima varia não só entre os solos, como também com a profundidade da amostragem no perfil do solo.

\subsubsection{Fatores que afetam a adsorção}

A pesquisa permitiu identificar os principais fatores que afetam a adsorção, tais como: natureza do complexo coloidal, $\mathrm{pH}$ do meio, tempo de reação, concentração do sulfato na solụção e cátions e ânions presentes (GASTON et alii, 1986).

\subsubsection{Natureza do complexo coloidal}

A importância da natureza do complexo coloidal na capacidade de adsorção do sulfato pelos solos, já observada por Mattson em 1927, foi reconfirmada nas inúmeras pesquisas que se seguiram.

ENSMINGER (1954) determinou a capacidade de adsorção de sulfato de um grande número de componentes coloidais do solo. Observou a seguinte ordem de magnitude de adsorção: alumina desidratada $>$ caulinita $>$ bauxita $>$ turfa (Florida peat) > limonita > alumina hidratada $>$ hematita $>$ goetita. É preciso lembrar, no entanto, que a adsorção foi medida em $\mathrm{pH}$ ao redor de 5,5 , podendo esta sequência ser diferente caso medida em outros valores de $\mathrm{pH}$.

KAMPRATH et alii (1956) observaram que solos com predomínio de argilas 1:1 e óxidos de ferro e alumínio adsorviam mais sulfato que solos com predomínio de argila $2: 1$, com a adsorção variando de zero a 2,71 meq de $S-$ $\mathrm{SO}_{4}^{2-} / 100 \mathrm{~g}$ solo.

A importância dos componentes mais intemperizados do solo foi 
constatada por muitos pesquisadores.

BERG \& THOMAS (1959) observaram que solos com predomínio de argila de 3 camadas (argilas do tipo 2:1) tinham pouca ou nenhuma atração por $\mathrm{Cl}^{-}$ou $\mathrm{SO}_{4}^{2-}$. Já a adsorção aniônica era bem evidente em solos com altos teores de argilas cauliníticas e óxidos de ferro e alumínio.

CHAO et alii (1962b), estudando o movimento do sulfato marcado com $S^{35}$ através de colunas de solo, observaram que solos com alta capacidade para retenção de sulfato caracterizavam-se por serem mais intemperizados, ácidos e com maiores teores de óxidos de ferro e alumínio livres, alumínio trocável e ainda, possivelmente, de compostos amorfos inorgânicos.

CHAO et alii (1962c) removeram alternadamente a matéria orgânica e os óxidos de ferro e alumínio livres de amostras de solos que reconhecidamente adsorviam sulfato e observaram que a retirada desses componentes causava redução na adsorção de sulfato. A seguir, CHAO et alii (1964) fizeram o experimento no sentido oposto, isto é, tomaram solos com baixa capacidade de retenção de sulfato e, através de tratamentos especiais, recobriram as partículas dos solos com óxidos de ferro ou de alumínio. Os autores observaram que esse recobrimento aumentava a adsorção de sulfato. No entanto, porcentualmente, com o óxido de alumínio a adsorção era maior que com o óxido de ferro. A adsorção, em ambos os casos, aumentou com a diminuição do $\mathrm{pH}$. Este aumento estacionou ao redor de $\mathrm{pH} \mathrm{4,0}$ para o óxido de alumínio, quando então ele começava a se dissolver. Já para o óxido de ferro,o aumento na adsorção foi medido até ao redor de $\mathrm{pH} 2,0$.

AYLMORE et alii (1967), estudando a adsorção e a dessorção do sulfato pelos constituintes do solo, observaram que apesar de serem diferentes os valores de adsorção de sulfato para a hematita $\left(\alpha-\mathrm{Fe}_{2} \mathrm{O}_{3}\right)$ e para a pseudoboemita $\left(\gamma-\mathrm{Al}_{2} \mathrm{O}_{3} \cdot \mathrm{H}_{2} \mathrm{O}\right)$, de 13,4 e $84,2 \mathrm{meq} / 100 \mathrm{~g}$, respectivamente, a adsorção apresentada por unidade de área superficial para ambos era a mesma, de 0,50 meq/m. Isto indicaria que o fenômeno de adsorção está relacionado com a área superficial disponível e que o mecanismo de adsorção é o mesmo tanto para o óxido de ferro como para o óxido de aJumínio. A adsorção máxima observada para a argila caulinítica (API-9) foi de 1,86 meq/100g. Outra constatação importante feita pelos autores foi quanto à reversibilidade do processo de adsorção nos materiais estudados. Enquanto ela foi quase completamente reversível na caulinita, já para os óxidos de ferro e alumínio ela foi quase irreversível, não tendo sido observado deslocamento significativo de sulfato até com o equivalente a $750 \mathrm{~mm}$ de chuva.

BARROW (1967) observou que a capacidade do solo em adsorver o sulfato correlacionava-se com o alumínio mas não com o ferro, ambos extraídos através de citrato-ditionito. 
HAQUE \& WALMSLEY (1974), trabalhando com amostras de solos das Índias Ocidentais, observaram adsorção máxima de sulfato variando de 100 a mais de $400 \mu \mathrm{g}$ de $S-S_{4}^{2-} / g$ de solo e que o sulfato adsorvido correlacionavase apenas com o teor de $\mathrm{Al}_{2} \mathrm{O}_{3}$. Estes autores, à semelhança de AYLMORE et alii (1967), observaram que apenas $32,7 \%$ do sulfato adsorvido na amostra Montserrat, com $40 \%$ de argila $\left(29,5 \%\right.$ de $\mathrm{Fe}_{2} \mathrm{O}_{3}$ e $1,38 \%$ de $\left.\mathrm{Al}_{2} \mathrm{O}_{3}\right)$ foram dessorvidos, em contraposição aos $76,4 \%$ da amostra Montreal, com 10

Os dados de pesquisa permitem-nos concluir que quanto à natureza do complexo coloidal a adsorção seguiria a seguinte ordem: óxido de alumínio livre > óxido de ferro livre $>$ caulinita > argilas 2:1. Nos solos com carga negativa permanente praticamente todo o sulfato está na solução do solo; já nos solos de cargas variáveis, especialmente aqueles com $\mathrm{pH}$ perto ou abaixo do ponto de carga zero, a maioria do sulfato está adsorvido.

\subsubsection{Efeito do $\mathrm{pH}$}

$\mathrm{O}$ aumento da adsorção de sulfato com o abaixamento do $\mathrm{pH}$ e vice-versa foram observados em vários trabalhos, tais como em ENSMINGER (1954), KAMPRATH et alii (1956), CHAO et alii (1963 e 1964), MEHLICH (1964), CHAO (1964), HARWARD \& REISENAUER (1966), CATANI et alii (1971), ELKINS \& ENSMINGER (1971), GEBHARDT \& COLEMAN (1974), COUTO et alii (1979), FOX (1982), MARSH et alii (1987) e ZHANG et alii (1987).

CHAO et alii (1963) observaram que o efeito do $\mathrm{pH}$ na adsorção de sulfato foi mais marcante nos solos com altos teores de sesquióxidos, alumínio trocável e/ou materiais amorfos.

MEHLICH (1964) alerta sobre a necessidade de se considerar o consumo de $\mathrm{OH}^{-}$no deslocamento de $\mathrm{SO}_{4}^{2-}$ adsorvido ao se avaliar a acidez do solo. O autor sugere que a acidez do solo seja dividida nos seus componentes $\mathrm{Hp}$ (cargas permanentes), $\mathrm{H}-\mathrm{v}$ (cargas $\mathrm{pH}$ dependentes ) e $\mathrm{H}$-an (cargas devidas a ânions, como o sulfato).

O aumento da adsorção com o abaixamento do $\mathrm{pH}$ é consistente com o aumento das cargas positivas do solo à medida que aumenta a acidez, conforme se verá ao discutir os mecanismos envolvidos na adsorção.

2.3.2.3. Tempo de reação 
Caso o período de tempo seja insuficiente para o adequado contato da super cie adsorvente com o sulfato que se move no solo, haverá menor adsorção e portanto maior mobilidade do sulfato no perfil do solo. Dados de pesquisa mostram que a adsorção é um processo dependente também do tempo de reação.

LIU \& THOMAS (1961) observaram que a adsorção do sulfato aumentou com o tempo até a 8 a semana, que foi o tempo máximo que eles estudaram. No entanto, o sulfato adsorvido nas primeiras vinte e quatro horas representa $73 \%$ do total adsorvido até a 8 a semana, indicando que a adsorção é um processo muito rápido na fase inicial.

CHAO et alii (1962a), estudando a adsorção de sulfato em 15 amostras de solos do Estado de Oregon (EUA) em função do tempo de equilibrio da suspensão solo:solução, de até 72 horas, observaram que com 4 horas de agitação o equilíbrio era atingido. Observaram, ainda, que não havia diferença quando a suspensão solo:solução era submetida a agitação contínua ou intermitente. Por conveniência prática, utilizaram nos seus estudos de adsorção a agitação da suspensão por 1 hora, descanso por 1 noite e agitação por mais 1 hora na manhã seguinte. Esta recomendação tornou-se de uso bastante generalizado nos estudos de adsorção de sulfato.

BARROW (1967), estudando a adsorção de sulfato em amostras superficiais de solos da Austrália, observou que o equilíbrio não era atingido mesmo com tempo de agitação de 48 horas. No entanto, para fins de padronização, estabeleceu como sendo de 24 horas o tempo necessário para o equilíbrio.

RAJAN (1978) observou que o equilíbrio de sulfato da solução com alumina hidratada, contendo pseudoboemita $[\mathrm{AlO}(\mathrm{OH})]$ e bayerita $\left[\mathrm{Al}(\mathrm{OH})_{3}\right]$ e com $\mathrm{PCZ}$ de 9,3 , era atingido muito rapidamente: $90 \%$ da reação se davam em 10 minutos e $95 \%$ em 1 hora. Observou, ainda, que não havia variação mensurável na adsorção no período entre 3 e 24 horas do início do experimento.

2.3.2.4. Concentração de sulfato na solução do solo

A adsorção de sulfato está intimamente relacionada com a concentração de sulfato na solução do solo. Assim, à medida que se aumenta a concentração de sulfato na solução, aumenta também sua adsorção pela fase sólida do solo. Esta relação é bastante estudada através das equações de Langmuir e de Freundlich.

A equação de Langmuir é dada por: 


$$
\frac{x}{m}=\frac{K b c}{1+K c}
$$

e a equação de Freundlich por:

$$
\frac{x}{m}=\mathrm{kc}^{n}
$$

onde:

$\frac{x}{m}=$ quantidade de sulfato adsorvido por unidade do adsorvente;

c = concentração do sulfato n a solução;

$\mathrm{b}=$ adsorção máxima de sulfato;

$K=$ constante de afinidade na equação de Langmuir;

$\mathrm{k}$ e $\mathrm{n}=$ constantes na equação de Freundlich.

A forma linear da equação de Langmuir é dada por :

$$
\frac{c}{x / m}=\frac{1}{K b}+\frac{1}{b} \cdot c
$$

e a de Freundlich por:

$$
\log \mathrm{x} / \mathrm{m}=\log \mathrm{k}+\mathrm{n} \log \mathrm{c}
$$

Ambas as equações são utilizadas para expressar matematicamente o aumento da adsorção de sulfato pela fase sólida do solo, à medida que aumenta sua concentração na solução. No entanto, são conflitantes as referências sobre qual das duas equações melhor expressaria a adsorção de sulfato.

ALOISI et alii (1980) e SINGH (1984) observaram que ambas as equações descreveram bem a adsorção do sulfato. KAMPRATH et alii (1956), AYLMORE et alii (1967), HASAN et alii (1970), ALVAREZ (1974), FOX (1984), entre outros, observaram que a equação de Langmuir expressava bem o fenômeno da adsorção. Já outros autores como CHAO et alii (1962a), BORNEMISZA \& LHANOS (1967), CATANI et alii (1971), observaram melhor correlação com a equação de Freundlich.

A principal razão em se preferir a equação de Langmuir é a possibilidade que ela oferece de se estimar o valor da adsorção máxima de sulfato do solo, o que não é possível através da equação de Freundlich.

Langmuir (1918), citado por HARTER \& SMITH (1981), ao desenvolver a sua equação fez várias considerações, muitas delas não encontra.das mesmo para a situação ideal para a qual ela foi elaborada, ou seja, a adsorção gasosa em uma superfície planar. 
HARTER \& BAKER (1977) afirmam que, apesar das restrições conceituais, o emprego da equação de Langmuir no estudo da adsorção é válido desde que utilizada para a obtenção da adsorção máxima e no estudo das correlações entre esta e outras propriedades do adsorvente. Contudo, não recomendam sua utilização quando se procura entender a dinâmica da adsorção e as forças de retenção. E na falta de algo melhor e mais prático ela foi e continua ainda sendo muito utilizada.

AYLMORE et alii (1967) observaram que abaixo da concentração de equilíbrio de $15 \mathrm{ppm}$ de $S-S_{4}^{2-}$ a adsorção podia ser descrita pela equação de Langmuir, mas para concentrações mais elevadas, a equação de Freundlich seria a mais indicada.

HASAN et alii (1970), estudando a adsorção de sulfato em solos vulcânicos do Havaí, observaram que quanto mais intemperizado o solo, menor era a concentração de sulfato na solução de equilíbrio necessária para a obtenção da adsorção máxima de sulfato, e que $5 \mathrm{ppm}$ de $S-S_{4}^{2-}$ na solução do solo já correspondiam a solos saturados com $60-80 \%$ da capacidade máxima de adsorção de sulfato.

RAJAN (1978), trabalhando com alumina hidratada, observou que acima da concentração de equilíbrio de $6 \mu \mathrm{eq} / \mathrm{ml}$ ou $96 \mathrm{ppm}$ de $S-S_{4}^{2-}$, havia um inexplicável e abrupto decréscimo na adsorção de sulfato, mostrando que nem sempre há aumento na adsorção com o aumento da concentração de sulfato.

COUTO et alii (1979) observaram que em baixas concentrações havia uma tendência em superestimar a adsorção máxima do sulfato, o oposto ocorrendo quando se trabalhava com concentrações elevadas.

FOX (1984) cita que , em geral, os solos não possuem valores bem definidos de adsorção máxima de sulfato. No entanto, dada a boa aplicabilidade prática deste parâmetro, principalmente para comparar solos, recomenda o cálculo da adsorção máxima com os dados de equilíbrios na solução do solo com menos de $10 \mu \mathrm{g}$ de $S-S_{4}^{2-} / \mathrm{ml}$.

2.3.2.5. Natureza dos ânions e cátions presentes no solo

AYRES \& HAGIHARA (1953), pesquisando a lixiviação de potássio aplicado ao solo como sais de diferentes ânions, observaram que praticamente não ocorriam perdas de fosfato e sulfato por lixiviação, em oposição ao que ocorria com o cloreto. Na falta de melhor explicação, os autores interpretaram 
os resultados como sendo uma adsorção simultânea de ânion e de cátion, ou seja, do fosfato e do sulfato de potássio.

Do ponto de vista agronômico, uma interação importante é a do fosfato com o sulfato. ENSMINGER (1954) e KAMPRATH et alii (1956) observaram que aumentando as doses de fosfato havia diminuição na adsorção de sulfato. METSON \& BLAKEMORE (1978), estudando a retenção de sulfato por solos da Nova Zelândia em relação ao efeito competitivo do fosfato, concluíram que em muitos solos pouco intemperizados, com baixo nivel de sulfato nativo adsorvido, o uso continuado apenas de superfosfato poderia causar um rápido declínio do enxofre disponível, pelos efeitos combinados da baixa capacidade de retenção de sulfato e da competição do íon fosfato mais fortemente adsorvido.

CHAO (1964) verificou que os seguintes ânions causavam redução na adsorção de sulfato: fosfato, molibdato, fluoreto, arsenato, selenato, oxalato e tartarato. Em pH variando de 4,0 a 6,0 o arsenato, o silicato, o acetato e o nitrato revelaram-se incapazes de reduzir a adsorção de sulfato.

KINJO \& PRATT (1971), em estudos de equilibrio de troca aniônica, observaram que o sulfato era mais fortemente adsorvido que o cloreto e o nitrato.

PARFITT (1978) dá a seguinte ordem de adsorção para os diferentes ânions: fosfato > molibdato > sulfato > cloreto > nitrato.

CHAO et alii (1963) observaram que a adsorção de sulfato, de acordo com os diferentes sais empregados, seguia a ordem $\mathrm{CaSO}_{4}>\mathrm{K}_{2} \mathrm{SO}_{4}>$ $\left(\mathrm{NH}_{4}\right)_{2} \mathrm{SO}_{4}>\mathrm{Na}_{2} \mathrm{SO}_{4}$. Notaram ainda que, dependendo do cátion que estiver saturando o solo, a adsorção segue a ordem de valência destes cátions, ou seja, $A l^{3+}>$ $\mathrm{Ca}^{2+}>\mathrm{K}^{+}$. Contudo, a influência do $\mathrm{pH}$ do meio foi maior que a da natureza dos cátions. Assim, à medida que o $\mathrm{pH}$ se aproximava da neutralidade a adsorção de sulfato diminuía, independentemente do cátion saturando o solo.

2.3.3. Mecanismos envolvidos na adsorção de sulfato

Desde as primeiras constatações da retenção do sulfato pelos solos procurou-se descobrir o mecanismo envolvido no fenômeno. No entanto, apesar das muitas pesquisas já realizadas, não existe ainda uma definição precisa sobre os mecanismos envolvidos na retenção de sulfato pelos solos. 
Mattson (1931), conforme citam CHANG \& THOMAS (1963), observando o aumento do $\mathrm{pH}$ com a adsorção de sulfato, concluiu que os ânions $\mathrm{OH}^{-}$ eram simplesmente substituídos pelos ânions $\mathrm{SO}_{4}^{2-}$. No entanto, este mecanismo não consegue explicar os experimentos onde a adsorção de sulfato se processa sem $\mathrm{o}$ aumento do $\mathrm{pH}$.

AYRES \& HAGIHARA (1953), ao tentarem explicar o porque da pouca lixiviação de $\mathrm{K}_{2} \mathrm{SO}_{4}$ e $\mathrm{K}_{3} \mathrm{PO}_{4}$ em solos onde havia pronta lixiviação de $\mathrm{KCl}$, concluíram que ocorria uma adsorção simultânea dos ânions e cátions daqueles sais , ou seja, a "adsorção molecular". No entanto, é difícil aceitar que sais tão ionizáveis possam ser retidos na forma molecular.

CHANG \& THOMAS (1963), para explicar o fenômeno do desaparecimento de ânions e cátions da solução, propõem um mecanismo que, para fins de facilidade de compreensão, foi dividido em reações com cátions e reações com ânions. Assumem, também, que inicialmente a argila está saturada com alumínio e recoberta com óxidos hidratados de $\mathrm{R}$ (ferro ou alumínio):

(1) Reações com cátions:

$$
y \mathrm{~K}^{+}+\mathrm{Al}_{x}-\operatorname{argila}+\mathrm{yH}_{2} \mathrm{O} \longrightarrow \mathrm{Al}_{x}(\mathrm{OH})_{y}-\left[\operatorname{argila}+\mathrm{y} \mathrm{H}^{+}\right.
$$

(2) Reações com ânions:

$$
z \mathrm{SO}_{4}+\mathrm{R}_{X}(\mathrm{OH})_{y}-\operatorname{argila} \longrightarrow \mathrm{R}_{X}\left[(\mathrm{OH})_{y-z}\left(\mathrm{SO}_{4}\right)_{z}\right]-\operatorname{argila}+z \mathrm{OH}^{-}
$$

Os sítios para a adsorção do potássio nos solos ácidos adviriam da troca e/ou hidrólise do alumínio da superfície das argilas, provocando o aumento de íons $\mathrm{H}^{+}$na solução. Ao mesmo tempo, o íon $\mathrm{SO}_{4}^{2-}$ substituiria os íons $\mathrm{OH}^{-}$ das coberturas oxídicas ( $\mathrm{ROH}$ ) das argilas. Estes íons $\mathrm{OH}^{-}$reagiriam então com os íons $\mathrm{H}^{+}$originados da primeira reação. $\mathrm{O} \mathrm{pH}$ final do sistema dependeria da taxa relativa das duas reações: hidrólise do alumínio provocada pelo cátion e deslocamento de $\mathrm{OH}^{-}$causado pelo $\mathrm{SO}_{4}^{2-}$. Em resumo, este mecanismo explicaria os fenômenos da seguinte maneira: (1) a adsorção de sulfato aumenta com o abaixamento do $\mathrm{pH}$, porque então as hidroxilas deslocadas são mais prontamente neutralizadas; (2) a maior afinidade do cátion com a fase trocável provocaria maior substituição do alumínio e consequentemente maior hidrólise; (3) do mesmo modo, o efeito do tempo favorecendo a adsorção seria explicado pela maior produção de $H^{+}$advinda da contínua hidrólise do alumínio, provocando neutralização de 
hidroxilas e levando a reação até o seu término. Seria, pois, uma reação dependente do $\mathrm{pH}$ e do tempo, na qual ambos, ânions e cátions, desapareceriam da solução.

HINGSTON et alii (1967) permitiram uma melhor visão do fenômeno ao distinguirem dois tipos de adsorção: não específica e específica. A adsorção não específica é definida como sendo aquela onde os ânions, na dupla camada difusa, estão equilibrando eletrostaticamente o excesso de carga positiva interna ao plano de Helmholtz. A magnitude destas cargas positivas, e portanto da adsorção não específica, varia com a força iônica da solução, a qualquer valor de $\mathrm{pH}$ abaixo do PCZ. A adsorção não específica é típica para ânions como $\mathrm{ClO}_{4}^{-}$, $\mathrm{Cl}^{-}$e $\mathrm{NO}_{3}^{-}$, e é ilustrada a seguir, tomando-se como exemplo o íon cloreto:

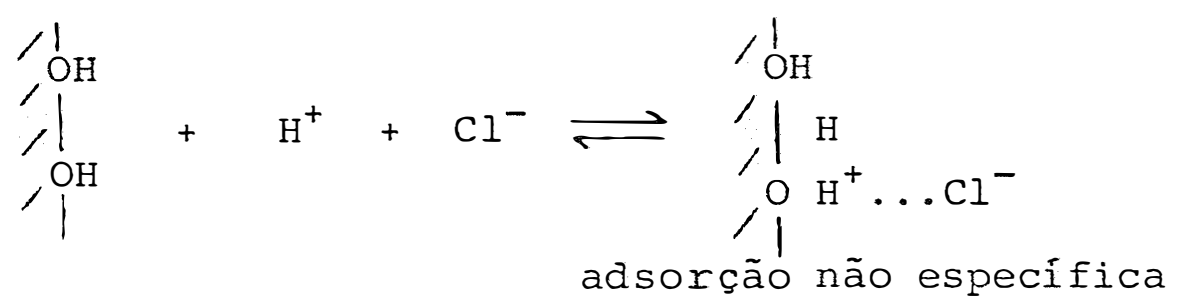

Já a adsorção específica é definida como sendo aquela onde os ânions entram na esfera de coordenação do íon metálico por deslocamento dos íons $\mathrm{OH}^{-}$, conforme ilustrado a seguir. De acordo com este modelo, um mol de $\mathrm{SO}_{4}^{2-}$ removido da solução (ou adsorvido como $\mathrm{HSO}_{4}^{-}$) neutraliza um mol de carga superficial:

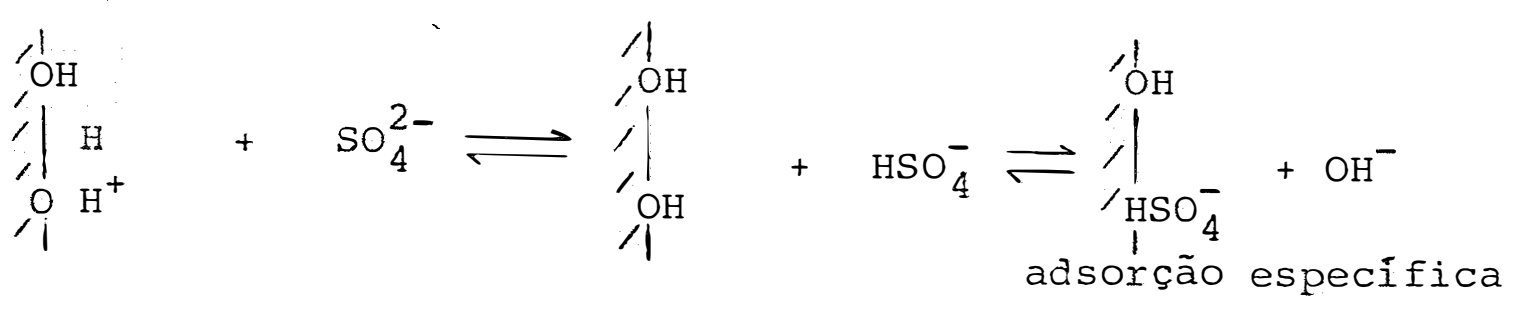

GEBHARDT \& COLEMAN (1974) apresentam dados suportando o mecanismo proposto por HINGSTON et alii (1967), onde o sulfato é especificamente adsorvido como $\mathrm{HSO}_{4}^{-}$. A necessidade da protonação do sítio de adsorção ou do $\mathrm{SO}_{4}^{2-}$,transformando-o em $\mathrm{HSO}_{4}^{-}$, é a explicação oferecida pelos autores para a dependência do $\mathrm{pH}$ do fenômeno, que tem seu máximo em $\mathrm{pH}=\mathrm{pKa}$, que no caso do $\mathrm{H}_{2} \mathrm{SO}_{4}$ é de 1,92 .

RAJAN (1978), não encontrando a estequiometria entre $\mathrm{SO}_{4}^{2-}$ adsorvido e $\mathrm{OH}^{-}$liberado, conforme proposto no modelo de HINGSTON et alii (1967), sugeriu um novo mecanismo para explicar a adsorção de sulfato por óxido hidratado de alumínio. Nele, as possíveis reações iniciais seriam $\mathrm{SO}_{4}^{2-}$ deslocando 
grupos $\mathrm{OH}_{2}$ dos sítios positivos (reação 1) ou ainda deslocando $\mathrm{OH}^{-}$dos sítios neutros (reação 2):

(1)

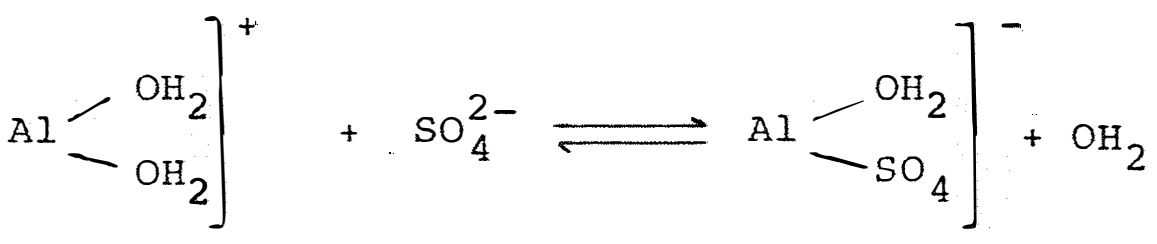

(2)

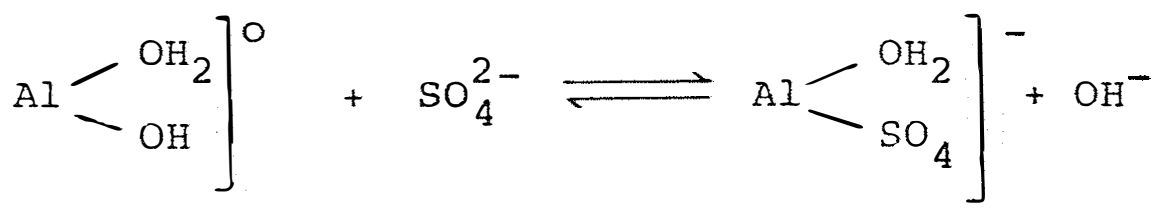

No entanto, como ambas as reações carregam a superfície com carga negativa, ao invés de carga neutra, a neutralização da carga negativa ocorreria, então, com o sulfato adsorvido deslocando outro elemento de ligação (tanto $\mathrm{OH}^{-}$de um sítio neutro ou $\mathrm{OH}_{2}$ de um sítio positivo) de um alumínio vizinho, dando uma formação anelada, como a seguir:

(3)

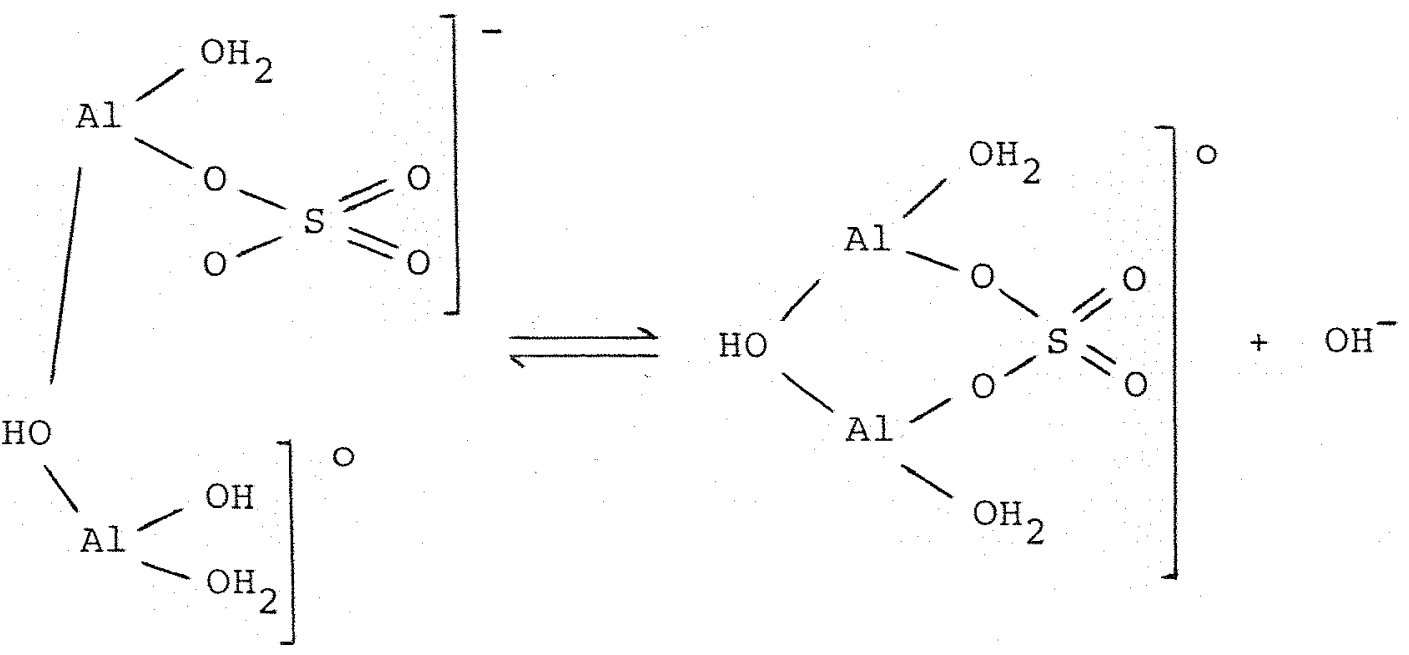

Na reação 3 , a neutralização da carga negativa se dá com o sulfato deslocando $\mathrm{OH}^{-}$do sítio neutro para a solução do solo. Quando o $\mathrm{SO}_{4}^{2-}$ adsorvido completa a estrutura anelar com um sítio positivo ao invés do sítio neutro, como 
na reação 3, o $\mathrm{OH}_{2}$ proveniente do sítio positivo será liberado na solução do solo.

$\mathrm{O}$ autor conclui que nas reações para a formação destas estruturas anelares pode ocorrer que 1 grupo $\mathrm{SO}_{4}^{2-}$ desloque 2 grupos $\mathrm{OH}_{2}$ ou 2 grupos $\mathrm{OH}^{-}$ ou ainda 1 grupo $\mathrm{OH}_{2}$ e um grupo $\mathrm{OH}^{-}$.

A estequiometria entre sulfato adsorvido e hidroxila liberada é dependente da proporção relativa dos grupos $\mathrm{OH}_{2}$ e $\mathrm{OH}^{-}$determinada pelo pH, que por sua vez determina a carga superficial:

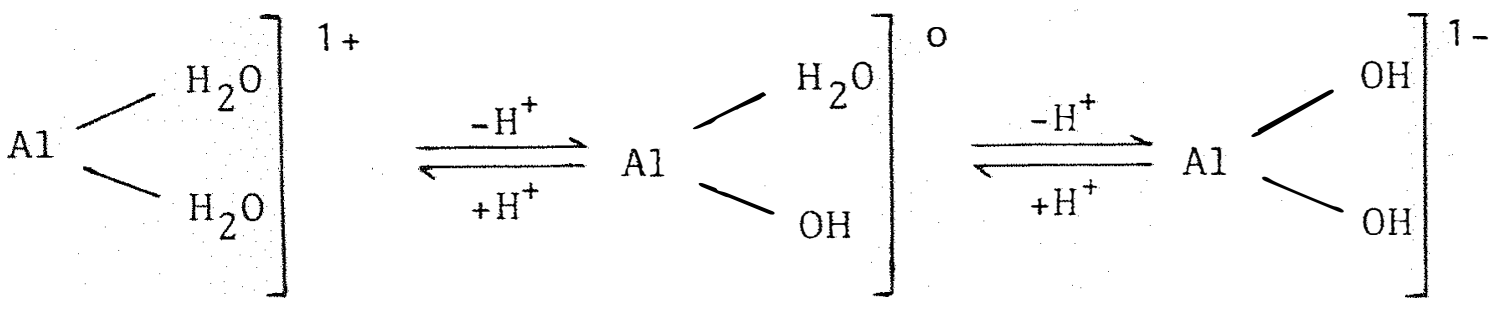

No ponto de carga zero há o mesmo número de grupos aquo e hidroxo na superfície. À medida que se aumenta a acidez do meio há a conversão dos grupos hidroxo em grupos aquo e vice-versa (RAJAN et alii, 1974).

PARFITT \& SMART (1978), estudando a adsorção de sulfato em óxidos de ferro com utilização inclusive de espectroscopia infravermelha, constataram que havia formação de uma estrutura binuclear complexa, conforme RAJAN (1978) havia proposto para o óxido de alumínio.

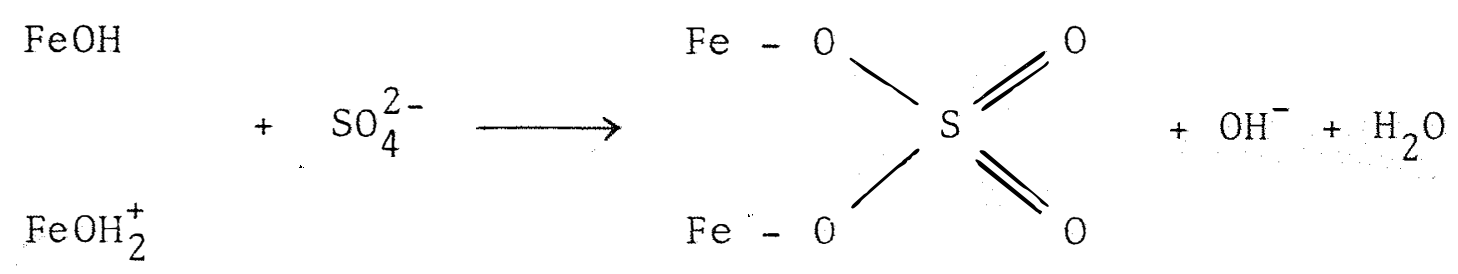

HINGSTON et alii (1974) já haviam observado que estas estruturas anelares favorecem a irreversibilidade, enquanto as ligações monodentadas são mais reversíveis.

Além destes mecanismos de adsorção, alguns autores consideram a hipótese de que o desaparecimento do sulfato da solução se daria por reações de precipitação, principalmente como sulfatos básicos de alumínio.

SINGH \& BRYDON (1967 e 1969) já haviam observado que em 
presença do íon sulfato o alumínio adsorvido à argila bentonita formava precipitados de sulfatos básicos de alumínio de composição geral $\mathrm{Al}_{4}(\mathrm{OH})_{10} \mathrm{SO}_{4} .5 \mathrm{H}_{2} \mathrm{O}$, similar à da basaluminita. Estudos posteriores, feitos por SINGH \& MILES (1978), provaram, através de exame de raio- $X$, que o produto formado era realmente a fase cristalina do sulfato básico de alumínio (basaluminita).

BREEMEN (1973), estudando a concentração de alumínio em solos ácidos ricos em sulfato, observou que o limite superior da concentração de alumínio era regulado por um sulfato básico de alumínio de composição estequiométrica $\mathrm{AlOHSO}_{4}$ e que a relação de solubilidade $\mathrm{pAl}+\mathrm{pOH}+\mathrm{pSO} \mathrm{S}_{4}=17,23$ era de utilidade na definição das condições ambientais, em termos de $\mathrm{pH}$ e de $\mathrm{SO}_{4}^{2-}$ na solução, para detectar concentrações de alumínio tóxicas às plantas. Assim, em concentrações de $S_{4}^{2-}$ de $5 \times 10^{-3} \mathrm{M}$, muito comuns nos solos estudados, a equação permite prever que a concentração tóxica de alumínio às plântulas de arroz ( 0,004 mM de alumínio) ocorre em valores de $\mathrm{pH}$ abaixo de 4,8.

GEBHARDT \& COLEMAN (1974) também citam não ser possível distinguir adsorção do sulfato da precipitação de sulfatos básicos de alumínio.

ADAMS \& RAWAJFIH (1977), baseando-se em trabalhos próprios, bem como em resultados obtidos por SINGH \& BRYDON (1967 e 1969) e BREEMEN (1973), propõem a precipitação dos íons sulfato formando basaluminita e alunita, sais básicos de alumínio de baixa solubilidade, como um possível mecanismo para explicar a retenção de sulfato pelos solos. $\mathrm{O}$ mesmo também se daria com o ferro. As seguintes reações explicariam o aumento do $\mathrm{pH}$ com a precipitação do sulfato:

$$
\begin{aligned}
& 4 \mathrm{Al}(\mathrm{OH})_{3}+\mathrm{SO}_{4}^{2-} \rightleftharpoons \frac{\mathrm{Al}_{4}(\mathrm{OH})_{10} \mathrm{SO}_{4}}{\text { basaluminita }}+2 \mathrm{OH}^{-} \\
& \text {3. } \mathrm{Al}(\mathrm{OH})_{3}+\mathrm{K}^{+}+2 \mathrm{SO}_{4}^{2-} \rightleftharpoons \frac{\mathrm{KAl}_{3}(\mathrm{OH})_{6}\left(\mathrm{SO}_{4}\right)_{2}}{\text { alunita }}+3 \mathrm{OH}^{-}
\end{aligned}
$$

Assim, para estes autores, a precipitação e a dissolução de basaluminita e alunita constituiriam mecanismos plausíveis para explicar os fenômenos de adsorção e dessorção de sulfato dos solos ácidos.

PAVAN (1988), em estudo de laboratório, observou a reação do 
$\mathrm{CaSO}_{4}$ com hidróxidos de alumínio formando basaluminita, na faixa de $\mathrm{pH}$ de 4,2 a 5,0, conforme diagrama na Figura 2.

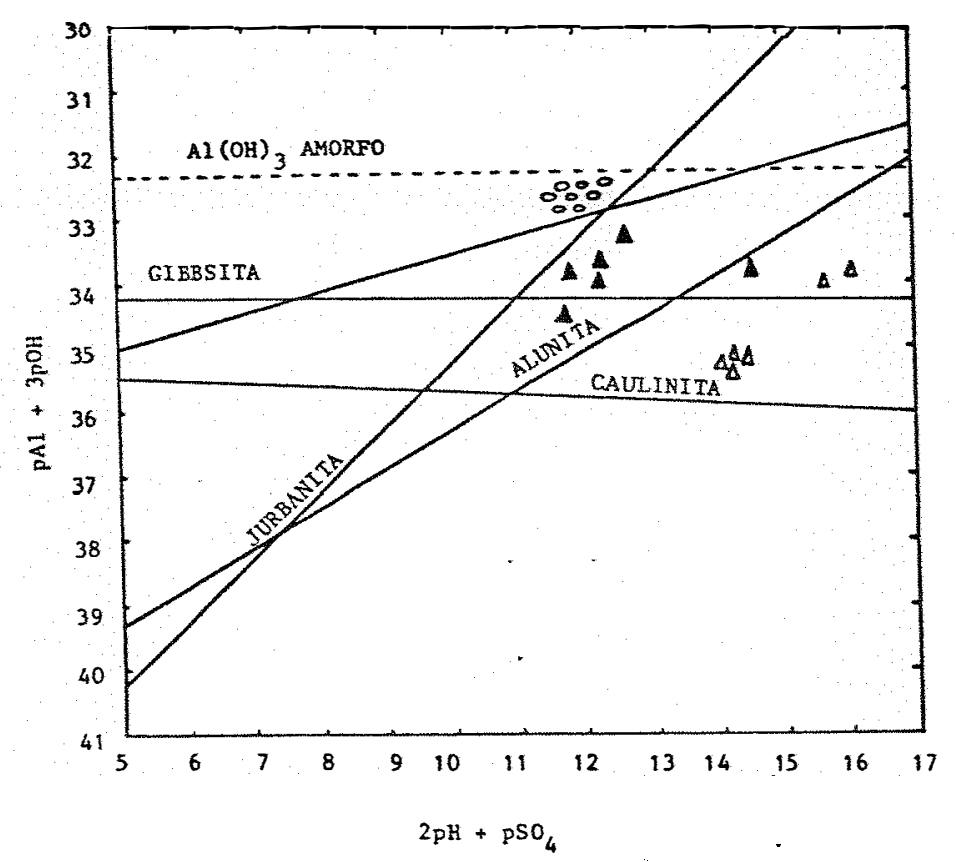

Figura 2. Diagrama de solubilidade para o sistema $A l-S O 4-H O H$ (PAVAN, 1988).

ADAMS \& HAJEK (1978) observaram que a concentração de $10^{-2} \mathrm{M}$ de $\mathrm{SO}_{4}^{2-}$ já era suficiente para precipitar o alumínio como sulfato básico de alumínio. A quantidade de basaluminita formada dependia diretamente da concentração de sulfato e inversamente do $\mathrm{pH}$ da solução reagente. A presença de íons $K^{+}$(a menor concentração estudada foi de $10^{-2} \mathrm{M}$ ) mostrou-se altamente efetiva na transformação da basaluminita amorfa em alunita cristalizada.

WOLT \& ADAMS (1979) estudaram a liberação do sulfato da basaluminita e da alunita aplicadas em solo com pH 6,5. Eles observaram que a taxa de liberação de sulfato pela basaluminita, medida através da absorção por plantas de algodoeiro, foi metade da apresentada pelo gesso. Já a liberação de sulfato pela alunita foi muito pequena. Os autores não explicam o porque da baixa liberação do sulfato pela alunita.

WOLT (1981), estudando a retenção de sulfato em solos poluídos com sulfato ácido na área de Copper Basin, no Tennessee (EUA), concluiu que ela era melhor explicada como consequência da baixa solubilidade do hidroxisulfato de alumínio formado. $\mathrm{O}$ produto de atividade iônica $\mathrm{p}(\mathrm{K})(\mathrm{Al})^{3}(\mathrm{OH})^{6}$ $\left(\mathrm{SO}_{4}\right)^{2}$ aproximou bastante com o pKsp da alunita na maioria das soluções dos solos analisados. 
NORDSTROM (1982), estudando as relações entre concentrações de alumínio e de sulfato na água concluiu que: (1) a força motriz para a transformação de minerais de argila como a caulinita e a gibbsita em sulfato básico de alumínio depende principalmente do $\mathrm{pH}$ e da atividade de sulfato; (2) uma concentração de sulfato de $10^{-4} \mathrm{M}$ e qualquer $\mathrm{pH}$ abaixo de 4,5 são condições suficientes para entrada no campo de estabilidade de um sulfato básico de alumínio; (3) a basaluminita amorfa é a primeira a precipitar, mesmo quando a alunita ou a gibbsita é a fase mais estável; (4) o sulfato acumulado é função do teor de alumínio do solo; (5) sob condições muito ácidas, como por ocasião da intemperização química pelas águas ácidas das minas, há a formação de alunogeno $\left[\left(\mathrm{Al}_{2}\left(\mathrm{SO}_{4}\right)_{3} \cdot 17 \mathrm{H}_{2} \mathrm{O}\right]\right.$. O autor também considera, da mesma maneira que ADAMS \& RAWAJFIH (1977), que a formação de compostos insolúveis de sulfato hidratado de alumínio pode ser a causa da retenção de sulfato pelos solos.

HUE et alii (1985), estudando a adsorção de sulfato no horizonte B de um Ultissolo com 17,3\% de argila, com predomínio de caulinita e gibbsita, concluíram que eram múltiplos os mecanismos envolvidos na adsorção. Assim, em pH abaixo de 5,l o mecanismo dominante era do tipo adsorção-precipitação, enquanto a $\mathrm{pH}$ maior que 5,6 o mecanismo dominante era do tipo de adsorção de eletrólito. Devido aos muitos resultados conflitantes sobre adsorção de sulfato pelo solo, e como o fenômeno não pode ser explicado adequadamente apenas por um único mecanismo, os autores sugerem a necessidade de experimentação adicional para os diferentes tipos de solos.

\subsection{Gesso agrícola}

\subsubsection{Casacterísticas}

De acordo com PAOLINELLI et alii (1986) o processo de obtenção de ácido fosfórico baseia-se na ação de um ácido sobre a rocha fosfática, finamente moída, previamente purificada e concentrada, seguindo-se a separação e a concentração do ácido fosfórico. O ácido empregado é o sulfúrico que, atacando a rocha fosfática, produz ácido fosfórico diluído, que é separado do sulfato de cálcio diidratado formado na reação. Este subproduto, também conhecido como fosfogesso, é produzido na razão de 4 a 5 toneladas por uma tonelada de $\mathrm{P}_{2} \mathrm{O}_{5}$ do ácido fosfórico.

A reação química do ataque do ácido sulfúrico sobre a rocha 
fosfática é:

$$
\begin{gathered}
\mathrm{Ca}_{10}\left(\mathrm{PO}_{4}\right)_{6} \mathrm{~F}_{2}+10 \mathrm{H}_{2} \mathrm{SO}_{4}+20 \mathrm{H}_{2} \mathrm{O} \rightarrow 10 \mathrm{CaSO}_{4} \cdot 2 \mathrm{H}_{2} \mathrm{O}+6 \mathrm{H}_{3} \mathrm{PO}_{4}+2 \mathrm{HF} \\
\text { Uma análise típica do gesso agrícola é dada a seguir: }
\end{gathered}
$$

$\begin{array}{lr}\text { Residuo insolưve1 } & 3,20 \% \\ \mathrm{R}_{2} \mathrm{O}_{3} & 0,59 \% \\ \mathrm{CaO} & 30,90 \% \\ \mathrm{~S} & 17,70^{\circ} \\ \mathrm{P}_{2} \mathrm{O}_{5} & 0,67 \% \\ \mathrm{~F} & 0,23 \% \\ \text { Unidade } & 15,50 \%\end{array}$

A solubilidade do $\mathrm{CaSO}_{4} \cdot 2 \mathrm{H}_{2} \mathrm{O}$ p.a. em g/100 $\mathrm{cm}^{3}$ é de $0,241 \mathrm{em}$ água fria e de $0,222 \mathrm{em}$ água quente a $100^{\circ} \mathrm{C}$ (WEAST, 1984).

seguir:

A reação de dissolução pode ser escrita conforme apresentado a

$$
\mathrm{CaSO}_{4} \cdot 2 \mathrm{H}_{2} \mathrm{O}=\mathrm{xCa}^{2+}+\mathrm{xSO}_{4}^{2-}+(1-\mathrm{x}) \mathrm{CaSO}_{4}^{0}+2 \mathrm{H}_{2} \mathrm{O}
$$

onde $\mathrm{x}<1$ e a notação $\mathrm{CaSO}_{4}^{0}$ representa um par iônico que é solúvel, porém sem carga (DONER \& LYNN, 1977).

2.4.2. Efeitos agronômicos do gesso

Os efeitos do gesso na melhoria do ambiente radicular no subsolo foram observados por SUMNER (1970) e REEVE \& SUMNER (1972).

No Brasil, o trabalho efetuado por RITCHEY et alii(1980), no Centro de Pesquisa Agropecuária dos Cerrados, da EMBRAPA, comprovou estes efeitos.

Informações recentes e abrangentes sobre o uso do gesso na agricultura encontram-se nas revisões feitas por RAIJ (1988) e SHAINBERG et alii (1988) e em SEMINÁRIO SOBRE USO DE FOSFOGESSO NA AGRICULTURA (1986). 
De uma maneira geral, os efeitos benéficos do gesso são explicados como sendo por: (1) fornecimento do enxofre como nutriente, (2) fornecimento do cálcio como nutriente e (3) diminuição da toxidez do alumínio.

McCLUNG et alii (1959), trabalhando com amostras de solos do cerrado, observaram que a adição de $20 \mathrm{~kg}$ de $\mathrm{S} /$ ha através do gesso era suficiente para se obter a produção máxima. VITTI et alii (1986) citam que o gesso é comprovadamente eficiente no fornecimento de enxofre em culturas anuais (leguminosas, gramíneas) e em culturas perenes (café) em doses que variam mais comumente de 20 a $40 \mathrm{~kg}$ de $\mathrm{S}$.

RITCHEY et alii (1983), trabalhando com amostra de terra retirada da camada de 90-105 cm de profundidade de um Latossolo Vermelho-Amarelo, com $\mathrm{pH}$ de $5,7, \mathrm{Ca}^{2+}=0,02 \mathrm{meq} / 100 \mathrm{~g}, \mathrm{Al}^{3+}=$ zero e aproximadamente $70 \%$ de argila, observaram que a mistura homogênea de 0,2 meq de $\mathrm{Ca}^{2+} / 100 \mathrm{~g}$ de solo proporcionava um crescimento na raiz do trigo consideravelmente maior que na amostra original e estabeleceram este teor como sendo o nível crítico de $\mathrm{Ca}^{2+}$ em solos sem problemas de toxidez de alumínio. DIAS et alii (1985) observaram que a adição de $0,2 \mathrm{meq}$ de $\mathrm{Ca}^{2+} / 100 \mathrm{~g}$ de solo, na forma de $\mathrm{CaSO}_{4}$, é suficiente para corrigir a deficiência de cálcio. Contudo, essa adição não é suficiente para possibilitar o crescimento satisfatório das raízes em solos que apresentam, além da deficiência de cálcio, também a toxidez de alumínio. Resultado idêntico já havia sido observado em solução nutritiva por PAVAN (1982), trabalhando com mudas de cafeeiro, ou seja,íons de $\mathrm{Ca}^{2+}$ fornecidos na forma de nitrato de cálcio, mesmo na dose máxima empregada de $1,25 \mathrm{mM}$, não amenizaram os efeitos tóxicos do alumínio, tanto na concentração de $0,074 \mathrm{mM}$ como na de $0,149 \mathrm{mM}$ de $A l^{3+}$.

Trabalhando com amostras de solo, PAVAN et alii (1982) observaram que o crescimento de mudas de cafeeiro correlacionou-se melhor com a atividade do alumínio da solução do solo, e que o provável efeito benéfico do gesso seria causado pela formação da espécie iônica $\mathrm{AlSO}_{4}^{+}$, o que diminuiria então a atividade do ín $A l^{3+}$ e, consequentemente, a sua toxidez para as raízes das plantas.

$\mathrm{Na}$ Figura 3 é apresentada a representação esquemática das reações de dissolução do gesso, associação iônica, adsorção, polimerização e movimentação dos íons no perfil do solo, de acordo com PAVAN \& VOLKWEISS (1986), com modificações. 


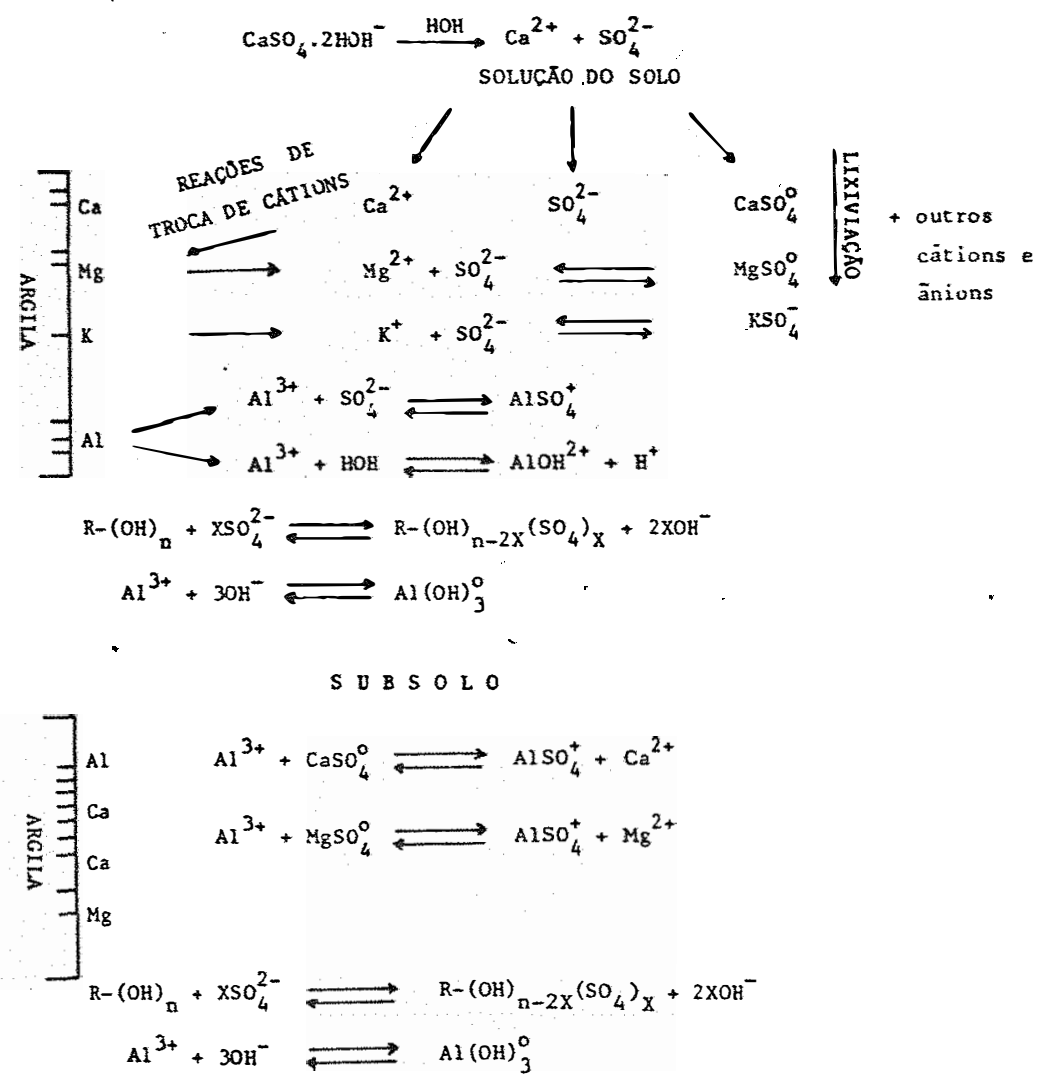

$$
\left\{\begin{array}{cc}
\mathrm{CaSO}_{4}^{\circ} & + \text { outros } \\
\mathrm{MgSO}_{4}^{\circ} & \text { cátions e } \\
& \text { ànions }
\end{array}\right.
$$

ÁGUA DE DRENAGEM

Figura 3. Representação esquemática das principais reações que ocorrem após a adição de gesso em solos ácidos (PAVAN \& VOLKWEISS, 1986, com modificações). 
2.4.3. Critérios de recomendação do gesso

Todos os critérios de recomendação da necessidade de gessagem existentes são critérios catiônicos, ou seja, baseiam-se na suposição da estequiometria entre doses aplicadas de gesso e efeitos desejados nos teores de $\mathrm{Ca}^{2+}$ e $\mathrm{Al}^{3+}$ do solo. Assim, PETROFERTIL (s.d.) recomenda como necessidade de gessagem (N.G.) a maior das doses obtidas pelas expressões abaixo, utilizando-se dos dados analíticos da camada subsuperficial $(20-40 \mathrm{~cm})$ do solo:

$$
\begin{aligned}
& \text { N.G. }(\mathrm{t} / \mathrm{ha})=\left(2-C a^{2+}\right) \times 2,5 \text { ou } \\
& \text { N.G. }(\mathrm{t} / \mathrm{ha})=\left(A l^{3+}-0,5\right) \times 2,5 .
\end{aligned}
$$

FREIRE et alii (1984) recomendam para o cafeeiro que o gesso seja usado preferivelmente em combinação com o calcário dolomítico, de maneira que 25 a $50 \%$ do $\mathrm{CaO}$ recomendado na calagem entre como gesso e os outros 50 a $75 \%$ como calcário, em função dos custos e disponibilidade destes insumos no local e do teor de $\mathrm{MgO}$ do calcário.

MALAVOLTA \& KLIEMANN (1985) sugerem, na falta de critério melhor, o uso de $2 \mathrm{t} /$ ha de gesso para cada 1 meq de $A l^{3+} / 100 \mathrm{~cm}^{3}$ de solo a "neutralizar" ou para cada 1 meq de $\mathrm{Ca}^{2+} / 100 \mathrm{~cm}^{3}$ de solo a aumentar, na camada de $20 \mathrm{~cm}$ do solo considerado.

UFG/EMGOPA (1988), para efeitos práticos e lembrando que o assunto ainda é polêmico no meio científico, recomenda, para Goiás, a aplicação simultânea de calcário e gesso na proporção de 25 a $30 \%$ deste em relação àquele, sem prejuízo da quantidade de calcário.

PAVAN (1988) cita o teste atualmente em estudo no laboratório do IAPAR para determinar a necessidade de gessagem em solos ácidos cultivados com frutíferas. O método consiste em preparar o extrato do solo com água e determinar a atividade de $\mathrm{Ca}^{2+}$ na solução com eletrodo específico. O teor de $\mathrm{Ca}^{2+}$ na solução tem que ser superior a $200 \mathrm{ppm}$. Devido às dificuldades na determinação da atividade de cálcio e à correlação existente entre este parâmetro e a condutividade elétrica, o autor estuda a possibilidade de utilizar a condutividade elétrica para estimar a atividade de cálcio. A eficiência do método está sendo testada pela relação entre a atividade de $\mathrm{Ca}^{2+}$ e/ou a condutividade elétrica com a porcentagem de $\mathrm{Ca}^{2+}$ nos frutos e a produção das plantas.

Não foi encontrado na presente revisão nenhum trabalho relacionando a adsorção de sulfato com a recomendação da necessidade de gessagem dos solos. Pelo exposto na revisão, tudo indica que a capacidade de adsorção de sulfato pelos solos seria um parâmetro adicional aos do $\mathrm{Ca}^{2+}$ e/ou do $\mathrm{Al}^{3+}$ de utilidade 
na recomendação da necessidade de gessagem. É, no entanto, um parâmetro adicional, pois ele não garante, "per se", que a dose para a adsorção máxima seja suficiente para provocar efeitos benéficos ao ambiente radicular. Indica, no entanto, se as doses recomendadas pelos critérios do $\mathrm{Ca}^{2+}$ e/ou do $\mathrm{Al}^{3+}$ são maiores ou menores que a capacidade do solo em retê-las, na camada do solo em estudo. 


\title{
3. MATERIAL E MÉTODOS
}

\author{
3.1. Material
}

3.1.1. Solos utilizados no estudo da adsorção de sulfato

Foram utilizadas 18 amostras de terra retiradas do horizonte B dos solos estudados, sendo 16 provenientes do Estadó de São Paulo, uma de Goiás e uma de Minas Gerais. A classificação ao nível de Grande Grupo e a análise granulométrica são dadas na Tabela 2, as características químicas das amostras na Tabela 3 e as características químicas da fração argila das amostras na Tabela 4. Os dados analíticos das Tabelas 2,3 e 4 foram obtidos no laboratório do Departamento de Solos, Geologia e Fertilizantes da ESALQ.

3.1.2. Solos utilizados no ensaio com ṫrigo

No estudo dos efeitos dos tratamentos no crescimento da raiz de trigo foram utilizadas 10 amostras escolhidas entre as 18 amostras citadas em 3.1.1., sendo três de solos PVA (amostras 6, 8 e 14), duas de LR (amostras 12 e 26 ), três de LE (amostras 16, 20 e 28) e duas de LVA (amostras 30 e 31). 
Tabela 2 - Classificação e granulometria ${ }^{1}$ das amostras do horizonte B dos solos estudados.

\begin{tabular}{|c|c|c|c|c|}
\hline Amostra & Classificaçãa & Areia & $\begin{array}{l}\text { Silte } \\
-(\%)-\end{array}$ & Argila \\
\hline 02 & Areia quartzosa & 74,0 & 7,9 & 18,1 \\
\hline 04 & Areia quartzosa & 75,8 & 9,5 & 14,7 \\
\hline 06 & Podzólico Vermelho-Amarelo latossólico & 72,5 & 11,5 & 16,0 \\
\hline 08 & Podzólico Vermelho-Amarelo abrupto & 61,9 & 17,5 & 20,6 \\
\hline 14 & Podzólico Vermelho-Amarelo & 24,9 & 31,0 & 44,1 \\
\hline 25 & Podzólico Vermelho-Amarelo Laras & 70,7 & 14,3 & 15,0 \\
\hline 22 & Planossolo & 6,2 & 29,0 & 64,8 \\
\hline 12 & Latossolo Roxo & 19,8 & 14,7 & 65,5 \\
\hline 26 & Latossolo Roxo & 20,6 & 23,7 & 55,7 \\
\hline 27 & Latossolo Roxo & 20,2 & 20,8 & 59,0 \\
\hline 16 & Latossolo Vermelho-Escuro & 20,4 & 15,9 & 63,7 \\
\hline 18 & Latossolo Vermelho-Escuro & 54,7 & 9,2 & 36,1 \\
\hline 20 & Latossolo Vermelho-Escuro & 32,9 & 16,6 & 50,5 \\
\hline 24 & Latossolo Vermelho-Escuro & 43,0 & 8,4 & 48,6 \\
\hline 28 & Latossolo Vermelho-Escuro & 32,8 & 17,1 & 50,1 \\
\hline 29 & Latossolo Vermelho-Amarelo & 35,7 & 17,8 & 46,5 \\
\hline 30 & Latossolo Vermelho-Amarelo & 41,3 & 22,0 & 36,7 \\
\hline 31 & Latossolo Vermelho-Amarelo & 26,3 & 19,4 & $54,3 \longleftarrow$ \\
\hline
\end{tabular}

1 Metodologia de BOUYOUCOS (1951). 
Tabela 3 - Características químicas das amostras estudadas ${ }^{1}$.

\begin{tabular}{|c|c|c|c|c|c|c|c|c|c|}
\hline \multirow[t]{2}{*}{ Amostra } & \multirow{2}{*}{$\begin{array}{c}p \mathrm{H} \\
\mathrm{H}_{2} \mathrm{O}\end{array}$} & \multirow{2}{*}{$\begin{array}{c}p H \\
\mathrm{CaCl}_{2}\end{array}$} & \multirow{2}{*}{$\begin{array}{l}\text { m.o. } \\
(\%)\end{array}$} & \multirow{2}{*}{$\begin{array}{l}\text { P resina } \\
\left(\mu \mathrm{g} / \mathrm{cm}^{3}\right)\end{array}$} & $K^{+}$ & $\mathrm{Ca}^{2+}$ & $M g^{2+}$ & $A l^{3+}$ & $T$ \\
\hline & & & & & \multicolumn{5}{|c|}{$-\cdots--\left(\mathrm{meq} / 100 \mathrm{~cm}^{3}\right)^{-\cdots-\cdots}$} \\
\hline 02 & 4,8 & 4,2 & 0,37 & 0,8 & 0,11 & 0,14 & 0,32 & 0,30 & 2,82 \\
\hline 04 & 4,4 & 3,8 & 0,19 & 0,8 & 0,06 & 0,06 & 0,20 & 3,14 & 12,44 \\
\hline 06 & 4,5 & 3,9 & 0,28 & 0,8 & 0,07 & 0,13 & 0,13 & 2,78 & 10,15 \\
\hline 08 & 4,6 & 3,8 & 0,28 & 0,4 & 0,10 & 1,08 & 0,75 & 5,07 & $20 ; 40$ \\
\hline 14 & 4,7 & 3,8 & 0,84 & 1,2 & 0,21 & 1,14 & 1,00 & 5,62 & 20,82 \\
\hline 25 & 4,6 & 3,9 & 0,37 & 0,8 & 0,09 & 0,14 & 0,11 & 5,12 & 20,86 \\
\hline 22 & 4,7 & 4,1 & 0,93 & 2,0 & 0,41 & 2,14 & 2,25 & 2,85 & 15,71 \\
\hline 12 & 4,8 & 4,2 & 1,30 & 1,6 & 0,07 & 0,47 & 0,21 & 0,86 & 7,91 \\
\hline 26 & 5,3 & 4,8 & 1,58 & 9,7 & 0,04 & 3,16 & 0,72 & 0,20 & 10,36 \\
\hline 27 & 4,7 & 4,4 & 1,30 & 4,1 & 0,21 & 1,94 & 0,79 & 0,50 & 7,64 \\
\hline 16 & 4,3 & 4,0 & 0,65 & 0,8 & 0,04 & 0,28 & 0,11 & 1,39 & 5,65 \\
\hline 18 & 4,5 & 3,9 & 1,30 & 1,2 & 0,03 & 0,45 & 0,13 & 0,67 & 8,56 \\
\hline 20 & 5,1 & 4,3 & 0,47 & 0,8 & 0,08 & 0,51 & 0,51 & 0,69 & 4,91 \\
\hline 24 & 4,7 & 4,3 & 0,74 & 1,2 & 0,02 & 0,94 & 0,11 & 0,54 & 4,88 \\
\hline 28 & 4,9 & 4,1 & 3,40 & 4,0 & 0,11 & 0,40 & 0,21 & 0,60 & 4,52 \\
\hline 29 & 4,8 & 4,4 & 2,70 & 1,0 & 0,12 & 0,66 & 0,27 & 0,99 & 6,85 \\
\hline 30 & 4,1 & 4,1 & 1,00 & 3,0 & 0,04 & 0,14 & 0,07 & 1,00 & 4,45 \\
\hline 31 & 5,1 & 4,9 & 0,90 & 1,0 & 0,03 & 0,10 & 0,06 & 0,10 & 1,49 \\
\hline
\end{tabular}

1 Metodologia: RAIJ \& QUAGGIO (1983), exceto pH em água $(1: 2,5)$ e $A l^{3+}$ por extração com $\mathrm{KCl} 1 \mathrm{~N}$. 
Tabela 4 - Porcentagem de argila e características químicas da fração argila das amostras estudadas.

\begin{tabular}{|c|c|c|c|c|c|c|c|}
\hline Amostra & $K i$ & Argila & $\mathrm{Al}_{2} \mathrm{O}_{3}^{(1)}$ & $\begin{array}{c}\mathrm{Fe}_{2} \mathrm{O}_{3}^{(2)} \\
\text { livre }\end{array}$ & Caulinita(3) & Gibbsita ${ }^{(3)}$ & $\begin{array}{c}\mathrm{Fe}_{2} \mathrm{O}_{3} \text { (livre) } \\
+ \text { gibbsita }\end{array}$ \\
\hline & $\cdots$ & $\cdots-\cdots$ & $\cdots \cdots$ & $\cdots \%$ & $\nabla S E) \ldots$ & $\ldots . .$. & $\ldots$ \\
\hline 02 & 0,7 & 18,1 & 10,0 & 1,4 & 7,9 & 8,8 & 10,2 \\
\hline 04 & 1,4 & 14,7 & 8,1 & 0,5 & 11,3 & 2,9 & 3,4 \\
\hline 06 & 1,3 & 16,0 & 8,0 & 0,7 & 11,6 & 3,7 & 4,4 \\
\hline 08 & 2,0 & 20,6 & 9,3 & 0,8 & 19,8 & 0,0 & 0,8 \\
\hline 14 & 2,3 & 44,1 & 14,6 & 2,2 & $41,9(4)$ & 0,0 & 2,2 \\
\hline 25 & 1,8 & 15,0 & 9,1 & 0,9 & 13,2 & 0,9 & 1,8 \\
\hline 22 & 2,6 & 64,8 & 20,4 & 2,4 & $62,4(4)$ & 0,0 & 2,4 \\
\hline 12 & 1,4 & 65,5 & 24,6 & 9,4 & 44,6 & 11,5 & 20,9 \\
\hline 26 & 1,5 & 55,7 & 21,7 & 7,2 & 40,4 & 8,1 & 15,3 \\
\hline 27 & 1,6 & 59,0 & 24,7 & 5,2 & 73,8 & 7,0 & 12,2 \\
\hline 16 & 1,7 & 63,7 & 23,2 & 6,4 & 51,8 & 5,5 & 11,9 \\
\hline 18 & 1,1 & 36,1 & 14,4 & 5,3 & 20,7 & 10,1 & 15,6 \\
\hline 20 & 1,4 & 50,5 & 22,2 & 3,8 & 37,2 & 9,5 & 13,3 \\
\hline 24 & 1,3 & 48,6 & 18,1 & 6,0 & 32,4 & 10,4 & 16,4 \\
\hline 28 & 1,2 & 50,1 & 22,2 & 6,1 & 31,4 & 12,6 & 18,7 \\
\hline 29 & 1,7 . & 46,5 & 19,3 & 5,7 & 36,9 & 3,9 & 9,6 \\
\hline 30 & 1,7 & 36,7 & 13,0 & 2,2 & 31,2 & 3,3 & 5,5 \\
\hline 31 & 1,7 & 36,7 & 26,0 & 4,0 & 38,0 & 12,3 & 16,3 \\
\hline
\end{tabular}

(1) $\mathrm{Al}_{2} \mathrm{O}_{3}$ extraído com $\mathrm{H}_{2} \mathrm{SO}_{4} \mathrm{~d}=1,47$ (VETTORI, 1969).

(2) $\mathrm{Fe}_{2} \mathrm{O}_{3}$ livre extraído por ditionito-citrato-bicarbonato de sódio (MEHRA \& JACKSON, 1960).

(3) Caulinita e gibbsita em \% de TFSE foram calculadas através das fórmulas de KINJO $(1988)^{1}$.

(caulinita + gibbsita) $\%=$ argila $\%-\mathrm{Fe}_{2} \mathrm{O}_{3}$ livre $\%$

gibbsita $\%=($ caulinita + gibbsita $) \cdot\left(1-\frac{0,833 . K i}{1+0.333 \cdot K \bar{i}}\right)$

(4) Caulinita + outras argilas silicatadas.

${ }^{1}$ KINJO, T. (Escola Superior de Agricultura "Luiz de Queiróz" - USP, Piracicaba) Comunicação Pessoal, 1988. 
3.1.3. Cultivar utilizado no ensaio com trigo

No ensaio de crescimento de raiz foram utilizadas sementes de trigo (Triticum aestivum), cultivar Anahuac, sensível ao alumínio. As sementes foram gentilmente cedidas pelo Dr. Carlos Eduardo de Oliveira Camargo, da Seção de Trigo do Instituto Agronômico de Campinas-SP.

3.2. Métodos

\subsubsection{Adsorção de sulfato}

Cinco gramas de TFSA foram transferidos para tubos de centrífuga de $50 \mathrm{ml}$ aos quais foram adicionados $25 \mathrm{ml}$ de solução de sulfato de cálcio $\left(\mathrm{CaSO}_{4} \cdot 2 \mathrm{H}_{2} \mathrm{O}\right)$ com concentrações de $10,20,30,40,60$ e $80 \mathrm{ppm}$ de $S-\mathrm{SO}_{4}^{2-}$. A seguir foram agitados durante 1 hora, deixados em repouso por 24 horas, adicionados $0,25 \mathrm{~g}$ de carvão ativado, agitados por mais 1 hora, centrifugados e filtrados. A concentração de sulfato no filtrado foi determinada por turbidimetria do $\mathrm{BaSO}_{4}$, conforme Vitti \& Suzuki (1978), citados por VITTI (1988).

Nas amostras $06,24,26,27,30$ e 31 foram utilizadas soluções de sulfato de cálcio em concentrações de $20,30,40,60,120$ e $240 \mathrm{ppm}$ de $S-S_{4}^{2-}$, que permitiram dados com melhor adequação à equação de Langmuir.

A adsorção em cada uma das concentrações utilizadas foi calculada pela diferença entre a quantidade de sulfato adicionado e a quantidade de sulfato remanescente no filtrado.

A adsorção máxima de sulfato foi calculada através da forma linear da equação de Langmuir:

$$
\frac{c}{x / m}=\frac{1}{K b}+\frac{1}{b} \cdot c
$$




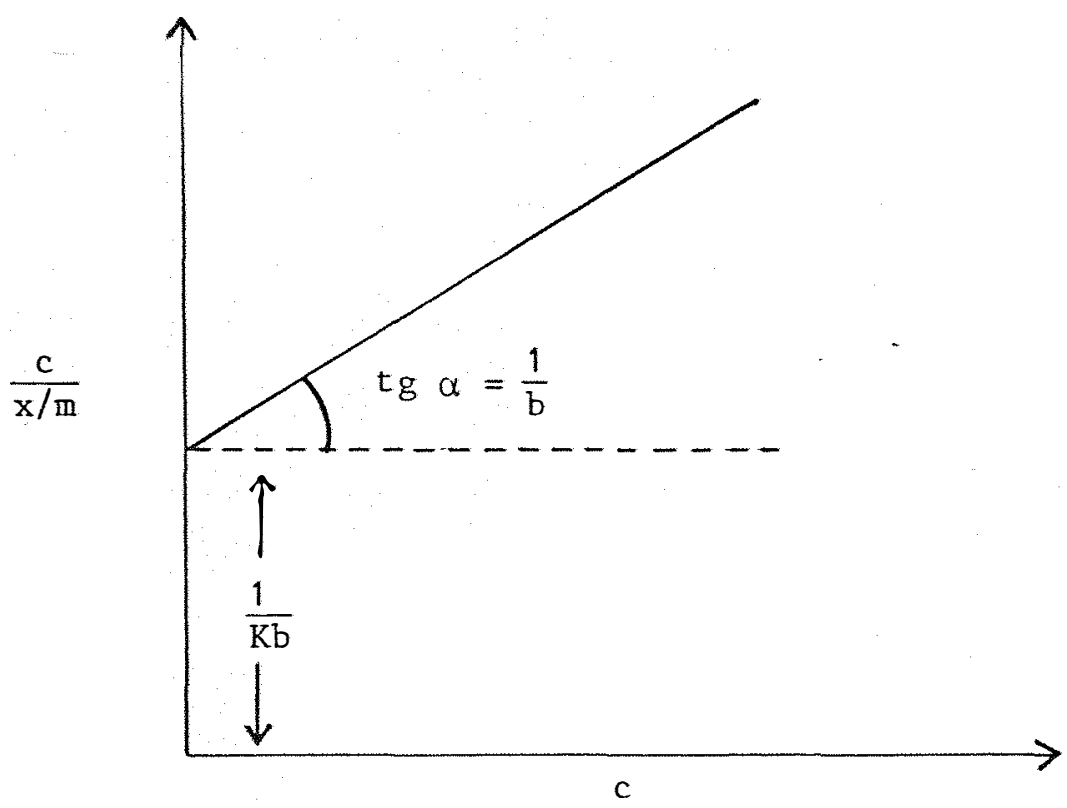

onde:

$\mathrm{x} / \mathrm{m}=$ sulfato adsorvido

c = concentração de sulfato na solução de equilíbrio

$\mathrm{K} \quad=$ constante de afinidade

$\mathrm{b} \quad=$ adsorção máxima de sulfato

3.2.2. $\mathrm{d} \mathrm{pH}=\mathrm{pH} \mathrm{K}_{2} \mathrm{SO}_{4}-\mathrm{pH} \mathrm{KCl}$

Soluções de $\mathrm{K}_{2} \mathrm{SO}_{4} 1 \mathrm{~N}$ e $\mathrm{KCl} 1 \mathrm{~N}$ foram adicionadas nas amostras na proporção solo : solução de $1: 5$, ou seja, $5 \mathrm{~g}$ de terra e $25 \mathrm{ml}$ da solução. A seguir, as amostras foram agitadas por 1 hora, deixadas em repouso por 24 horas e agitadas novamente por 1 hora, sendo então lido o $\mathrm{pH}$ das suspensões em $\mathrm{K}_{2} \mathrm{SO}_{4}$ e em $\mathrm{KCl}$.

3.2.3. Ensaio com trigo: método biológico

Foi utilizado o método biológico descrito por RITCHEY et alii (1983) com algumas modificações. O método consiste basicamente na medição 
do comprimento da maior raiz de plântulas crescidas por quatro dias em copos plásticos descartáveis de $250 \mathrm{ml}$ de capacidade, contendo a amostra de solo com o tratamento desejado.

Os tratamentos consistiram da testemunha, 5 doses de $\mathrm{CaSO}_{4} \cdot 2 \mathrm{H}_{2} \mathrm{O}$ e uma dose de $\mathrm{CaCl}_{2} \cdot 2 \mathrm{H}_{2} \mathrm{O}$, conforme Tabelas 5 e 6, com quatro repetições em blocos inteiramente casualizados.

Após o tratamento as amostras de solo nos copos foram umedecidas até $60 \%$ das respectivas capacidades de embebição, colocadas dentro de caixa com fundo forrado com papel toalha umedecido, cobertas com plástico translúcido e deixadas em repouso durante uma semana. Após este período o plástico foi retirado e 5 sementes de trigo pré-germinadas foram plantadas em orifícios abertos na superfície do solo de cada copo. As caixas contendo os copos foram recobertas novamente com o plástico translúcido. Após o período de crescimento de quatro dias as plântulas de trigo foram retiradas dos copos. Foi medida a raiz mais longa de 3 plântulas por copo e utilizado o valor médio dos comprimentos anotados. De cada 4 repetições duas amostras foram enviadas para a análise de solo de rotina e as duas restantes foram transformadas numa amostra única para a análise do extrato de saturação.

Tabela 5 - Tratamentos efetuados nas diferentes amostras de terra no ensaio com trigo.

\begin{tabular}{cl} 
Tratamento & \multicolumn{1}{c}{ Dose } \\
\hline$T_{0}$ & Testemunha \\
$T_{1}$ & $12,5 \%$ da dose $T_{4}$ em $\mathrm{CaSO}_{4} \cdot 2 \mathrm{H}_{2} \mathrm{O}$ \\
$T_{2}$ & $25 \%$ \\
$T_{3}$ & $50 \%$ \\
$T_{4}$ & $100 \%$ \\
$T_{5}$ & $200 \%$ \\
$T_{6}$ & $100 \%$ da dose $T_{4} \mathrm{em} \mathrm{CaCl}_{2} \cdot 2 \mathrm{H}_{2} \mathrm{O}$
\end{tabular}


Tabela 6 - Quantidades de $\mathrm{CaSO}_{4} \cdot 2 \mathrm{H}_{2} \mathrm{O}$ aplicadas no tratamento $\mathrm{T}_{4}$ das diferentes amostras de terra no ensaio com trigo.

\begin{tabular}{cc}
\hline Amostra & $\mathrm{C}_{\star} \mathrm{SO}_{4} \cdot 2 \mathrm{H}_{2} \mathrm{O}\left(\mathrm{meq} / 100 \mathrm{~cm}^{3}\right)$ \\
\hline 6 & 0,47 \\
8 & 1,86 \\
14 & 2,05 \\
12 & 2,37 \\
26 & 0,87 \\
16 & 2,14 \\
20 & 2,22 \\
28 & 1,97 \\
30 & 0,95 \\
31 & 1,72 \\
\hline
\end{tabular}


3.2.4. Extrato da pasta saturada

O extrato da pasta saturada foi obtido conforme RHOADES (1982). No extrato determinou-se $\mathrm{Ca}, \mathrm{Mg}, \mathrm{Mn}, \mathrm{Zn}$ e Fe por espectrofotometria de absorção atômica; $\mathrm{K}$ por fotometria de chama; $\mathrm{NO}_{3}^{-}$por colorimetria (MIYAZAWA et alii, 1985); $\mathrm{SO}_{4}^{2-}$ indiretamente por absorção atômica (HUE \& ADAMS, 1979); $\mathrm{Cl}^{-}$por titulação automática com nitrato de prata (ESTADOS UNIDOS, 1969).

Os dädos obtidos foram submetidos a especiação química através do programa de computação GEOCHEM (SPOSITO \& MATTIGOD, 1980). 


\title{
4. RESULTADOS E DISCUSSÃo
}

\author{
4.1. Adsorção de sulfato
}

A capacidade de adsorção máxima de sulfato (b) e a constante de afinidade $(\mathrm{K})$ das amostras de terra em estudo, calculadas através da forma linear da equação de Langmuir, são apresentadas na Tabela 7 .

As quantidades de sulfato adsorvidas pelas amostras de terra quando em equilíbrio com soluções de $\mathrm{CaSO}_{4}$, com concentração inicial de 20, 30 e 40 ppm de $S-S O_{4}^{2-}$, são dadas na Tabela 8.

Os valores de $\mathrm{pH}$ medidos nas suspensões solo: solução (1:5) com $\mathrm{K}_{2} \mathrm{SO}_{4} 1 \mathrm{~N}$ e $\mathrm{KCl} 1 \mathrm{~N}$ e os da diferença entre ambos (dpH) são apresentados na Tabela 9 .

As correlações estudadas entre a capacidade de adsorção máxima de sulfato e algumas características das amostras são apresentadas na Tabela 10. Das características analisadas, quatro deram correlações estatisticamente significativas: as quantidades de sulfato adsorvidas de soluções contendo 20,30 e $40 \mathrm{ppm}$ de $S-S_{4}^{2-}$ (Figuras 4, 5 e 6) e o dpH (Figura 7). 
Tabela 7 - Capacidade de adsorção máxima de sulfato (b) e constante de afinidade (K) das amostras, obtidas através da equação de Langmuir.

\begin{tabular}{|c|c|c|c|c|}
\hline \multirow[t]{2}{*}{ Amostra } & \multirow[t]{2}{*}{ Classificação } & \multicolumn{2}{|c|}{$\begin{array}{c}\text { Capacidade de adsorção máxima } \\
\text { de Sulfato (b) }\end{array}$} & \multirow{2}{*}{$\begin{array}{l}\text { Constante de } \\
\text { Afinidade (K) } \\
(m l / \mu g)\end{array}$} \\
\hline & & $\begin{array}{c}\left(\mu g S-S O_{4}^{2-} / g\right. \\
T F S E)\end{array}$ & $\begin{array}{c}\left(m e q S-S O_{4}^{2-} / 100 \mathrm{~g}\right. \\
T F S E)\end{array}$ & \\
\hline 02 & $\mathrm{AQ}$ & 109 & 0,68 & 0,146 \\
\hline 04 & $\mathrm{AQ}$ & 169 & 1,06 & 0,278 \\
\hline 06 & PVA & 260 & 1,62 & 0,370 \\
\hline 08 & PVA & 176 & 1,10 & 0,243 \\
\hline 14 & PVA & 171 & 1,06 & 0,296 \\
\hline 25 & PVA & 173 & 1,08 & 0,235 \\
\hline 22 & Plan & 177 & 1,11 & 0,245 \\
\hline 12 & LR & 166 & 1,03 & 0,122 \\
\hline 26 & $\mathrm{LR}$ & 119 & 0,74 & 0,133 \\
\hline 27 & $\mathrm{LR}$ & 114 & 0,71 & 0,028 \\
\hline 16 & $\mathrm{LE}$ & 168 & 1,05 & 0,266 \\
\hline 18 & $\mathrm{LE}$ & 159 & 0,99 & 0,123 \\
\hline 20 & $\mathrm{LE}$ & 282 & 1,76 & 0,240 \\
\hline 24 & LE & 268 & 1,67 & 0,097 \\
\hline 28 & $\mathrm{LE}$ & 218 & 1,36 & 0,075 \\
\hline 29 & LVA & 154 & 0,96 & 0,167 \\
\hline 30 & LVA & 87 & 0,54 & 0,516 \\
\hline 31 & LVA & 233 & 1,45 & 0,529 \\
\hline
\end{tabular}


Tabela 8 - Quantidades de sulfato adsorvidas pelas amostras de terra após equilíbrio com soluções de $\mathrm{CaSO}_{4}$ de diferentes concentrações iniciais de sulfato.

\begin{tabular}{cccc}
\hline \multirow{2}{*}{ Amostra } & \multicolumn{2}{c}{ Sulfato adsorvido $\left(\mu g S-S O_{4}^{2-} / g\right.$ TFSE) de soluçôes com } \\
\cline { 2 - 4 } & $20 p p m S-S O_{4}^{2-}$ & $30 p p m S-S O_{4}^{2-}$ & $40 p p m S-S O_{4}^{2-}$ \\
\hline 02 & 55,743 & 75,241 & 89,157 \\
04 & 83,013 & 113,517 & 134,513 \\
06 & 95,526 & 140,881 & 179,799 \\
08 & 81,535 & 114,621 & 135,757 \\
14 & 86,499 & 115,747 & 137,062 \\
25 & 81,314 & 114,316 & 158,137 \\
22 & 83,681 & 117,586 & 139,163 \\
12 & 71,493 & 95,675 & 136,150 \\
26 & 62,757 & 76,807 & 90,910 \\
27 & 16,701 & 43,392 & 67,617 \\
16 & 81,551 & 114,643 & 158,594 \\
18 & 70,882 & 90,252 & 112,437 \\
20 & 91,979 & 134,118 & 181,086 \\
24 & 84,833 & 119,966 & 135,574 \\
28 & 70,895 & 94,904 & 121,455 \\
29 & 62,679 & 98,000 & 116,000 \\
30 & 67,429 & 86,635 & 67,186 \\
31 & 94,562 & 139,464 & 164,639 \\
\hline
\end{tabular}


Tabela 9 - pH das amostras de solo tratadas com $\mathrm{K}_{2} \mathrm{SO}_{4} 1 \mathrm{~N}$ e com $\mathrm{KCl} 1 \mathrm{~N}$ e respectivos valores de $\mathrm{dpH}\left(\mathrm{pH} \mathrm{K}_{2} \mathrm{SO}_{4}-\mathrm{pH} \mathrm{KCl}\right)$.

\begin{tabular}{lccc}
\hline Amostra & $p \mathrm{H}_{2} \mathrm{SO}_{4} 1 \mathrm{~N}$ & $p \mathrm{H} \mathrm{KCl} 1 \mathrm{~N}$ & $d p \mathrm{H}=p \mathrm{H}_{2} \mathrm{SO}_{4}-\mathrm{pH} \mathrm{KCl}$ \\
\hline 02 & 5,25 & 4,80 & 0,45 \\
04 & 4,49 & 3,73 & 0,76 \\
06 & 4,48 & 3,78 & 0,70 \\
08 & 4,25 & 3,55 & 0,70 \\
14 & 4,14 & 3,50 & 0,64 \\
25 & 4,32 & 3,70 & 0,62 \\
22 & 4,30 & 3,60 & 0,70 \\
12 & 4,66 & 4,04 & 0,62 \\
26 & 5,14 & 4,61 & 0,53 \\
27 & 4,70 & 4,19 & 0,51 \\
16 & 4,57 & 3,90 & 0,67 \\
18 & 4,61 & 4,01 & 0,60 \\
20 & 5,09 & 4,22 & 0,87 \\
24 & 4,94 & 4,32 & 0,62 \\
28 & 4,69 & 4,16 & 0,53 \\
29 & 4,77 & 4,23 & 0,54 \\
30 & 4,74 & 4,14 & 0,60 \\
31 & 6,12 & 5,13 & 0,99 \\
\hline
\end{tabular}


Tabela 10 - Correlações entre a adsorção máxima de sulfato (b) obtida pela equação de Langmuir e algumas características dos solos estudados.

\begin{tabular}{|c|c|c|}
\hline $\begin{array}{l}\text { Características } \\
\text { dos solos }\end{array}$ & $\begin{array}{l}\text { Equação de } \\
\text { regressãa }\end{array}$ & $\begin{array}{l}\text { Coeficiente de } \\
\text { correlação }(r)\end{array}$ \\
\hline $\mathrm{Ki}$ & $Y=198,9158-13,2326 x$ & $-0,1048$ \\
\hline Argila (\%) & $Y=174,7051+0,0859 x$ & 0,0264 \\
\hline Caulinita (\%) & $Y=192,1995-0,4115 x$ & $-0,1326$ \\
\hline $\mathrm{Al}_{2} \mathrm{O}_{3}(\%)$ & $Y=161,0809+1,002 x$ & 0,1131 \\
\hline Fe livre (\%) & $Y=179,4664-0,2909 x$ & $-0,0100$ \\
\hline $\begin{array}{l}\text { Gibbsita (\%) } \\
\text { (Fe livre }+\end{array}$ & $Y=158,6584+3,2047 x$ & 0,2559 \\
\hline gibbsita) $(\%)$ & $Y=163,8434+1,4416 x$ & 0,1685 \\
\hline P-resina & $Y=196,6613-9,3731 x$ & $-0,3744$ \\
\hline$K^{+}\left(\mathrm{meq} / 100 \mathrm{~cm}^{3}\right)$ & $Y=186,8038-82,8795 x$ & $-0,1407$ \\
\hline $\mathrm{Ca}^{2+}$ & $Y=191,2621-17,2354 x$ & $-0,2692$ \\
\hline$M g^{2+}$ & $Y=183,7356-12,2352 x$ & $-0,1179$ \\
\hline$A l^{3+}$ & $Y=176,4866+1,0244 x$ & 0,0331 \\
\hline CTC & $Y=186,0215-0,8129 x$ & $-0,0905$ \\
\hline $\mathrm{pH}\left(\mathrm{H}_{2} \mathrm{O}\right)$ & $Y=-68,7631+52,5733 x$ & 0,2769 \\
\hline $\mathrm{pH}\left(\mathrm{CaCl}_{2}\right)$ & $Y=173,0294+1,2742 x$ & 0,0073 \\
\hline $\mathrm{pH}\left(K_{2} S_{4}\right)-\mathrm{pH}(K C l)$ & $Y=10,8453+258,7773 x$ & $0,6100 * *$ \\
\hline $\mathrm{S}$ adsorvido $20 \mathrm{ppm}$ & $Y=24,6302+2,0599 x$ & $0,6817 * *$ \\
\hline $\mathrm{S}$ adsorvido $30 \mathrm{ppm}$ & $Y=-6,4231+1,7635 x$ & $0,7855 * *$ \\
\hline S adsorvido $40 \mathrm{ppm}$ & $\mathrm{Y}=5,0013+1,3418 \mathrm{x}$ & $0,8224 * *$ \\
\hline$S-S O_{4}^{2-}(1)$ & $Y=201,2487+0,0395 x$ & 0,0188 \\
\hline$S-S_{4}^{2-}(2)$ & $\mathrm{Y}=215,9867-0,1994 \mathrm{x}$ & $-0,1179$ \\
\hline
\end{tabular}

** Significativo a $1 \%$ de probabilidade.

(1) Sulfato extraído com $\mathrm{CaCl}_{2}$ 0,04 M.

(2) Sulfato extraído com $\mathrm{Ca}\left(\mathrm{H}_{2} \mathrm{PO}_{4}\right)_{2} \quad 0,04 \mathrm{M}$. 


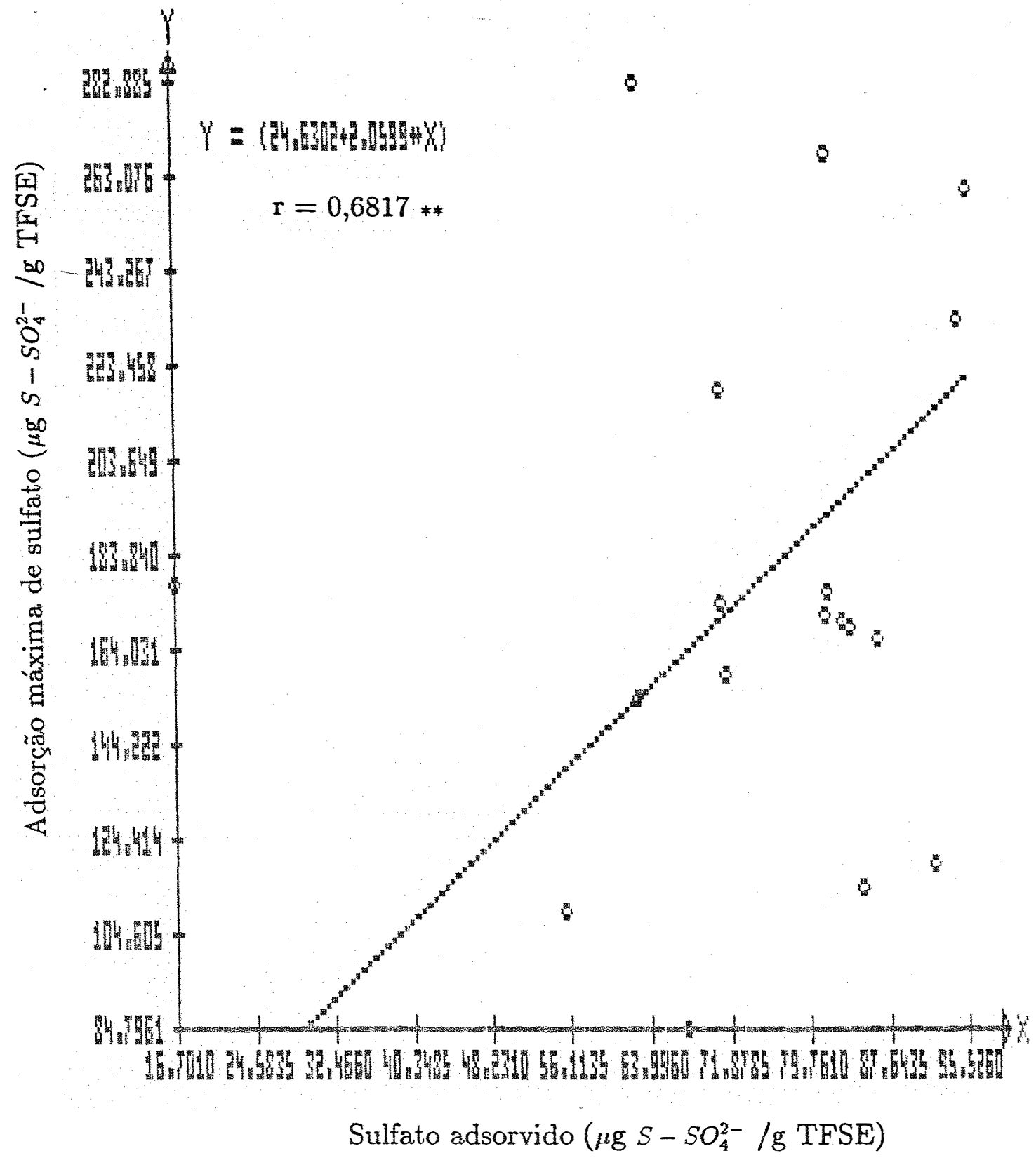

Figura 4. Correlação entre a capacidade de adsorção máxima de sulfato e a quantidade de sulfato adsorvida da solução com $20 \mathrm{ppm}$ de $S-\mathrm{SO}_{4}^{2-}$. 


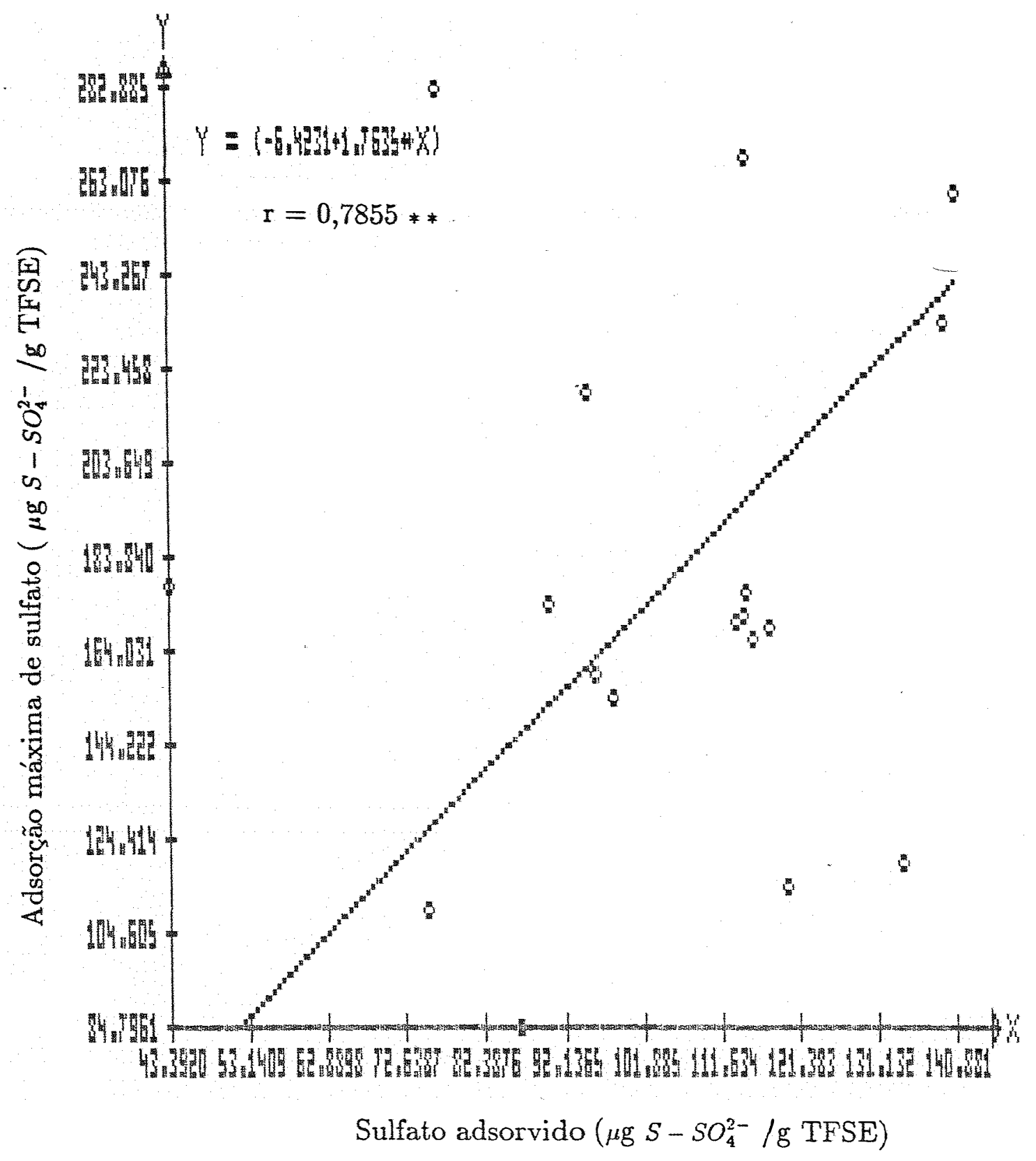

Figura 5. Correlação entre a capacidade de adsorção máxima de sulfato e a quantidade de sulfato adsorvida da solução com $30 \mathrm{ppm}$ de $S-S_{4}^{2-}$. 


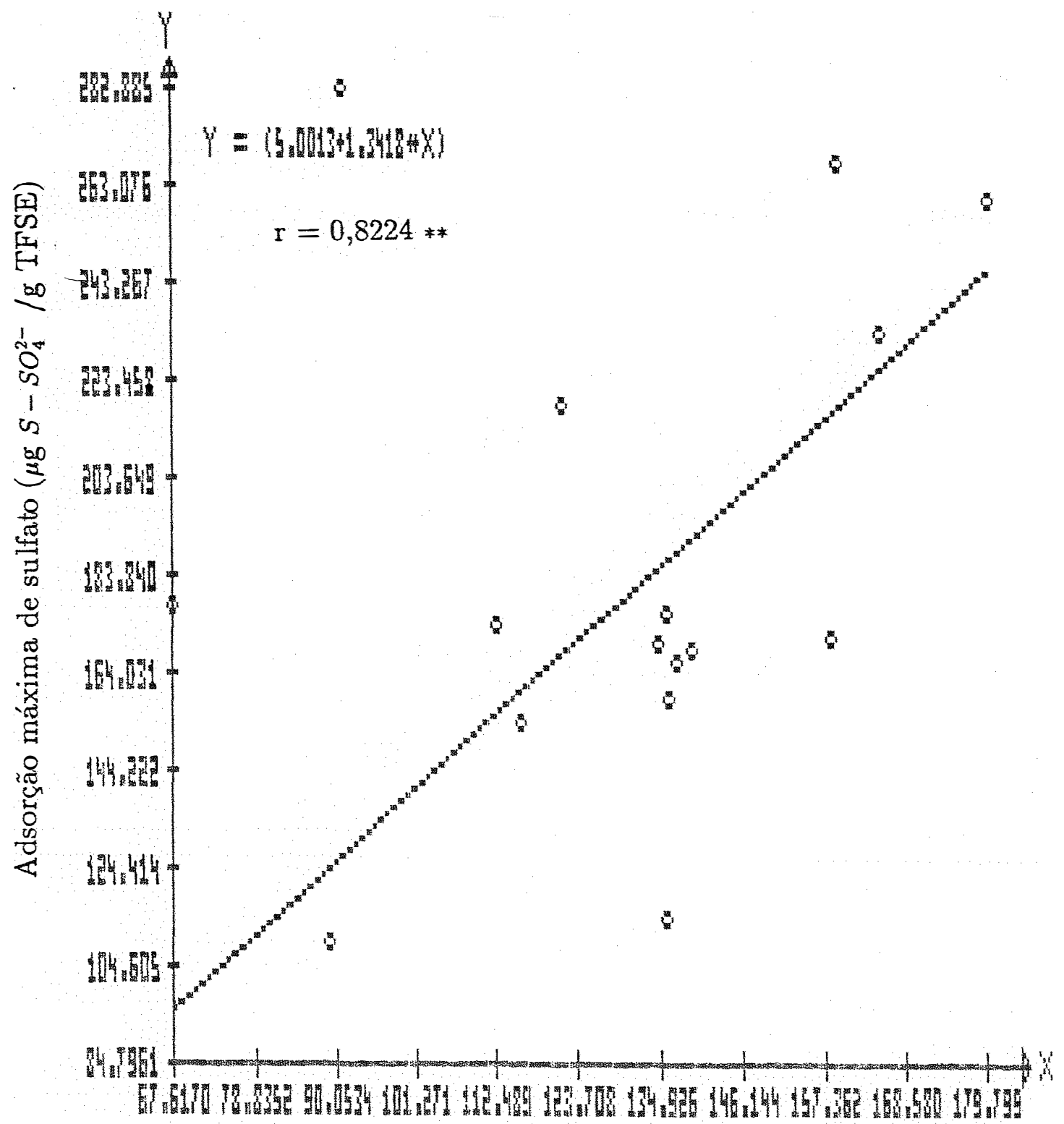

Sulfato adsorvido ( $\mu \mathrm{g} S-\mathrm{SO}_{4}^{2-} / \mathrm{g}$ TFSE)

Figura 6. Correlação entre a capacidade de adsorção máxima de sulfato e a quantidade de sulfato adsorvida da solução com $40 \mathrm{ppm}$ de $S-\mathrm{SO}_{4}^{2-}$. 


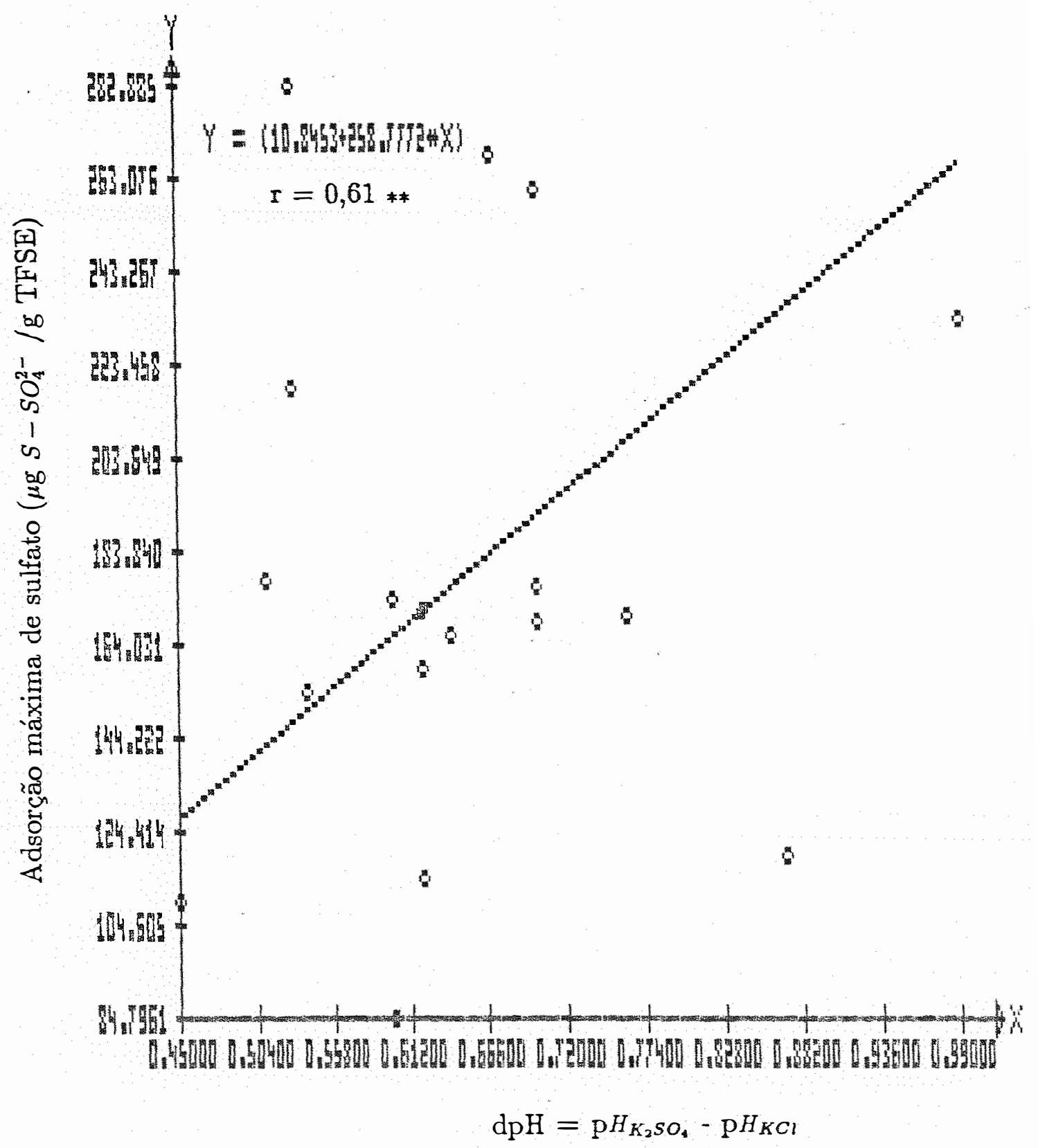

Figura 7. Correlação entre a capacidade de adsorção máxima de sulfato e o valor da diferença entre o $\mathrm{pH}$ medido em $\mathrm{K}_{2} \mathrm{SO}_{4} 1 \mathrm{~N}$ e o medido em $\mathrm{KCl} 1 \mathrm{~N}$ $(\mathrm{dpH})$. 
De acordo com observações de CHAO et alii (1962b, 1962c), CHAO et alii (1964), AYLMORE et alii (1967), HAQUE \& WALMSLEY (1974) e ALOISI et alii (1980), eram esperadas correlaçōes significativas entre a capacidade de adsorção máxima de sulfato e os teores em argila, $\mathrm{Fe}_{2} \mathrm{O}_{3}$ livre e gibbsita, além do pH. No entanto, não foram observadas correlações entre a capacidade de adsorção máxima de sulfato e as características da fração argila e nem com as características químicas das amostras de terra.

As correlações significativas encontradas entre a capacidade de adsorção máxima de sulfato e as quantidades de sulfato adsorvido pelas amostras em equilíbrio com soluções de 20,30 e $40 \mathrm{ppm}$, assim como com a diferença entre os valores de $\mathrm{pH}$ em $\mathrm{K}_{2} \mathrm{SO}_{4} 1 \mathrm{~N}$ e $\mathrm{KCl} 1 \mathrm{~N}$, têm possíveis utilizações práticas. Elas permitem estimar facilmente a capacidade de adsorção máxima de sulfato, cuja obtenção, através da equação de Langmuir, é bastante complexa para ser colocada em rotina laboratorial.

Destas correlações, a que apresentou o melhor coeficiente de correlação $(\mathrm{r}=0,82)$ foi a adsorção de sulfato medida através da solução de $\mathrm{CaSO}_{4} \mathrm{com}$ $40 \mathrm{ppm}$ de $S-\mathrm{SO}_{4}^{2-}$. No entanto, mesmo apresentando um coeficiente de correlação menor $(\mathrm{r}=0,61)$, o valor dpH, da diferença entre o $\mathrm{pH}$ das suspensões com $\mathrm{K}_{2} \mathrm{SO}_{4}$ $1 \mathrm{~N} \mathrm{e} \mathrm{KCl} 1 \mathrm{~N}$, é o que apresenta a maior praticidade para incorporação na rotina laboratorial.

ENSMINGER (1954) utilizou soluções de sulfato de cálcio contendo $40 \mathrm{ppm}$ de $S-\mathrm{SO}_{4}^{2-}$ e BARROW (1967) recomenda trabalhar com soluções de 20 ppm de $S-S_{4}^{2-}$ para estimar a capacidade de adsorção de sulfato dos solos. Trabalhando com amostras de solo provenientes de oito localidades do Estado de Minas Gerais, Alvarez et alii (1983), citados por ACCIOLY et alii (1985), observaram que o teor de enxofre (S) remanescente de solução inicialmente com $20 \mathrm{ppm}$, apresentava estreita correlação com a capacidade máxima de adsorção de sulfato, corroborando os dados obtidos no presente trabalho.

A diferença entre os valores de $\mathrm{pH}(\mathrm{dpH})$ em suspensões com $\mathrm{K}_{2} \mathrm{SO}_{4}$ e $\mathrm{KCl}$ foi estudada por $\mathrm{CHAO}$ et alii (1965) para estimar a capacidade de adsorção de sulfato dos solos, pressupondo que a reação de troca de $\mathrm{OH}^{-}$por $\mathrm{SO}_{4}^{2-}$ não se daria com o $\mathrm{Cl}^{-}$.

$\mathrm{OH}$
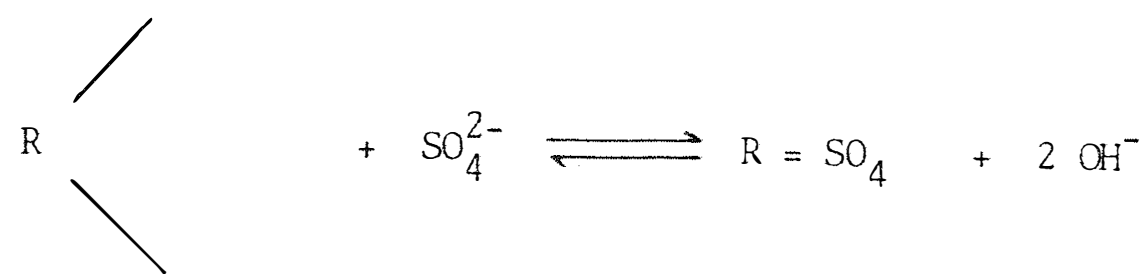
Os autores observaram que a diferença entre os valores de $\mathrm{pH}$ aumentava com a capacidade de retenção de sulfato dos solos, bem como com a concentração de sulfato da solução. No entanto, concluíram que, devido à complexidade do sistema em estudo, não era possível estimar a capacidade de adsorção de sulfato através do $\mathrm{dpH}$.

A revisão da literatura mostrou os problemas relacionados com a falta de constância na estequiometria da troca entre ânions sulfato e hidroxila (HINGSTON et alii, 1967; RAJAN et alii, 1974; RAJAN, 1978). No entanto, a correlação significativa observada demonstra que houve estequiometria na troca de $\mathrm{OH}^{-}$por $\mathrm{SO}_{4}^{2-}$. Entre as possíveis justificativas para essa correlação significativa, temos: (1) os valores de $\mathrm{pH}$ das amostras, todos com $\Delta \mathrm{pH}<0$, ou seja, a diferença entre o valor do $\mathrm{pH}$ medido em $\mathrm{KCl} 1 \mathrm{~N}$ e o medido em água era negativa, indicando predomínio do grupo hidroxo sobre o grupo aquo nos óxidos de ferro e de alumínio; (2) a alta concentração em sulfato na solução $\mathrm{K}_{2} \mathrm{SO}_{4} 1 \mathrm{~N}$ que, de acordo com RAJAN (1978), favoreceria o deslocamento do grupo hidroxo, em detrimento do grupo aquo.

A constante de afinidade $(\mathrm{K})$, obtida através da equação de Langmuir, mostrou correlação significativa apenas para a diferença entre os valores de pH (Tabela 11 e Figura 8), enquanto que ALOISI et alii (1980) obtiveram correlações de $\mathrm{K}$ com o $\mathrm{pH}$ em $\mathrm{KCl}$ e o $\mathrm{pH}$ em $\mathrm{CaCl}_{2}$ e ainda com a CTC. Explicam os autores que como a adsorção de sulfato é influenciada por vários fatores atuando em conjunto, fica difícil avaliar o efeito de cada um deles isoladamente, com o que também concorda o autor do presente trabalho. 
Tabela 11 - Correlações entre a constante de afinidade (K) obtida pela equação de Langmuir e algumas características dos solos estudados.

\begin{tabular}{|c|c|c|}
\hline $\begin{array}{l}\text { Características } \\
\text { dos solos }\end{array}$ & $\begin{array}{l}\text { Equação de } \\
\text { regressão }\end{array}$ & $\begin{array}{l}\text { Coeficiente de } \\
\text { correlação (r) }\end{array}$ \\
\hline $\mathrm{Ki}$ & $Y=0,1278+0,0645 x$ & 0,2055 \\
\hline Argila (\%) & $\mathrm{Y}=0,2942-0,0015 \mathrm{x}$ & $-0,2054$ \\
\hline Caulinita (\%) & $Y=0,2782-0,0015 x$ & $-0,1926$ \\
\hline $\mathrm{Al}_{2} \mathrm{O}_{3}(\%)$ & $Y=0,3060-0,0045 x$ & $-0,2088$ \\
\hline Fe livre (\%) & $Y=0,3274-0,0254 x$ & $-0,4848$ \\
\hline Gibbsita (\%) & $Y=0,2844-0,0091 x$ & $-0,2939$ \\
\hline \multicolumn{3}{|l|}{ (Fe livre +} \\
\hline gibbsita) (\%) & $Y=0,3134-0,0084 x$ & $-0,3986$ \\
\hline m.o. (\%) & $Y=0,2941-0,0638 x$ & $-0,3912$ \\
\hline P-resina (ppm) & $Y=0,2620-0,0173 x$ & $-0,2779$ \\
\hline$K^{+}\left(\mathrm{meq} / 100 \mathrm{~cm}^{3}\right)$ & $\mathrm{Y}=0,2503-0,2167 \mathrm{x}$ & $-0,1480$ \\
\hline $\mathrm{Ca}^{2+}$ & $Y=0 ; 2705-0,0563 \cdot x$ & $-0,3540$ \\
\hline$M g^{2+}$ & $Y=0.2422-0,0317 x$ & $-0,1231$ \\
\hline$A l^{3+}$ & $Y=0,1989+0,0162 x$ & 0,2155 \\
\hline CTC & $Y=0,2290-0,000088 x$ & $-0,0039$ \\
\hline $\mathrm{pH}\left(\mathrm{H}_{2} \mathrm{O}\right)$ & $Y=0,8678-0,1361 x$ & $-0,2882$ \\
\hline $\mathrm{pH}\left(\mathrm{CaCl}_{2}\right)$ & $Y=0,2233+0,0012 x$ & 0,0027 \\
\hline $\mathrm{pH}\left(K_{2} S_{4}\right)-\mathrm{pH}(K C l)$ & $Y=-0,2095+0,6763 x$ & $0,6408 * *$ \\
\hline$S-S O_{4}^{2-}(1)$ & $Y=0,2639-0,0011 x$ & $-0,3314$ \\
\hline$S-S_{4}^{2-}(2)$ & $Y=0,3123-0,0012 x$ & $-0,4613$ \\
\hline
\end{tabular}

* Significativo a $1 \%$ de probabilidade.

(1) Sulfato extraído com $\mathrm{CaCl}_{2} \quad 0,04 \mathrm{M}$.

(2) Sulfato extraído com $\mathrm{Ca}\left(\mathrm{H}_{2} \mathrm{PO}_{4}\right)_{2} \quad 0,04 \mathrm{M}$. 


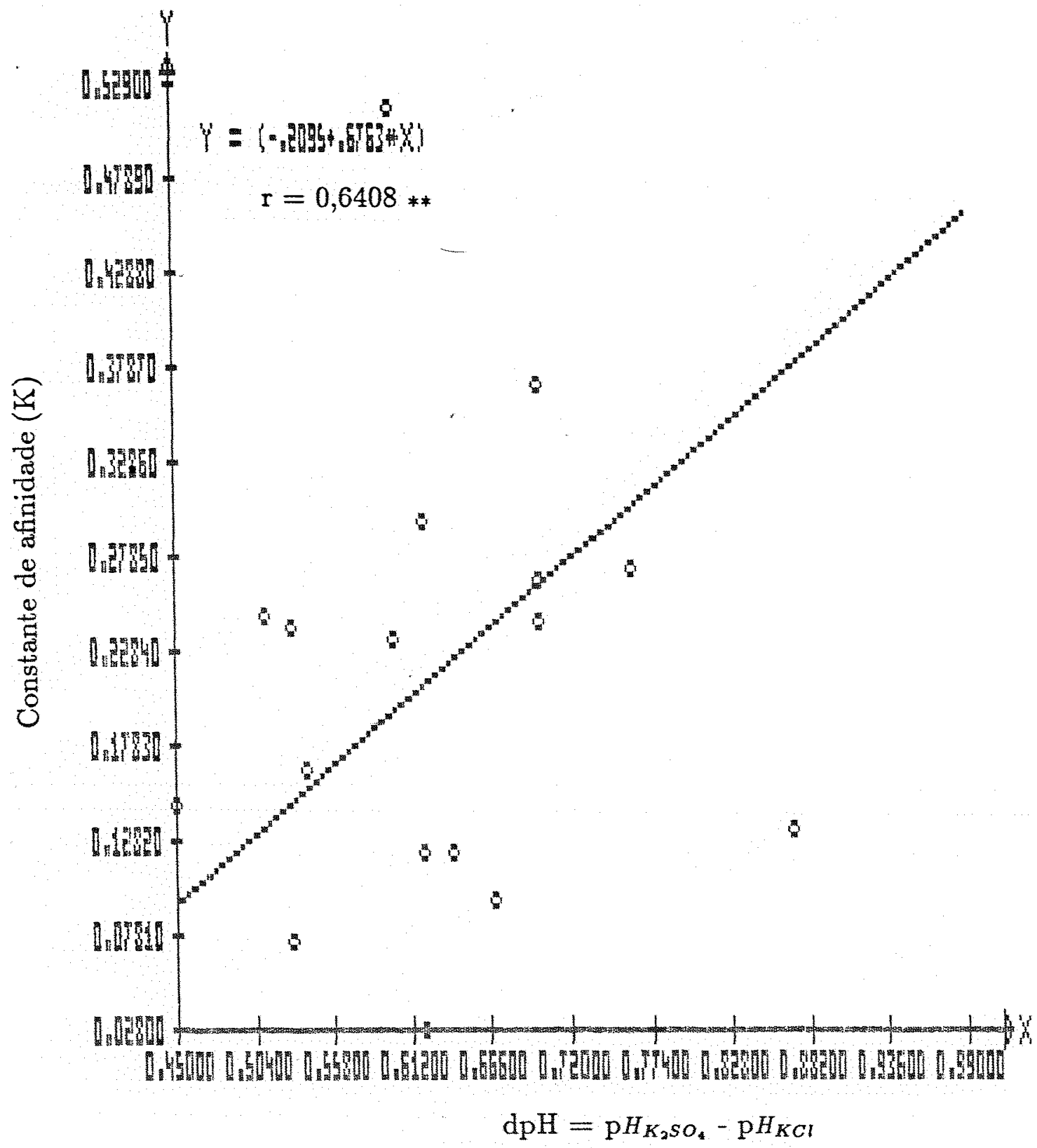

Figura 8. Correlação entre a constante de afinidade $(K)$ calculada através da equação de Langmuir e o valor da diferença entre o $\mathrm{pH}$ medido em $\mathrm{K}_{2} \mathrm{SO}_{4} 1 \mathrm{~N}$ e o medido em $\mathrm{KCl} 1 \mathrm{~N}(\mathrm{dpH})$. 
4.2. Ensaio com trigo

O efeito dos diferentes tratamentos no comprimento da maior raiz de plântulas de trigo e a análise da variância em cada um dos solos estudados são apresentados na Tabela 12.

Nos solos podzolizados (amostras 6, 8 e 14) as respostas às doses de $\mathrm{CaSO}_{4} \cdot 2 \mathrm{H}_{2} \mathrm{O}$ e à dose de $\mathrm{CaCl}_{2} \cdot 2 \mathrm{H}_{2} \mathrm{O}$ foram estatisticamente significativas, sendo positiva na amostra 14, negativa na amostra 8 e nula na amostra 6 . No entanto, o maior comprimento médio da raiz de trigo nos solos podzolizados foi ainda inferior a $20 \%$ da maior média observada nos Latossolos. Assim, do ponto de vista agronômico não se considera que houve resposta aos tratamentos nas amostras dos solos podzolizados estudados. Uma possível explicação para esta falta de resposta estaria nos elevados teores de alumínio apresentados pelas amostras. As respostas mostram também uma tendência à diminuição do comprimento da raiz com o aumento das doses de $\mathrm{CaSO}_{4} \cdot 2 \mathrm{H}_{2} \mathrm{O}$, sugerindo a impossibilidade deste produto em resolver o problema da toxidez de alumínio nestas amostras de solo. 
Tabela 12 - Efeito dos tratamentos com $\mathrm{CaSO}_{4} \cdot 2 \mathrm{H}_{2} \mathrm{O}$ e $\mathrm{CaCl}_{2} \cdot 2 \mathrm{H}_{2} \mathrm{O}$ no comprimento da raiz de trigo cultivado durante 4 dias nos solos estudados.

\section{Comprimento da raiz de trigo (cm) nas amostras de terro}

$\begin{array}{llll}\text { TRAT. } & L R & L E & L V A\end{array}$

\begin{tabular}{|c|c|c|c|c|c|c|c|c|c|c|c|c|c|c|c|c|c|c|c|}
\hline & 12 & & 26 & & 16 & & 20 & & 28 & & 30 & & 31 & & 06 & 08 & & 14 & \\
\hline $\mathrm{T} 1$ & 9,37 & $\mathrm{BC}$ & 16,80 & $\mathrm{AB}$ & 3,62 & C & 4,80 & $D$ & 13,85 & $\mathrm{AB}$ & 4,50 & $\mathrm{D}$ & 7,45 & C & 0,95 & 1,55 & $\mathrm{AB}$ & 2,02 & $\mathrm{C}$ \\
\hline T3 & 13,32 & A & 16,20 & $A B$ & 5,90 & B. & 11,10 & B & 15,80 & A & 7,27 & $\mathrm{~B}$ & 14,70 & A & 0,92 & 1,82 & A & 3,40 & $\mathrm{AB}$ \\
\hline T4 & 12,92 & A & 17,15 & A & 9,82 & A & 12,35 & A & 15,55 & A & 8,65 & A & 14,15 & $\mathbf{A}$ & 0,87 & 1,30 & $\mathrm{AB}$ & 3,92 & A \\
\hline MÉDIA & 11,02 & & 15,81 & & 5,89 & & 8,75 & & 13,84 & & 5,81 & & 10,65 & & 0,83 & 1,53 & & 2,71 & \\
\hline F & ** & & $* *$ & & $* *$ & & ** & & $* *$ & & $* *$ & & $* *$ & & $* *$ & ** & & ** & \\
\hline CV\% & 7,63 & & 4,97 & & 8,43 & & 5,40 & & 5,41 & & 6,30 & & 9,92 & & 14,00 & 14,20 & & 15,20 & \\
\hline $\operatorname{dms}(1 \%)$ & 2,37 & & 2,22 & & 1,40 & & 1,33 & & 2,12 & & 1,03 & & 2,99 & & 0,33 & 0,61 & & 1,16 & \\
\hline
\end{tabular}

Médias seguidas por letras distintas diferem entre si (apenas na vertical) no nível de significância de $1 \%$, pelo Teste de Tukey. 
Nos Latossolos, excetuando a amostra 26 que apresentava teor adequado de cálcio $\left(3,16 \mathrm{meq} / 100 \mathrm{~cm}^{3}\right)$ e tolerável de alumínio $\left(0,56 \mathrm{meq} / 100 \mathrm{~cm}^{3}\right)$, as demais apresentaram respostas positivas e estatisticamente significativas para os tratamentos com $\mathrm{CaSO}_{4} \cdot 2 \mathrm{H}_{2} \mathrm{O}$. A falta de resposta ao tratamento com $\mathrm{CaCl}_{2} .2 \mathrm{H}_{2} \mathrm{O}$ nas amostras $12,16,28$ e 30 indica que a ação benéfica do $\mathrm{CaSO}_{4} \cdot 2 \mathrm{H}_{2} \mathrm{O}$ nestas amostras não foi devida ao fornecimento de cálcio e sim à diminuição da toxidez de alumínio. Nas amostras 20 e 31 houve resposta ao $\mathrm{CaCl}_{2} \cdot 2 \mathrm{H}_{2} \mathrm{O}$, que foi também estatisticamente diferente da resposta ao tratamento $T_{4}$ com mesma dose de cálcio, fornecida como $\mathrm{CaSO}_{4} \cdot 2 \mathrm{H}_{2} \mathrm{O}$. Isto indica que nas amostras 20 e 31 o $\mathrm{CaSO}_{4} \cdot 2 \mathrm{H}_{2} \mathrm{O}$, além de fornecer o cálcio como nutriente, proporcionou também uma diminuição na toxidez do alumínio.

Para fins comparativos são apresentadas na Tabela 13 as doses de $\mathrm{CaSO}_{4} \cdot 2 \mathrm{H}_{2} \mathrm{O}$ que proporcionaram as melhores respostas, as possíveis causas das respostas e as doses de $\mathrm{CaSO}_{4} \cdot 2 \mathrm{H}_{2} \mathrm{O}$, expressas em meq/100 $\mathrm{cm}^{3}$ necessárias para elevar o teor de cálcio ao nível de $2,0 \mathrm{meq} / 100 \mathrm{~cm}^{3}$ e para "neutralizar" o alumínio ao nível de $0,5 \mathrm{meq} / 100 \mathrm{~cm}^{3}$, conforme critérios adotados pela PETROFERTIL (s.d.) e ainda para atingir a capacidade de adsorção máxima de sulfato nas amostras empregadas no ensaio com trigo.

Percebe-se na Tabela 13 que nos solos podzolizados as doses mais elevadas são as para a "neutralização" do alumínio, enquanto nos Latossolos são as para aumentar o teor em cálcio ao nível de $2,0 \mathrm{meq} / 100 \mathrm{~cm}^{3}$. Em ambos os casos estas recomendações excedem, em geral, a capacidade de adsorção máxima de sulfato das amostras, sendo, no entanto, esta diferença mais significativa nos solos podzolizados. As doses que proporcionaram as melhores respostas ao $\mathrm{CaSO}_{4} \cdot 2 \mathrm{H}_{2} \mathrm{O}$ não se relacionaram com as doses recomendadas por nenhum dos parâmetros considerados. 
Tabela 13 - Doses de $\mathrm{CaSO}_{4} \cdot 2 \mathrm{H}_{2} \mathrm{O}$ que proporcionaram as melhores respostas, os possíveis efeitos e as doses calculadas através de diferentes critérios.

\begin{tabular}{|c|c|c|c|c|c|c|}
\hline \multirow[t]{2}{*}{ Amostra } & \multicolumn{2}{|c|}{ Anál. solo } & \multicolumn{4}{|c|}{ Doses de $\mathrm{CaSO}_{4} \cdot 2 \mathrm{H}_{2} \mathrm{O}\left(\mathrm{meq} / 100 \mathrm{~cm}^{3}\right)$ para } \\
\hline & $\mathrm{Ca}^{2+}$ & $A l^{3+}$ & $\begin{array}{c}\text { Aumentar } \\
\mathrm{Ca}\end{array}$ & $\begin{array}{c}\text { Diminuir } \\
A l\end{array}$ & $\begin{array}{c}\text { Ads. máx. } \\
\text { sulfato }\end{array}$ & $\begin{array}{c}\text { Melhor resp } \\
\text { observada }\end{array}$ \\
\hline 06 PVA & 0,13 & 2,78 & 1,87 & 2,28 & 2,22 & - \\
\hline 08 PVA & 1,08 & 5,07 & 0,92 & 4,57 & 1,41 & - \\
\hline 14 PVA & 1,14 & 5,62 & 0,80 & 5,12 & 1,44 & - \\
\hline $12 \mathrm{LR}$ & 0,47 & 0,86 & 1,53 & 0,38 & 1,21 & 0,59 \\
\hline $26 \mathrm{LR}$ & 3,16 & 0,20 & - & - & 0,85 & - \\
\hline $16 \mathrm{LE}$ & 0,28 & 1,39 & 1,72 & 0,89 & 1,17 & 2,14 \\
\hline $20 \mathrm{LE}$ & 0,51 & 0,69 & 1,49 & 0,19 & 1,99 & 2,22 \\
\hline $28 \mathrm{LE}$ & 0,40 & 0,60 & 1,60 & 0,10 & 1,64 & 0,49 \\
\hline 30 LVA & 0,14 & 1,00 & 1,86 & 0,50 & 0,76 & 0,95 \\
\hline 31 LVA & 0,10 & 0,10 & 1,90 & - & 1,66 & 0,86 \\
\hline
\end{tabular}

(1) Adsorção máxima sulfato $(\mathrm{meq} / 100 \mathrm{~g}) \times$ densidade $=S-S O_{4}^{2-}\left(\mathrm{meq} / 100 \mathrm{~cm}^{3}\right)$. 
A capacidade de adsorção máxima de sulfato é um indicativo do limite superior da dose a aplicar e não é "per se" suficiente para a recomendação da necessidade de gessagem.

Na Tabela 14 e nas Figuras 9, 10,11, 12, 13, 14 e 15 são dadas as correlações entre o comprimento médio da maior raiz de plântulas de trigo e algumas características químicas dos solos estudados.

As melhores correlações foram observadas com os parâmetros: $\mathrm{pH} \mathrm{CaCl}_{2}$, porcentagem de matéria orgânica, alumínio trocável e porcentagem de saturação em alumínio e em cálcio. As correlações com o cálcio trocável e a soma de bases foram inferiores às observadas para a porcentagem de saturação em cálcio e em bases, mostrando a importância dos valores relacionados com a capacidade de troca catiônica das amostras. Entre as correlações, a com a porcentagem de saturação em alumínio obtida na análise de rotina foi a que apresentou o maior coeficiente de correlação.

$\mathrm{Na}$ Tabela 15 são dadas as correlações entre o comprimento médio da maior raiz de plântulas de trigo e algumas características dos extratos das pastas saturadas das amostras de terra, após a coleta do ensaio com doses de $\mathrm{CaSO}_{4} \cdot 2 \mathrm{H}_{2} \mathrm{O}$ e a de $\mathrm{CaCl}_{2} \cdot 2 \mathrm{H}_{2} \mathrm{O}$. Devido a dificuldades laboratoriais não foi possível quantificar as concentrações de alumínio no extrato da pasta saturada, todas com valores inferiores a $1 \mathrm{ppm}$. Dos parâmetros restantes a melhor correlação obtida foi com o ìon $\mathrm{Fe}^{2+}$, no entanto com um coeficiente de correlação (r) de apenas 0,5057 para -log atividade de $\mathrm{Fe}^{2+}$. Assim, não se justifica a utilização do extrato de pasta saturada caso não for possível medir a concentração do alumínio. 
Tabela 14 - Correlações entre comprimento da raiz de plântulas de trigo e algumas características químicas das amostras de terra após a coleta do ensaio.

\begin{tabular}{|c|c|c|}
\hline $\begin{array}{l}\text { Características } \\
\text { dos solos }\end{array}$ & $\begin{array}{c}\text { Equação de } \\
\text { regressão }\end{array}$ & $\begin{array}{l}\text { Coeficiente de } \\
\text { correlação (r) }\end{array}$ \\
\hline $\mathrm{pH} \mathrm{CaCl} 2$ & $Y=-28,0664+8,3330 x$ & $0,7488 * *$ \\
\hline m.o. (\%) & $Y=2,6010+4,4990 x$ & $0,7238 * *$ \\
\hline P-resina (ppm) & $Y=0,5008+1,4712 x$ & $0,4716 * *$ \\
\hline$S-S O_{4}^{2-}(1)$ & $Y=6,0701+0,0084 x$ & $0,3048 *$ \\
\hline$S-S_{4}^{2-}(2)$ & $Y=5,7842+0,0087 x$ & $0,3153 * *$ \\
\hline$K^{+}\left(\right.$meq $\left./ 100 \mathrm{~cm}^{3}\right)$ & $Y=9,8854-42,2453 x$ & $-0,3490 * *$ \\
\hline $\mathrm{Ca}^{2+}$ & $Y=5,3341+1,1186 x$ & $0,3466 * *$ \\
\hline$M g^{2+}$ & $Y=7,1499+0,7810 x$ & 0,0428 \\
\hline$A l^{3+}$ & $Y=11,2017-1,9684 x$ & $-0,7211 * *$ \\
\hline $\mathrm{S}$ & $Y=5,2828+0,8554 x$ & $0,3030 *$ \\
\hline$K^{+} / \mathrm{CTC}$ ef. $(\%)$ & $Y=7,1288+0,3748 x$ & 0,0726 \\
\hline $\mathrm{Ca}^{2+} / \mathrm{CTC}$ ef. (\%) & $Y=-0,5819+0,1825 x$ & $0,7706 * *$ \\
\hline$M g^{2+} /$ CTC ef. $(\%)$ & $Y=3,8961+0,2197 x$ & $0,3315 * *$ \\
\hline$A l^{3+} /$ CTC ef. (\%) & $Y=14,2694-0,1824 x$ & $-0,8396 * *$ \\
\hline$K^{+} / \mathrm{CTC}$ pH $7,0(\%)$ & $Y=7,9639-0,5527 x$ & 0,0291 \\
\hline $\mathrm{Ca}^{2+} / \mathrm{CTC} \mathrm{pH} 7,0(\%)$ & $Y=2,5302+0,2226 x$ & $0,6283 * *$ \\
\hline $\mathrm{Mg}^{2+} / \mathrm{CTC} \mathrm{pH} 7,0(\%)$ & $Y=1,3506+0,7997 x$ & $0,4511 * *$ \\
\hline$A l^{3+} / \mathrm{CTC}$ pH $7,0(\%)$ & $Y=13,5924-0,3456 x$ & $-0,8407 * *$ \\
\hline V \% & $Y=0,6457+0,2228 x$ & $0,6756 * *$ \\
\hline
\end{tabular}

$S-S_{4}^{2-}(1):$ extração com $\mathrm{CaCl}_{2}, 0,04 \mathrm{M}$,

$\mathrm{S}-\mathrm{SO}_{4}^{2-}(2)$ : extração com $\mathrm{Ca}\left(\mathrm{H}_{2} \mathrm{PO}_{4}\right)_{2} \quad 0,04 \mathrm{M}$. 
Tabela 15 - Correlações entre o comprimento da raiz de plântulas de trigo e algumas características dos extratos das pastas saturadas das amostras de terra após a coleta do ensaio.

\begin{tabular}{|c|c|c|}
\hline $\begin{array}{l}\text { Características } \\
\text { dos extratos }\end{array}$ & $\begin{array}{l}\text { Equação de } \\
\text { regressãao }\end{array}$ & $\begin{array}{l}\text { Coeficiente } \\
\text { correlação ( } r\end{array}$ \\
\hline $\mathrm{pH}$ & $-42,7037+11,5406 x$ & $0,4634 * *$ \\
\hline \multicolumn{3}{|c|}{ log concentração total } \\
\hline $\mathrm{Ca}^{2+}$ & $Y=14,2855-2,6129 x$ & $-0,2741 *$ \\
\hline$M g^{2+}$ & $Y=8,8699-0,3557 x$ & $-0,0314$ \\
\hline$K^{+}$ & $Y=5,0849+0,6406 x$ & 0,0571 \\
\hline$M n^{2+}$ & $Y=5,6784+0,4357 x$ & 0,0488 \\
\hline $2 n^{2+}$ & $Y=5,6015+0,3920 x$ & 0,0263 \\
\hline$F e^{2+}$ & $Y=-16,6419+4,8896 x$ & $0,4713 * *$ \\
\hline $\mathrm{SO}_{4}^{2-}$ & $Y=12,7309-1,8739 x$ & $-0,2064$ \\
\hline $\mathrm{Cl}^{-}$ & $Y=12,2589-1,6087 x$ & 0,1547 \\
\hline
\end{tabular}

$\log$ atividade

$\begin{array}{lll}\mathrm{Ca}^{2+} & \mathrm{Y}=16,9921-3,3272 \times & 0,2775 * \\ \mathrm{Mg}^{2+} & \mathrm{Y}=5,9577+0,4570 \mathrm{x} & 0,0336 \\ \mathrm{~K}^{+} & \mathrm{Y}=6,3852+0,3291 \times & 0,0282 \\ \mathrm{Mn}^{2+} & \mathrm{Y}=3,8771+0,7881 \mathrm{x} & 0,0935 \\ \mathrm{Zn}^{2+} & \mathrm{Y}=-0,0122+1,3940 \mathrm{x} & 0,1054 \\ \mathrm{Fe}^{2+} & \mathrm{Y}=-18,6678+5,0388 \mathrm{x} & 0,5057 * * \\ \mathrm{SO}_{4}^{2-} & \mathrm{Y}=12,1742-1,5290 \mathrm{x} & 0,1552 \\ \mathrm{Cl}^{-} & \mathrm{Y}=12,7141-1,7060 \mathrm{x} & 0,1656\end{array}$

log concentração livre

$\begin{array}{lll}\mathrm{Ca}^{2+} & \mathrm{Y}=14,5417-2,6532 \mathrm{x} & 0,2658 * \\ \mathrm{Mg}^{2+} & \mathrm{Y}=7,0150-0,1819 \mathrm{x} & 0,0151 \\ \mathrm{~K}^{+} & \mathrm{Y}=6,9442+0,1858 \mathrm{x} & 0,0162 \\ \mathrm{Mn}^{2+} & \mathrm{Y}=5,0427+0,5694 \mathrm{x} & 0,0661 \\ \mathrm{Zn}^{2+} & \mathrm{Y}=3,2079+0,8398 \mathrm{x} & 0,0612 \\ \mathrm{Fe}^{2+} & \mathrm{Y}=-16,3461+4,7863 \mathrm{x} & 0,4752 * * \\ \mathrm{SO}_{4}^{2-} & \mathrm{Y}=12,5279-1,7544 \mathrm{x} & -0,1886 \\ \mathrm{Cl}^{-} & \mathrm{Y}=11,8622-1,4502 \mathrm{x} & -0,1477 \\ \text { Força iônica }(\mathrm{mM}) & \mathrm{Y}=7,0909+0,0276 \mathrm{x} & 0,1014\end{array}$




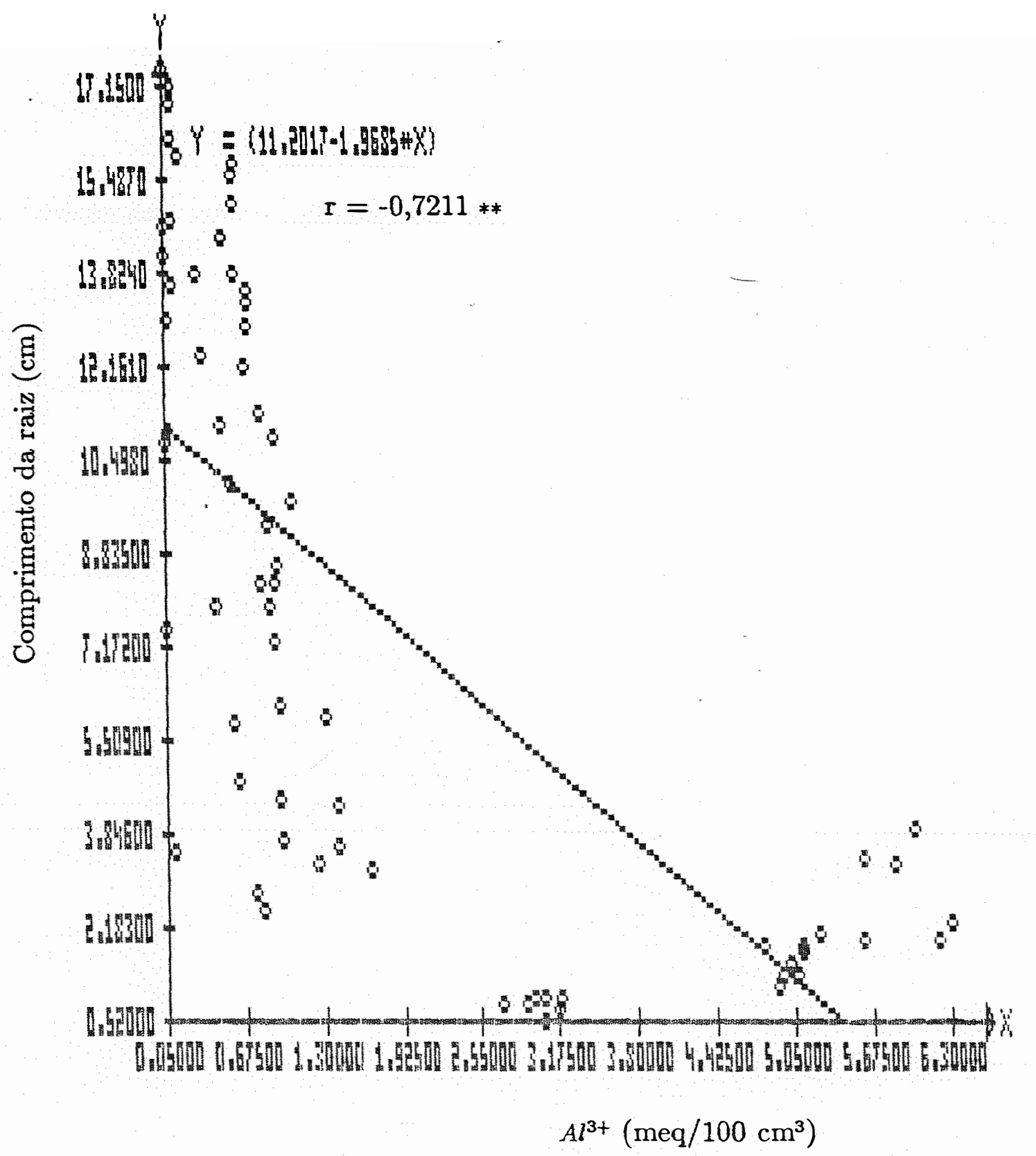

Figura 9. Correlação entre o teor de alumínio trocável das amostras de terra e o comprimento da raiz de trigo. 


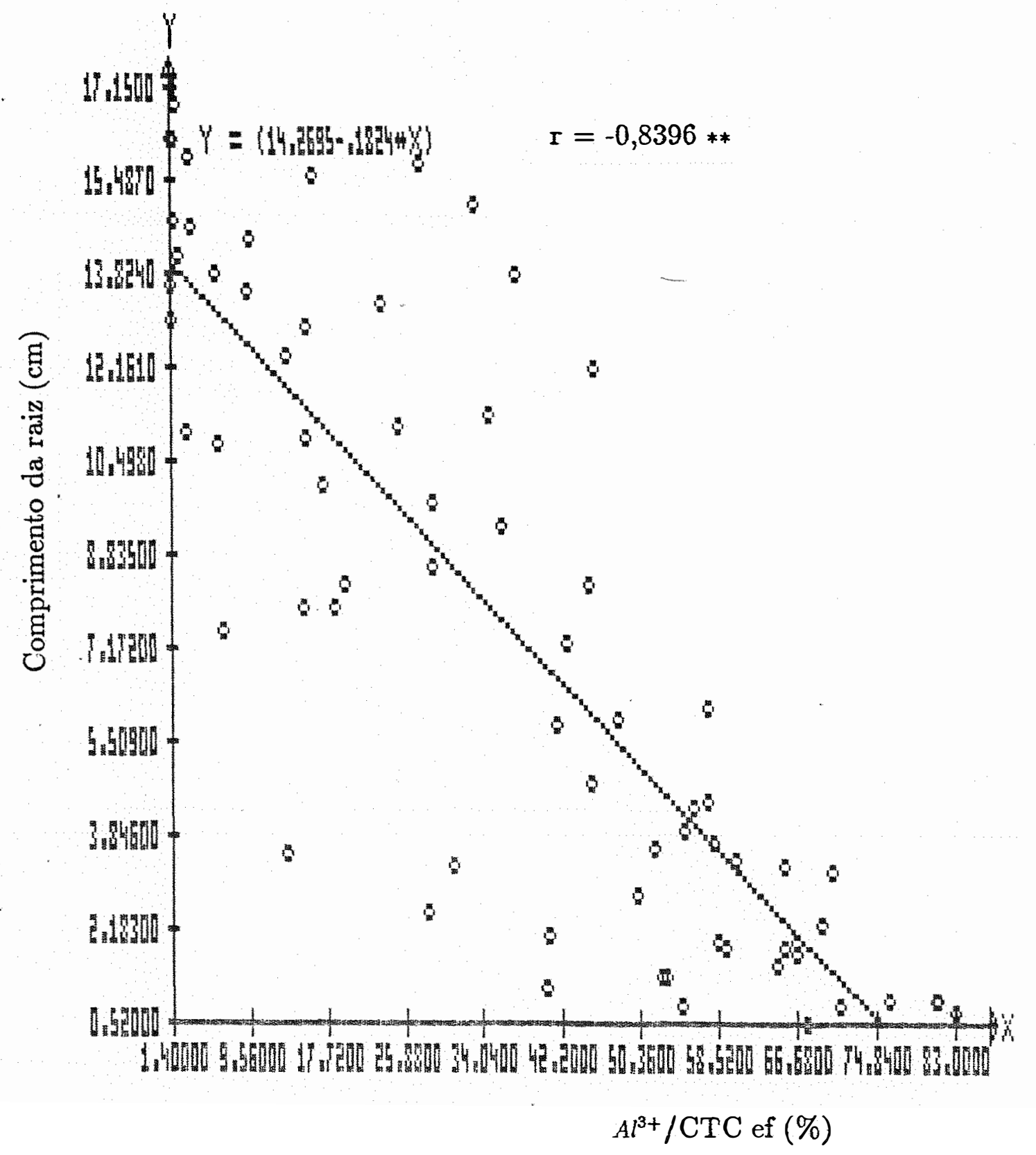

Figura 10. Correlação entre a porcentagem de saturação em alumínio na CTC efetiva das amostras de terra e o comprimento da raiz de trigo. 


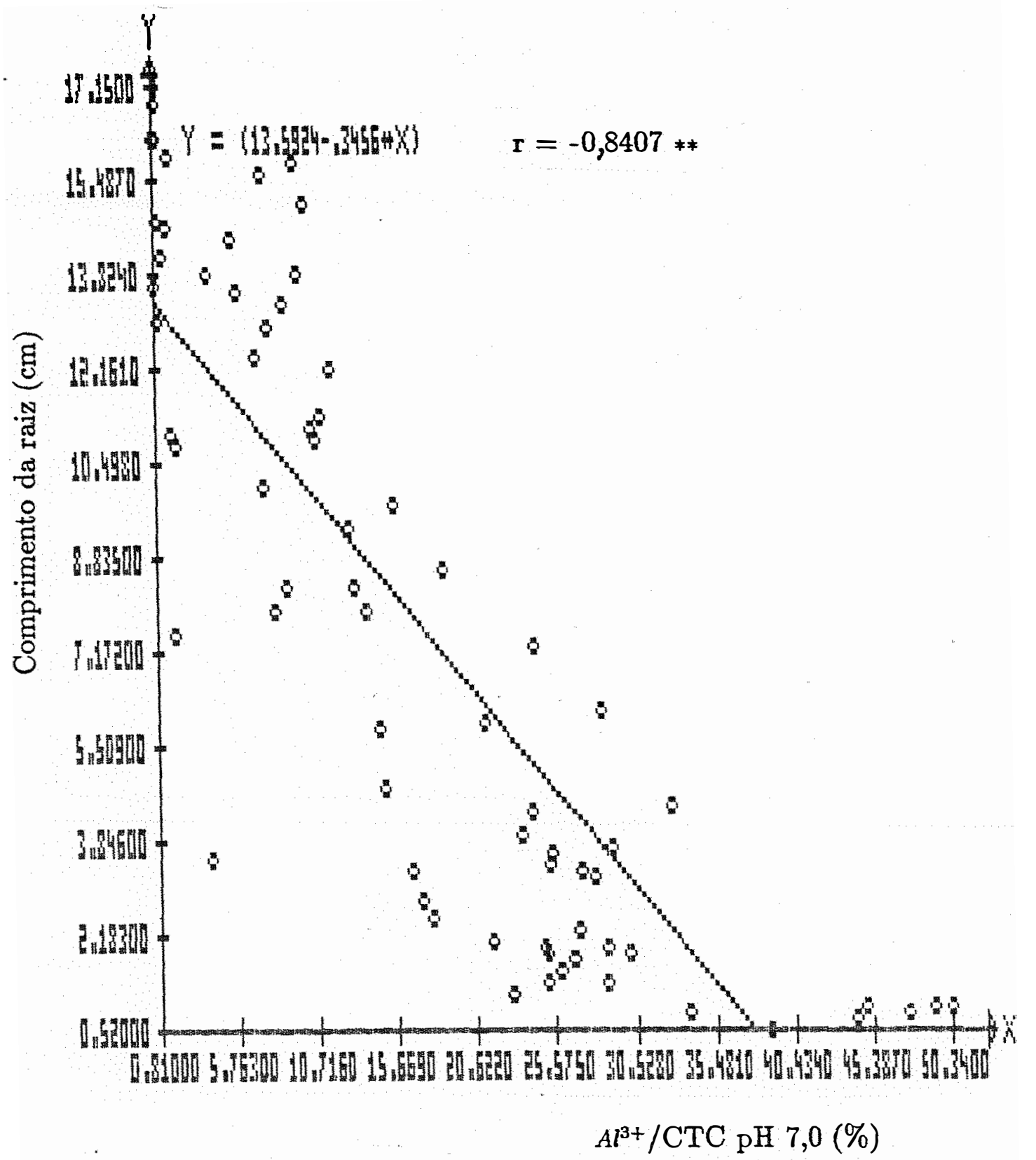

Figura 11. Correlação entre a porcentagem de saturação em alumínio na CTC a $\mathrm{pH} 7,0$ das amostras de terra e o comprimento da raiz de trigo. 


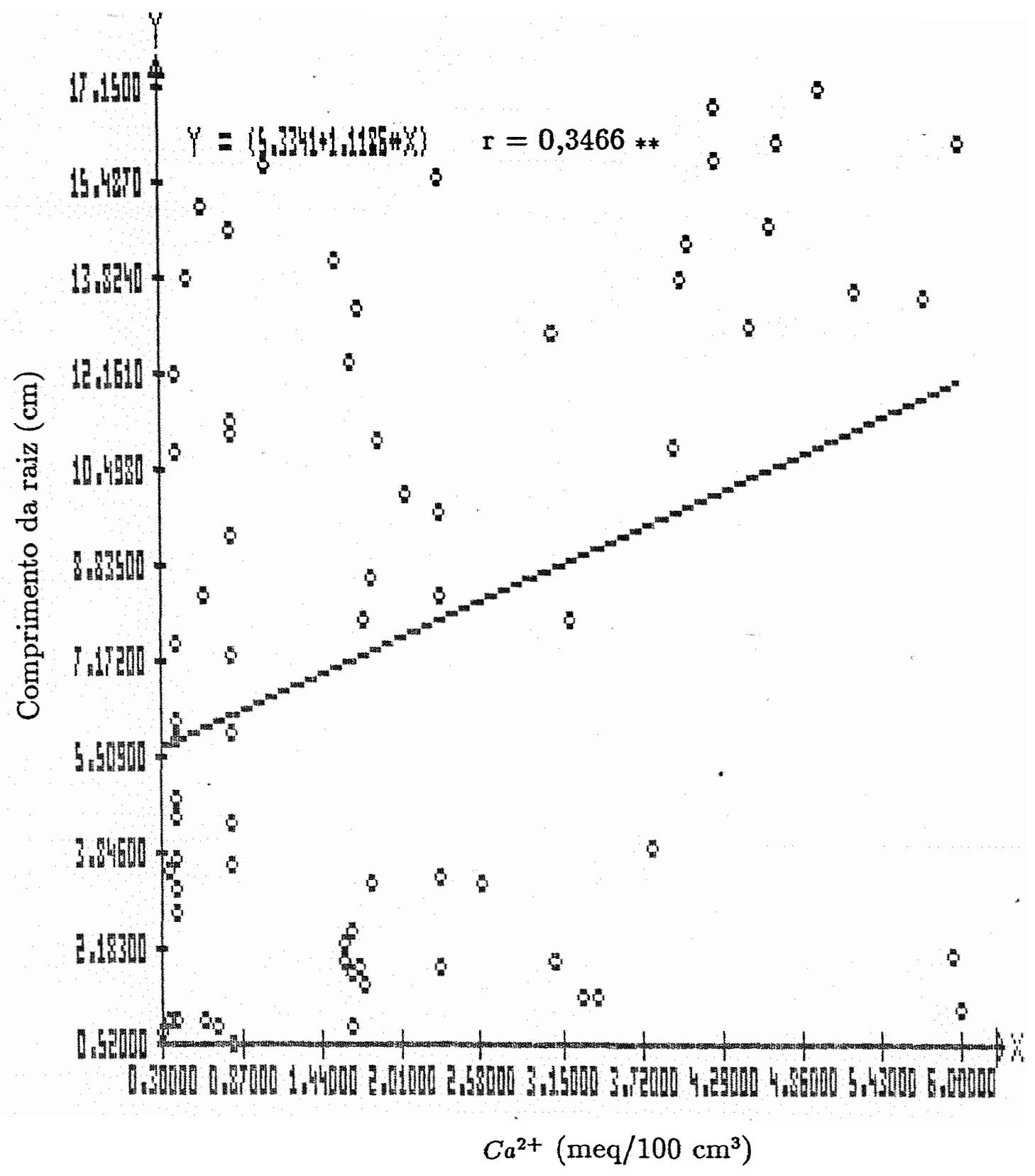

Figura 12. Correlação entre o teor de cálcio trocável das amostras de terra e o comprimento da raiz de trigo. 


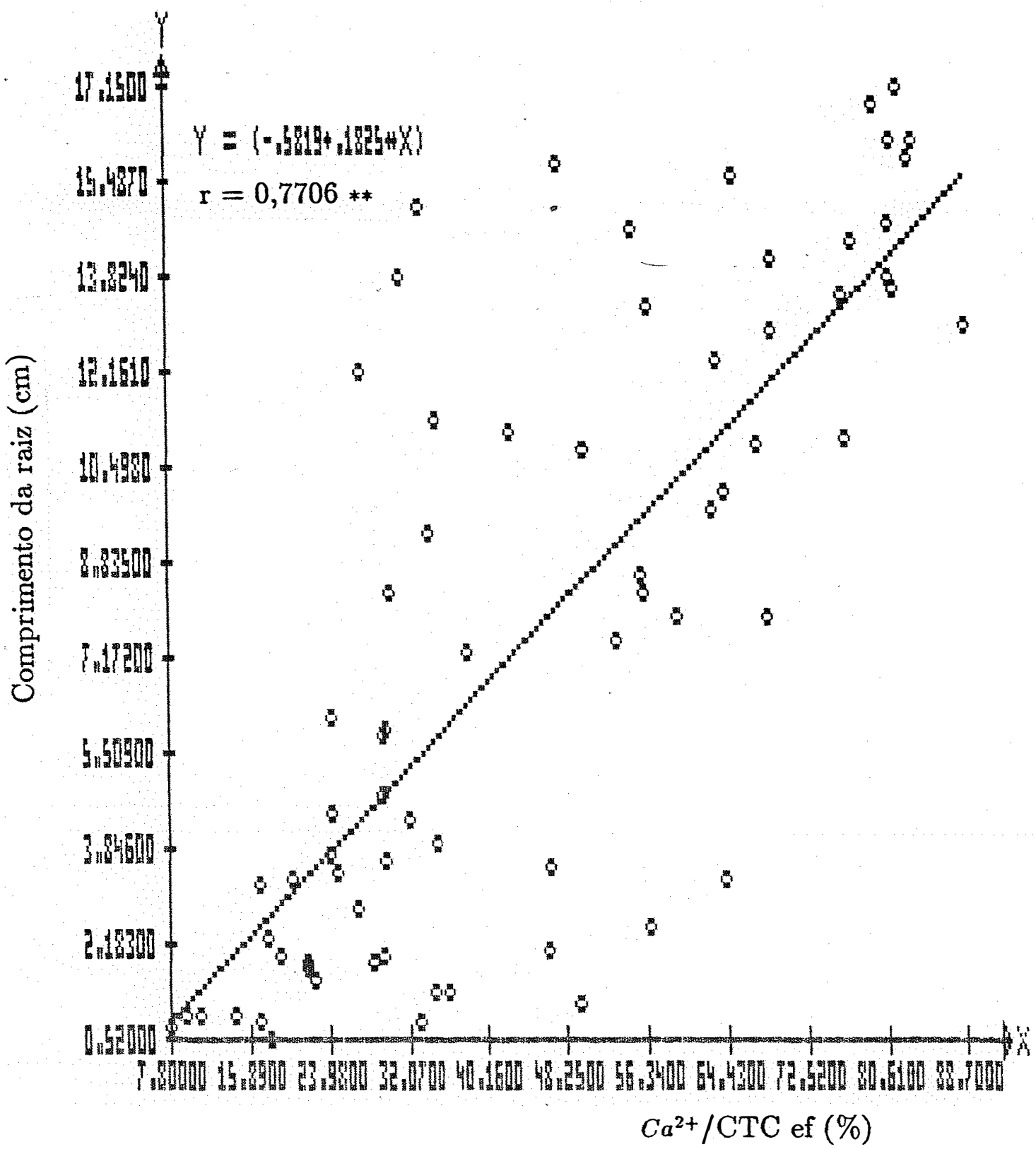

Figura 13. Correlação entre a porcentagem de saturação em cálcio trocável na CTC efetiva das amostras de terra e o comprimento da raiz de trigo. 


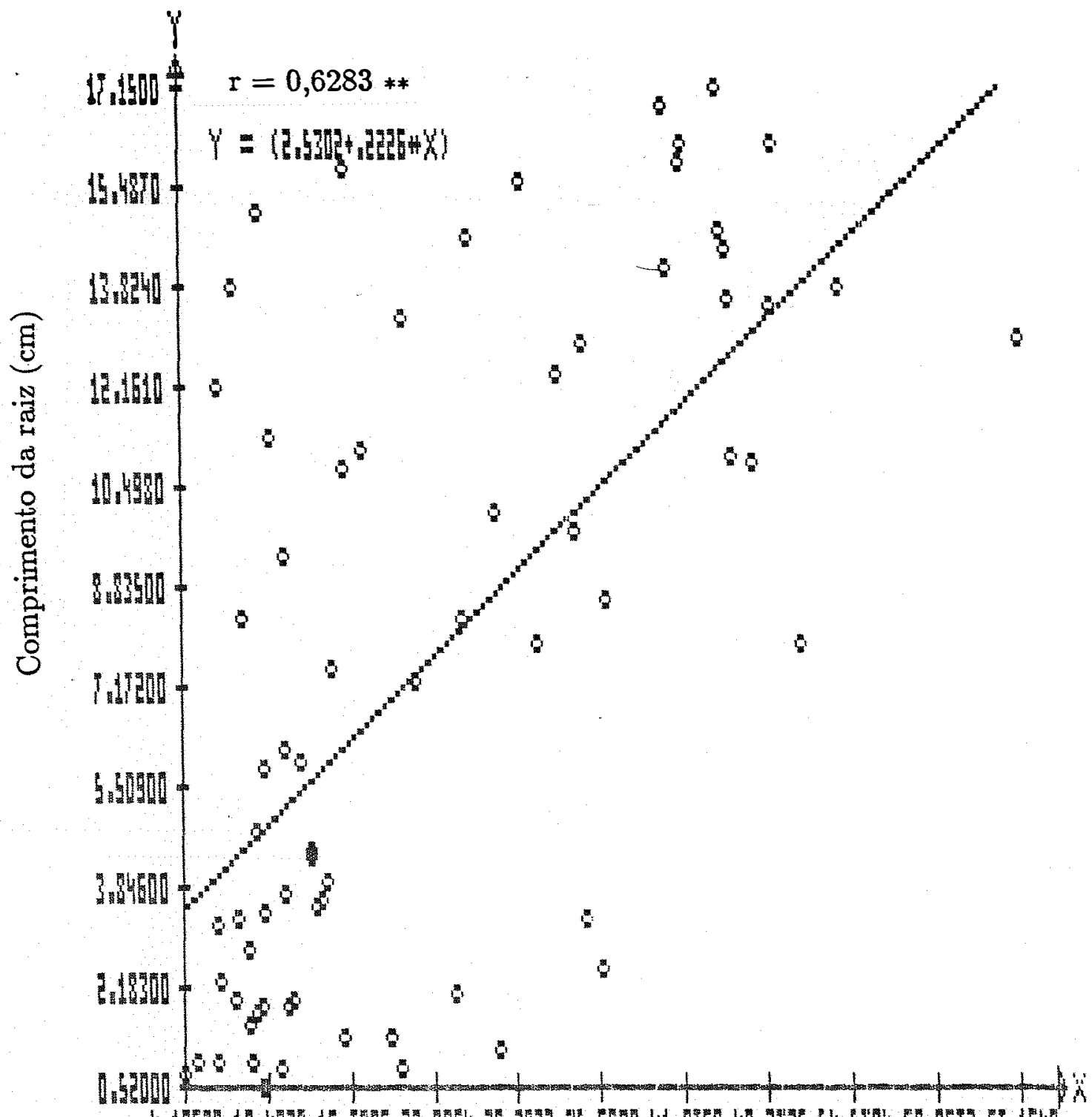

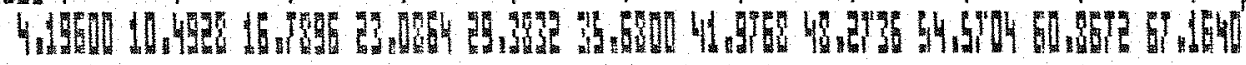

$$
\mathrm{Ca}^{2+} / \mathrm{CTC} \mathrm{pH} 7,0(\%)
$$

Figura 14. Correlação entre a porcentagem de saturação em cálcio trocável na CTC a pH 7,0 das amostras de terra e o comprimento da raiz de trigo. 


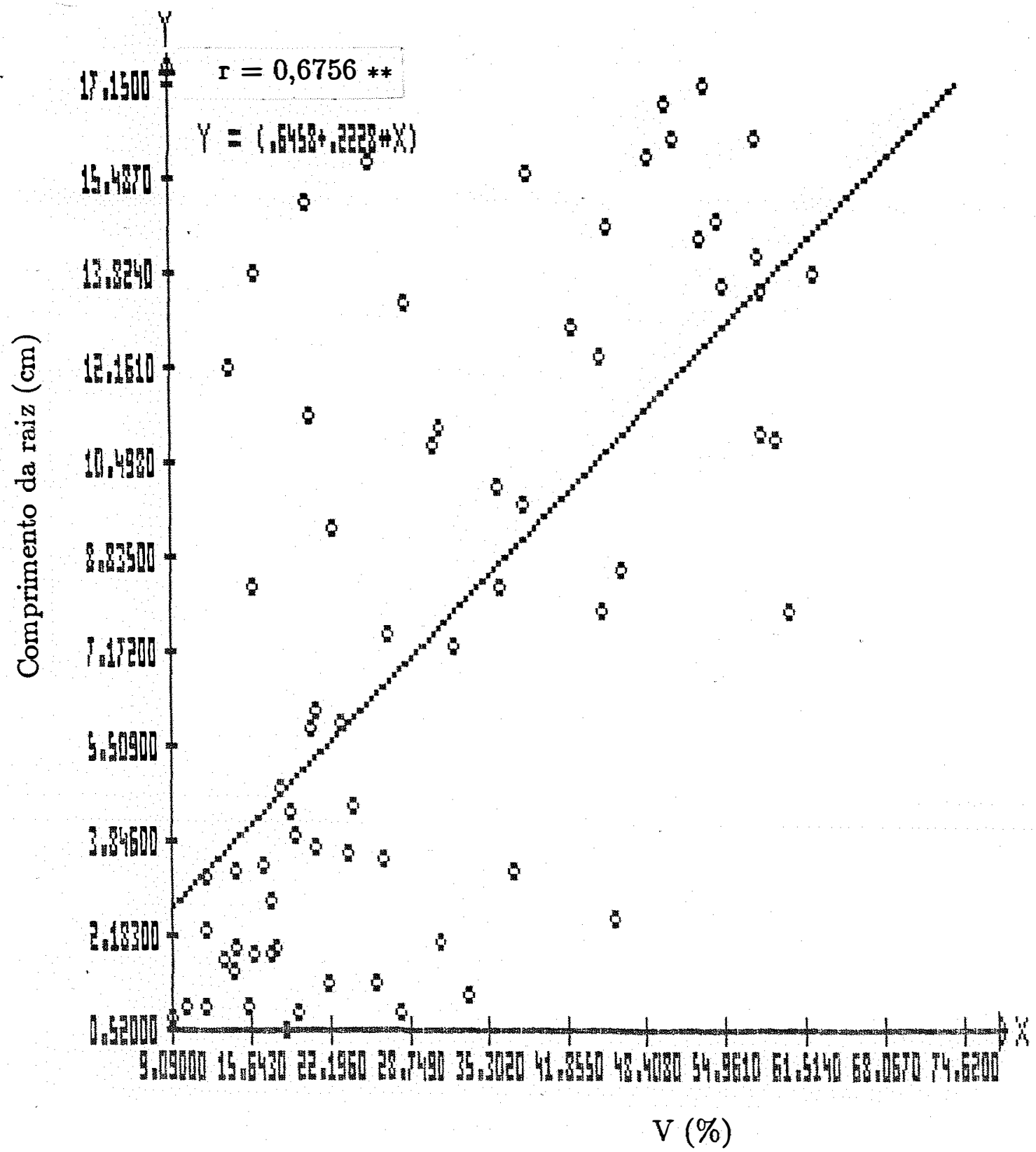

Figura 15. Correlação entre a porcentagem de saturação em bases das amostras de terra e o comprimento da raiz de trigo. 


\section{CONCLUSÕES}

(1) As doses de $\mathrm{CaSO}_{4} \cdot 2 \mathrm{H}_{2} \mathrm{O}$ recomendadas para elevar o teor de cálcio para $2,0 \mathrm{meq} / 100 \mathrm{~cm}^{3}$ ou para "neutralizar" alumínio ao nível de 0,5 $\mathrm{meq} / 100 \mathrm{~cm}^{3}$ são superiores às capacidades de adsorção máxima de sulfato na maioria das amostras de terra estudadas.

(2) A capacidade de adsorção máxima de sulfato que indica o limite superior da dose de gesso a ser recomendada apresenta correlação significativa com as quantidades de sulfato adsorvidas através do equilíbrio com soluções de 20,30 ou $40 \mathrm{ppm}$ de $S-S_{4}^{2-}$ e ainda com a diferença entre os valores do $\mathrm{pH}$ da suspensão solo:solução, em $\mathrm{K}_{2} \mathrm{SO}_{4} 1 \mathrm{~N}$ e $\mathrm{KCl} 1 \mathrm{~N}$; estas correlações permitem estimar a capacidade de adsorção máxima de sulfato através de análises químicas facilmente adotáveis na rotina laboratorial.

(3) Nas amostras de terra dos podzolizados do presente estudo, com teores elevados de alumínio, não há efeitos de interesse agronômico do $\mathrm{CaSO}_{4} \cdot 2 \mathrm{H}_{2} \mathrm{O}$ e do $\mathrm{CaCl}_{2} \cdot 2 \mathrm{H}_{2} \mathrm{O}$ no comprimento da raiz de plântulas de trigo.

(4) Nas amostras de terra dos latossolos em estudo os tratamentos com $\mathrm{CaSO}_{4} \cdot 2 \mathrm{H}_{2} \mathrm{O}$ afetam positivamente o comprimento da raiz de plântulas de trigo nas amostras de terra com excesso de alumínio e/ou com deficiência de cálcio. $\mathrm{O}$ $\mathrm{CaCl}_{2} \cdot 2 \mathrm{H}_{2} \mathrm{O}$ é efetivo apenas nas amostras sem problemas de toxidez de alumínio.

(5) As doses recomendadas pelos critérios do cálcio e do alumínio não se relacionam com as doses de $\mathrm{CaSO}_{4} \cdot 2 \mathrm{H}_{2} \mathrm{O}$ onde foram observadas as melhores respostas no ensaio com trigo.

(6) A porcentagem de saturação em alumínio é o parâmetro de 
solo que melhor se correlaciona com o comprimento da raiz de plântulas de trigo. 


\section{REFERÊNCIAS BIBLIOGRÁFICAS}

ACCIOLY, L.J. de; DAL BÓ, M.A.; ALVAREZ, V., V.H.; RIBEIRO, A.C. Método para determinação do potencial de sulfato em solos. R. bras. Ci. Solo, Campinas, 9:103-6, 1985.

ADAMS, F. Ionic concentrations and activities in soil solution. Soil Sci. Soc. Amer. Proc., Madison, 35:420-6, 1971.

ADAMS, F. \& HAJEK, B.F. Effects of solution sulfate, hydroxide, and potassium concentrations on the crystallization of alunite, basaluminite and gibbsite from dilute aluminum solution. Soil Sci., Baltimore, 126:169-73, 1978.

ADAMS, F. \& RAWAJFIH, B.F. Basaluminite and alunite: a possible cause of sulfate retention by acid soils. Soil Sci. Soc. Am. J., Madison, 41:68692, 1977.

ALOISI, A.M. do M.; ROCHA FILHO, J.V. de; BITTENCOURT, V.C. de. Comportamento do sulfato em alguns solos do Estado de São Paulo. Energ. Nucl. Agric., Piracicaba, 2(2):139-48, 1980.

ALVAREZ V., V.H. Equilíbrio de formas disponíveis de fósforo e enxofre em dois latossolos de Minas Gerais. Viçosa, 1974. 125 p. [Mestrado- Universidade Federal de Viçosa]

AYLMORE, L.A.G.; KARIM, M.; QUIRK, J.P. Adsorption and dessorption of sulfate ions by soil constituents. Soil Sci., Baltimore, 103(1):10-5, 1967. 
AYRES, A.S. \& HAGIHARA, H.H. Effect of the anion on the sorption of potassium by some humic and hydrol humic latosols. Soil Sci. Baltimore, 75(1):1-17, 1953.

BARBER, S.A. Soil nutrient bioavailability; a mechanistic approach. New York, John Wiley \& Sons, 1984. 398 p.

BARROW, N.J. Studies on the adsorption of sulfate by soils. Soil Sci., Baltimore, 104(5):342-9, 1967.

BARROW, N.J. Comparison of the adsorption of molybdate, sulfate and phosphate by soils. Soil Sci., Baltimore, 109:282-8, 1970.

BERG, W.A. \& THOMAS, G.W. Anion elution patterns from soils and soil clays. Soil Sci. Soc. Amer. Proc., Madison, 23(5):348-50, 1959.

BLAIR, G.J. Chemistry of S and S cycle in the tropics. In: SYMPOSIUM ON SULPHUR IN INDIAN AGRICULTURE, New Delhi, 1988. Proceedings. New Delhi, The Sulphur Institute, The Fertiliser Association of India, 1988. p. SI/1-10.

BORNEMISZA, F. \& LHANOS, R. Sulfate movement, adsorption and desorption in three Costa Rican Soils. Soil Sci. Soc. Amer. Proc., Madison, 31:356-60, 1967.

BOUYOUCOS, G.J. A recalibration of the hydrometer methods for making analysis of soils. Agron. Journal, Madison, 43:434-8, 1951.

BREEMEN, N. van. Dissolved aluminum in acid sulfate soils and acid mine waters. Soil Sci. Soc. Amer. Proc., Madison, 37:694-7, 1973.

CATANI, R.A.; GLORIA, N.A.; VITTI, G.C. Adsorção de sulfato pelo solo. Anais da Escola Superior de Agricultura "Luiz de Queiroz", Piracicaba, 28:235-45, 1971.

CHNAG, M.L. \& THOMAS, G.W. A suggested mechanism for sulfate adsorption by soils. Soil Sci. Soc. Amer. Proc., Madison, 27(3):281-3, 
1963.

CHAO, T.T. Anionic effects on sulfate adsorption by soils. Soil Sci. Soc. Amer. Proc., Madison, 28(4):581-3, 1964.

CHAO, T.T.; HARWARD, M.E.; FANG, S.C. Adsorption and desorption phenomena of sulfate ions in soils. Soil Sci. Soc. Amer. Proc., Madison, 26:234-7, 1962a.

CHAO, T.T.; HARWARD, M.E.; FANG, S.C. Cationic effects on sulfate adsorption by soils. Soil Sci. Soc. Amer. Proc., Madison, 27(1):35-8, 1963.

CHAO, T. T.; HARWARD, M.E.; FANG,S.C. Exchange reactions between hydroxil and sulfate ions in soils. Soil Sci., Baltimore, 90(2):104-8, 1965.

CHAO, T.T.; HARWARD, M.E.; FANG, S.C. Iron or aluminum coatings in relation to sulfate adsorption characteristics of soils. Soil Sci. Soc. Amer. Proc., Madison, 28(5):632-5, 1964.

CHAO, T.T.; HARWARD, M.E.; FANG, S.C. Movement of $\mathrm{S}^{35}$ tagged sulfate through soil columns. Soil Sci. Soc. Amer. Proc., Madison, 26(1):27-32, $1962 \mathrm{~b}$.

CHAO, T.T.; HARWAR.D, M.E.; FANG, S.C. Soil constituents and properties in the adsorption of sulfate ions. Soil Sci., Baltimore, 94(5):276-83, 1962c.

COUTO, W.; LATHWELL, D.J.; BOULDIN, D.R. Sulfate sorption by two oxisols and an alfisol of the tropics. Soil Sci., Baltimore, 127(2):108-16, 1979.

DIAS, L.E.; CARVALHO, L.J.C.B.; RITCHEY, K.D. Avaliação da deficiência de $\mathrm{Ca}$ em diferentes solos de cerrado, por meio do crescimento de raizes. Rev. Ceres, Viçosa, 32(180):102-9, 1985.

DONER, H.E.\& LYNN, W.C. Carbonate, halide, sulfate, and sulfide minerals. In: DIXON, J.B.; WEED, S.B.; KITTRICK, J.A.; MILFORD, M.H.; 
WHITE, J.L. ed. Minerals in soil environments. Madison, Soil Science Society of America, 1977. p. 75-98.

ELKINS, D.M. \& ENSMINGER, L.E. Effect of $\mathrm{pH}$ on the availability of adsorbed sulfate. Soil Sci. Soc. Amer. Proc., Madison, 35(6):931-4, 1971.

ENSMINGER, L.E. Some factors affecting the adsorption of sulfate by Alabama soils. Soil Sci. Soc. Amer. Proc., Madison, 18(3):259-64, 1954.

ESTADOS UNIDOS. Salinity Laboratory STAFF. Diagnosis and improvement of saline and alkali soils. Riverside, USDA, 1969. p. 98-9. (Agriculture handbook, 60)

FREIRE, F.M.; GUIMARÃES, P.T.G.; AlVAREZ, V., V.H.; MELlES, C.C.A. Calagem, gessagem e adubação do cafeeiro. Belo Horizonte, EPAMIG, 1984. $20 \mathrm{p}$.

FOX, R.L. Some highly weathered soils of Puerto Rico. 3. Chemical properties. Geoderma, Amsterdam, 27:139-76, 1982.

FOX, R.L. Sulphur in tropical soils: sorbeb, soluble and available. In: SULPHUR-84, 1984. Proceedings. Calgary, SUDIC, 1984. p. 799-803.

FRIED, M. \& SHAPIRO, R.E. Soil-plant relationships in ion uptake. Ann. Rev. Plant Physiol., Stanford, 12:91-112, 1961.

GASTON, L.A.; MANSELL,R.S.; RHUE, R.D. Sulfate mobility in acid soils and implications with respect to cation leaching; a review. Soil Crop Sci. Soc. Proc., Gainesville, 15:67-72, 1986.

GEBHARDT, H. \& COLEMAN, N.T. Anion adsorption by allophanic tropical soils: II. Sulfate adsorption. Soil Sci. Soc. Amer. Proc., Madison, 38:259-62, 1974.

HAQUE, I. \& WALMSLEY, K. Sulphur investigations in some West Indian soils. Trop. Agric., Trinidad, 51(2):253-63, 1974. 
HARTER, R.D. \& BAKER, D.E. Applications and misapplications of the Langmuir equation to soil adsorption phenomena. Soil Sci. Soc. Am. J., Madison, 41(6):1077-80, 1977.

HARTER, R.D. \& SMITH,G. Langmuir equation and alternate methods of studying "adsorption" reactions in soils. In: DOWDY, R.H.; RYAN, J.A.; VOLK, V.V.; BAKER, D.E. ed. Chemistry in the soil environment. Madison, ASA/SSSA, 1981. p. 167-82. ( ASA Special Publication, 40)

HARWARD, M.E. \& REISENAUER, H.M. Reactions and movement of inorganic soil sulfur. Soil Sci., Baltimore, 101(4):326-35, 1966.

HASAN, S.M.; FOX, R.L.; BOYD, C.C. Solubility and availability of sorbed sulfate in Hawaiian soils. Soil Sci. Soc. Amer. Proc., Madison, 34(6):897-901, 1970.

HINGSTON, F.J.; ATKINSON, R.J.; POSNER,A.M.; QUIRK, J.P. Specific adsorption of anions. Nature, London, 215:1459-61, 1967.

HINGSTON, F.J.; POSNER, A.M.; QUIRK, J.P. Anion adsorption by goethite and gibbsite. II. Desorption of anions from hydrous oxide surfaces. J. Soil Sci., Oxford, 25(1):16-26, 1974.

HUE, N.V.\& ADAMS, F. Indirect determination of micrograms of sulfate by barium absorption spectroscopy. Commun. Soil. Sci. Pl. Anal., New York, 10:341-51, 1979.

HUE, N.V.; ADAMS, F.; EVANS, C.E. Sulfate retention by an acid BE horizon of an Ultisol. Soil Sci. Soc. Am. J., Madison, 49:1196-1200, 1985.

KAMPRATH, E.J.; NELSON, W.L.; FITTS, J.W. The effect of pH, sulfate and phosphate concentrations on the adsorption of sulfate by soils. Soil Sci. Soc. Amer. Proc., Madison, 20:463-6, 1956.

KAMPRATH, E.J. \& TILL, A.R. Sulfur cycling in the tropics. In: BLAIR, G.J. \& TILL, A.R. ed. Sulfur S.E. Asian S. Pacific Agriculture. Armidale, ADAB/TSI, UNE, 1983. p.1-14. 
KINJO, T. \& PRATT, P.F. Nitrate adsorption. II. In competition with chloride, sulfate and phosphate. Soil Sci. Soc. Amer. Proc., Madison, 35(5):725-8, 1971.

LINDSAY, W.L. Chemical equilibria in soil. New York, John Wiley, 1979. $447 \mathrm{p}$.

LIU, M. \& THOMAS, G.W. Nature of sulfate retention by acid soils. Nature, London, 192:384, 1961.

MALAVOLTA, E. Estudos químico-agrícolas sobre o enxofre. Anais da Escola S uperior de Agricultura "Luiz de Queiroz", Piracicaba, 9:39-130, 1952.

MALAVOLTA, E. \& KLIEMANN, H.J. Desordens nutricionais no cerrado. Piracicaba, POTAFOS, 1985. $136 \mathrm{p}$.

MARSH, K.B.; TILLMAN, R.W.; SYERS, J.K. Adsorption of sulphate and fluoride by variable charge soils. J. Soil Sci., Madison, 38(1):29-38, 1987.

McCLUNG, A.C.; FREITAS,L.M.M. de; LOTT, W.L. Analyses of several Brazilian soils in relation to plant responses to sulfur. Soil Sci. Soc. Amer. Proc., Madison, 23:221-4, 1959.

MEHLICH, A. Influence of sorbed hydroxyl and sulfate on neutralization of soil acidity. Soil Sci. Soc. Amer. Proc., Madison, 28(4):492-6, 1964.

MEHRA, O.P. \& JACKSON, M.L. Iron oxide removal from soils and clays by a dithionite-citrate system buffered with sodium bicarbonate. In: NATIONAL CONFERENCE ON CLAYS AND MINERALS, 7. Proceedings. London, Pergamon Press, 1960. v. 7, p. 317-27.

METSON, A.J. \& BLAKEMORE, L.C. Sulphate retention by New Zealand soils in relation to the competitive effect of phosphate. New Zealand J. Agric. Res., Wellington, 21:243-53, 1978.

MIYAZAWA, M.; PAVAN, M.A.; BLOCK, M. de F.M. Determinação espec- 
trofotométrica de nitrato em extratos de solo sem redução química. Pesq. Agrop. Bras., Brasília, 20(1):129-33, 1985.

NASCIMENTO, J.A.L. do \& MORELLI, M. Enxofre em solos do Rio Grande do Sul. I. Formas no solo. R. bras. Ci. Solo, Campinas, 4:131-5, 1980.

NEPTUNE, A.M.L.; TABATABAI, M.A.; HANWAY, J.J. Sulfur fractions and carbon-nitrogen-phosphorus-sulfur relationships in some Brazilian and Iowa soils. Soil Sci. Soc. Amer. Proc., Madison, 39:51-5, 1975.

NORDSTROM, D.K. The effect of sulfate on aluminum concentrations in natural waters: some stability relations in the system $\mathrm{Al}_{2} \mathrm{O}_{3}-\mathrm{SO}_{3}-\mathrm{H}_{2} \mathrm{O}$ at $298^{\circ}$ K. Geochim. Cosmochim. Acta, London, 46:681-92, 1982.

PAOLINELLI, M.T., OLIVEIRA, P.M., SANTOS, P.R.R.S., LEANDRO, V.P. \& MORAES, W.V. Aplicação direta do fosfogesso. In: SEMINÁRIO SOBRE O USO DO FOSFOGESSO NA AGRICULTURA, 1., Brasília, 1986. A nais. Brasília, EMBRAPA-DDT, 1986. p. 197-207.

PARFITT, R.L. Anion adsorption by soils and soil materials. Adv. Agron., New York, 30:1-49, 1978.

PARFITT, R.L. \& SMART, R.S.C. The mechanisms of sulfate adsorption on iron oxides. Soil. Sci. Soc. Am. J., Madison, 42:48-50, 1978.

PAVAN, M.A. Efeitos tóxicos de alumínio em mudas de cafeeiro em relação à nutrição do cálcio. R. bras. Ci. Solo, Campinas, 6:209-13, 1982.

PAVAN, M.A. O gesso agrícola e a fertilidade dos solos ácidos. In: CURSO DE ATUALIZAÇÃO EM FERTILIDADE DO SOLO, 2., Londrina, 1988. Londrina, AEAPR;IAPAR; EMBRAPA; ANDA; POTAFOS, 1988. 17 p.

PAVAN, M.A.; BINGHAM, F.T.; PRATT, P.F. Toxicity of aluminum to coffee in Ultisols and Oxisols amended with $\mathrm{CaCO}_{3}, \mathrm{MgCO}_{3}$ and $\mathrm{CaSO}_{4}$. Soil Sci. Soc. Am. J., Madison, 46:1201-7, 1982.

PAVAN, M.A. \& VOLKWEISS, S.J. Efeitos do gesso nas relações solo-planta; 
princípios. In: SEMINARIO SOBRE O USO DO FOSFOGESSO NA AGRICULTURA, 1. Brasilia, 1986. Anais. Brasilia, EMBRAPA-DDT, 1986. p. 107-18.

PETROFERTIL. Gesso agrícola. GEAGRO, São Paulo, s.d. (Folheto informativo)

PROBERT, M.E. \& SAMOSIR, S.S.R. Sulfur in non-flooded tropical soils. In: BLAIR, G. J. \& TILL, A.R., ed. Sulfur S.E. Asian S. Pacific Agriculture. Armidale, ADAB/TSI, UNE, 1983. p.15-27.

RAIJ, B. van. Gesso agrícola na melhoria do ambiente radicular no subsolo. São Paulo, ANDA, 1988, 88 p.

RAIJ, B. van \& QUAGGIO, J.A. Métodos de análise de solo para fins de fertilidade. Campinas, IAC, 1983. 31p. (Boletim técnico, 81)

RAJAN, S.S.S. Sulfate adsorbed on hydrons alumina, ligands displaced, and changes in surface charge. Soil Sci. Soc. Am. J., Madison, 42:39-44, 1978.

RAJAN, S.S.S.; PERROT, K.W.; SAUNDERS, W.M.H. Identification of phosphate-reactive sites of hydrons alumina from proton consumption during phosphate adsorption at constant $\mathrm{pH}$ values. J. Soil Sci., Madison, 25(4):438-47, 1974.

REEVE, N.G. \& SUMNER, M.E. Amelioration of subsoil acidity in Natal Oxisols by leaching surface applied amendments. Agrochemophysica, Pretoria, 4:1-6, 1972.

RHOADES, J.R. Soluble salts. In: PAGE, A.L. ed. Methods of soil analysis. 2. ed. Madison, ASA, 1982. p.167-79. (Agronomy, 9)

RITCHEY, K.D.; SILVA, J.E.; SOUZA, D.M.G. Relação entre teor de cálcio no solo e desenvolvimento de raízes avaliado por um método biológico. $\mathbf{R}$. bras. Ci. Solo, Campinas, 7:269-75, 1983. 
RITCHEY, K.D.; SOUZA, D.M.G.; LOBATO, E.; CORREA, O. Calcium leaching to increase rooting depth in a Brazilian Savannah Oxisol. Agron. J., Madison, 72:40-4, 1980.

SHAINBERG, I.; SUMNER, M.E.; MILLER, W.P.; FARINA, M.P.W.; PAVAN, M.A.; FEY, M.V. Use of gypsum on soils; A review. Adv. Soil Sci., New York, 9:1-111, 1988.

SINGH, B.R. Sulfate sorption by acid forest soils: 1. Sulfate adsorption isotherms and comparison of different adsorption equations in describing sulfate adsorption. Soil Sci., Baltimore, 138(3):189-97, 1984.

SINGH, S.S. \& BRYDON, J.E. Precipitation of aluminum by calcium hydroxide in the presence of Wyoming bentonite and sulfate ions. Soil Sci., Baltimore, 103(3):162-7, 1967.

SINGH, S.S. \& BRYDON, J.E. Solubility of basic aluminum sulfates at equilibrium in solution and in the presence of montmorillonite. Soil Sci., Baltimore, 107(1):12-6, 1969.

SINGH, S.S. \& MILES, M. Effect of sulfate ions on the stability and exchange characteristics of an aluminum-interlayered Wyoming bentonite. Soil Sci., Baltimore, 126(6):323-9, 1978.

SPOSITO, G. \& MATTIGOD, S.V. GEOCHEM; a computer program for the calculation of chemical equilibria in soil solutions and other natural water systems. Riverside, University of California, Kearney Foundation of Soil Science, 1980. $82 \mathrm{p}$.

SUMNER, M.E. Aluminum toxicity ; a growth limiting factor in some Natal sands. Proc. S. Af. Sugar Tech. Assoc., Pretoria, 44:197-203, 1970.

UFG/EMGOPA. Recomendações de corretivos e fertilizantes para Goiás; 5 aproximação. Goiânia, 1988. 101 p. (Informativo técnico, 1)

VETTORI, L. Métodos de análises de solos. Rio de Janeiro, Ministério da Agricultura, Equipe de Pedologia e Fertilidade do Solo, 1969. 24 p.(Boletim técnico, 7). 
VITTI, G.C. Enxofre do solo. In: SIMPÓSIO SOBRE INTERPRETAÇÃO DE ANÁLISE QUÍMICA DE SOLO E DE PLANTA PARA FINS DE FERTILIDADE, 1., Botucatu, 1988. Anais. Botucatu, UNESP/FCA, 1988. p. 1-39.

VITTI, G.C.; FERREIRA, M.E.; MALAVOLTA, E. O fosfogesso como fonte de cálcio e enxofre: respostas de culturas anuais e perenes. In: SEMINÁRIO SOBRE O USO DO FOSFOGESSO NA A GRICULTURA, 1., Brasília, 1986. Anais. Brasília, EMBRAPA-DDT, 1986. p. 17-43.

WEAST, R.C. ed. CRC Handbook of chemistry and physics. 65. ed. Boca Raton, CRC Press, 1984. p. 382-5.

WOLT, J.D. Sulfate retention by acid sulfate-poluted soils in the Copper Basin area of Tennessee. Soil Sci. Soc. Am. J., Madison, 45:283-7, 1981.

WOLT, J.D. \& ADAMS, F. The release of sulfate from soil- applied basaluminite and alunite. Soil Sci. Soc. Am. J., Madison, 43:118-21, 1979.

ZHANG, G.Y.; ZHANG, X.N.; YU, T.R. Adsorption of sulphate and fluoride by variable charge soils. J. Soil Sci., Madison, 38(1):29-38, 1987. 